Zweiter Beratungsgegenstand:

\title{
Die Rechtsformen der sozialen Sicherung und das Allgemeine Verwaltungsrecht
}

1. Bericht von Professor Dr. Wilhelm Henke, Erlangen-Nürnberg

\section{Vorbemerkung}

Die Fragestellung, die das Thema aufwirft, ist von Herrn Rüfner und mir dahin aufgefaßt worden, daß die Einwirkungen der beiden Rechtsbereiche - Sozialrecht und Allgemeines Verwaltungsrecht - aufeinander diskutiert werden sollen. Meine Frage heißt: wie wirkt das Sozialrecht auf das Allgemeine Verwaltungsrecht, oder wie könnte es darauf einwirken?

Ich sehe von Definitionen des Sozialrechts und des Allgemeinen Verwaltungsrechts $a b$ und halte mich hierzu an das herrschende Verständnis.

Alle wirklichen oder möglichen Einwirkungen des Sozialrechts auf das Allgemeine Verwaltungsrecht zu erörtern ist unmöglich. Ich habe einige Fragen ausgewählt, die mir bei der Beschäftigung mit dem Thema besonders auffielen und die mir für eine Erörterung unter den gegenwärtigen Umständen geeignet und interessant erschienen. Es sind dies: das Verhältnis von öffentlichem und privatem Recht, das Gewaltverhältnis, die Selbstverwaltung, die öffentlichrechtliche Entschädigung und abschließend die Gefahr einer Sozialisierung des Verwaltungsrechts.

Ich habe es nicht als meine Aufgabe angesehen, zu diesen Fragen abgeschlossene Forschungsergebnisse vorzulegen, sondern einige Thesen für eine Diskussion zu liefern.

\section{Offentliches Recht und Privatrecht}

Allgemeines Verwaltungsrecht und Sozialrecht gelten beide als öffentliches Recht. Die Unterscheidung von öffentlichem und privatem Recht ist problematisch' ${ }^{1}$ ), und zwar seit so langer Zeit und in so tiefgreifender und widerstandsfähiger Weise, daß die Annahme naheliegt, es gehe nicht um Definition und $\mathrm{Ab}$ -

1) Vgl. vor allem Bullinger, Offentliches Recht und Privatrecht, 1968 m. Nachw.; Werner Weber, Art. Offentliches Recht in HdSW; H.J. Wolff, VerwR I, §22. 
grenzung, sondern um eine innere Spannung zwischen zwei gegensätzlichen, tragenden Elementen unserer Rechtsordnung, die das immer neue Finden des Gleichgewichts und nicht die Befestigung einer Grenze zur Aufgabe macht.

Das Sozialrecht zeigt dies deutlicher als andere Rechtsgebiete, denn es ist mit privatrechtlichen Erscheinungen besonders eng verflochten und seine Zugehörigkeit zum öffentlichen Recht war anfangs durchaus unsicher und bestritten ${ }^{2}$ ).

Die Verflechtung zeigt sich z. B. bei den Sach- und Dienstleistungen der Krankenversicherung. Der Kranke steht in einem öffentlichrechtlichen Mitgliedsschaftsverhältnis zu seiner Kasse, einer Körperschaft öffentlichen Rechts ${ }^{3}$ ). Der Arzt steht im gleichen Verhältnis zur kassenärztlichen Vereinigung, ebenfalls Körperschaft öffentlichen Rechts $\left.{ }^{4}\right)$. Das Verhältnis zwischen Arzt und Patient ist durch das zwischen Kasse und kassenärztlicher Vereinigung, nämlich durch öffentlichrechtliche Rahmenvereinbarungen bestimmt $t^{5}$ ). Der Patient hat einen öffentlichrechtlichen Anspruch gegenüber seiner Kasse auf ärztliche Versorgung"), der Arzt eine öffentlichrechtliche Pflicht zur Behandlung des Patienten gegenüber seiner Vereinigung, zu deren Erfüllung er mit Verwarnung, Verweis und Geldbuße angehalten werden $\mathbf{k a n n}^{7}$ ). Die kassenärztliche Vereinigung hat gegenüber der Kasse die öffentlichrechtliche Pflicht, die ärztliche Behandlung zu gewährleisten, diese gegenüber jener die Pflicht, die Gesamtvergütung zu zahlen ${ }^{8}$ ). Zwischen Arzt und Patient besteht weder ein Vertrag noch ein öffentlichrechtliches Verhältnis. §368 d Abs. 4 RVO überbrückt diese Lücke durch einen undeutlichen Rückgriff auf bürgerliches Recht: „Die Ubernahme der Behandlung verpflichtet den Kassenarzt . . . dem zu Behandelnden gegenüber zur Sorgfalt nach den Vorschriften des bürgerlichen Vertragsrechts." Ob ein solcher Vertrag hier besteht - die freie Arztwahl könnte dafür sprechen - oder ob er fingiert wird, oder ob nur bürgerliches Recht für entsprechend anwendbar erklärt wird, bleibt offen, also eben die Frage, die überall offen bleibt, wo BGB-Vertragsrecht in öffentlichrechtlichen Verhältnissen gelten soll, z. B. bei Sub-

2) Jetzt gilt es im Ganzen als öffentliches Recht, vgl. Wertenbruch, Sozialverwaltungsrecht, in Besonderes VerwR, hrsg. v. von Münch, 1969, S. 297.

3) $\$ 306$ ff., $\$ 4$. RVO. Der öffentlichrechtliche Charakter ergibt sich nicht aus der RVO.

4) $\$ 368 \mathrm{k}$ Abs. 3 RVO.

5) $\$ 368 \mathrm{~g}$ RVO.

9) $\$ 182$ Abs. 1 und 2, 368 e RVO.

7) $\$ \S 368$ k Abs. 1 S. 1,368 n RVO.

8) $\$ \S 368 n, 368$ f RVO. 
ventionsleistungen. Ein Vertrag und ein Honoraranspruch, also wirkliches Privatrecht, werden jedenfalls dann angenommen, wenn der Patient binnen 10 Tagen keinen Krankenschein beibringt, das öffentlichrechtliche Krankenversorgungssystem also zwischen Arzt und Patient nicht zur Auswirkung kommt ${ }^{9}$ ).

Wandert der Patient vom Arzt zur Apotheke, so wandert er, obwohl er innerhalb des Sozialversicherungssystems bleibt, in ein anderes Rechtsgebiet. Er kauft das Medikament nach Privatrecht. Er kauft es für Rechnung seiner Kasse ${ }^{10}$ ) und der Apotheker erwirbt einen privatrechtlichen Kaufpreisanspruch gegen die Kasse, denn die Rahmenvereinbarungen zwischen Kassen- und Apothekerverbänden gelten als privatrechtlich, weil letztere keinen öffentlichrechtlichen Status haben $\left.{ }^{11}\right)$. Die Rezeptgebühr, die bei dem Kauf zu zahlen ist, ist allerdings eine öffentlichrechtliche Abgabe, ein Sonderbeitrag des Patienten an seine Kasse, der von der Apotheke anläßlich des Kaufs mit eingezogen und an die Kasse abgeführt wird, alles im Rahmen des öffentlichen Rechts ${ }^{12}$ ). Auch die Befugnis des Arztes zur Verschreibung und die Befugnis des Patienten zum Kauf für Rechnung der Kasse beruhen auf öffentlichem Recht.

Diese Litanei ließe sich ganz entsprechend für die Zahlung der Sozialversicherungsbeiträge im Lohnabzugsverfahren wiederholen. Privatrechtliches Arbeitsverhältnis und öffentlichrechtliches Dreiecksverhältnis zwischen Arbeitgeber, Arbeitnehmer und Sozialversicherungsträger verflechten sich und überschneiden sich sogar, z. B. wenn der Streit zwischen Arbeitgeber und Arbeitnehmer um rückständige Beiträge privatrechtlich eingeordnet wird ${ }^{13}$ ) oder der Arbeitgeber privatrechtlich auf Einbehaltung der Beiträge verzichtet und sie selbst voll übernimmt ${ }^{14}$ ).

Grund für die Zurechnung zum öffentlichen Recht ist hier offenbar die öffentlichrechtliche Organisation der Sozialversicherungsträger. Nicht die Anwendung von Zwang oder die typischen Hoheitsaufgaben oder die einseitige Entscheidung im Gegensatz zum Vertrag sind maßgebend, sondern die Beteiligung eines Rechtssubjekts mit öffentlichem Status. Selbst der quasi fiskalische, jedenfalls vertragliche Beschaffungsvorgang,

9) Brackmann, Hdb. d. Soz.vers. (Losebl.ausg.), S. 441.

10) Vgl. Kracht, NJW 1962, 187.

11) Vgl. Kracht, NJW 1962, 187; Brackmann, Hdb. S. 467; §§407, $414 \mathrm{e}, 375$ RVO.

12) § 182 a RVO; Brackmann, Hdb. S. 438 b.

15) G. Wannagat, Lb. d. Sozialvers.rechts Bd. 1, 1965, S. 194 N. 3; vgl. auch BAG v. 14. 7. 1960, ZAZR 485/59 zit. bei Wannagat, aaO., S. 194.

14) Brackmann, Hdb. S. 370 b f. 
im Verhältnis zu Privaten wie den Apothekern privatrechtlich, wird im Verhältnis zu öffentlichen Körperschaften, den kassenärztlichen Vereinigungen, öffentlichrechtlich eingeordnet.

Umgekehrt wird die öffentliche Beitragspflicht privatrechtlich beurteilt, wenn sie zwischen Arbeitgeber und Arbeitnehmer als Privatrechtssubjekten streitig wird. Offentliches Recht erscheint so als das Recht der öffentlichen Gewalt, als Amtsrecht, im Gegensatz zum Recht der Privaten für ihr privates Handeln ${ }^{15}$ ). Es ist mit dem Privatrecht in dem Maße verflochten wie amtliches Handeln mit privatem verflochten ist.

Die Einordnung des Sozialrechts in das öffentliche Recht war anfangs, noch um die Jahrhundertwende, umstritten ${ }^{16}$ ). Die für die Zuordnung angewandten Maßstäbe waren aber andere als heute. Als Argument gegen die Einordnung in das Privatrecht und für die Einordnung in das öffentliche Recht wurde vor allem vorgebracht, daß das Sozialversicherungsverhältnis nicht durch Vertrag, sondern durch Gesetz entstehe, daß die Vertrags- und die Dispositionsfreiheit eingeschränkt seien - Verbot abweichender Vereinbarungen zu Lasten des Versicherten ${ }^{17}$ ), Verbot der Ubertragung, Verpfändung, Pfändung und Aufrechnung von Versicherungsansprüchen ${ }^{18}$ ). Privatrecht war hier der Bereich der sog. Privatautonomie, in dem der freie Wille der - für Schadensersatzansprüche - das Verschulden einzelner Privater der Grund aller Rechtsverhältnisse ist, im Gegensatz zum Bereich staatlicher Rechtsetzung oder Reglementierung, wo der sog. Staatswille Grund der Rechtsverhältnisse ist. Daß diese Vorstellung vom Privatrecht dem BGB zugrundeliegt, ist durch Gierkes bekannte Kritik bewußt geworden ${ }^{10}$ ). Die Folge ist, daß die notwendigen Bindungen der Privatrechtspartner vom Arbeitsvertrag bis zu den Abzahlungsgeschäften außerhalb des BGB bestimmt sind. Sie gelten

15) Vgl. H.J. Wolf, Verwaltungsrecht I, §22 II; H. F. Zacher, Verwaltung durch Subventionen, VVDStRL 25 (1967) S. $350 \mathrm{f}$.

10) Vgl. dazu vor allem H.F.Zacher, Die Sozialversicherung als Teil des öffentlichen Rechts, Festschrift Kurt Jantz, 1968, S. 29 ff., hier S. 30 ff., mit Nachweisen, insbes. Adolf Menzel, Die rechtliche Natur der Unterstützungsansprüche . . . Arch. f. bürg. R. 1 (1889), S. $327 \mathrm{ff}$. und Richard Weyl, Lb. d. Sozialvers.rechts 1894, S. $908 \mathrm{ff}$. als Hauptvertreter beider Ansichten.

17) Heute $\$ 139$ RVO. Er gilt auch für das Verhältnis zwischen Versicherungsträger und Versicherten, vgl. Wannagat, Der Anwendungsbereich des öffentlichrechtlichen Vertrages im Sozialversicherungsrecht, NJW 1961, 1191.

19) Heute $\$ \S 119,223,629,1299,1312$ RVO; 4 Abs. 1 S. 2 SHG; $\$ 67$ BVersG. Vgl. Adolf Menzel, aaO., S. 328, 329, 333; Richard Weyl, aaO., S. 913, $914 \mathrm{f}$.

19) u. a. Der Entwurf eines BGB und das deutsche Recht, 1889. 
dennoch nicht als öffentliches Recht. Schon um 1890 waren nämlich die Kriterien der Zurechnung andere geworden. So verteidigte Adolf Menzel 1889 den privatrechtlichen Charakter der Sozialversicherungsansprüche indem er sagte, es sei „nicht richtig, daß das Privatrecht ausschließlich die Domäne der freien Selbstbestimmung des Individuums bilde und daß jede Einschränkung derselben etwas dem Privatrecht fremdes

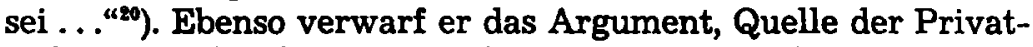
rechte sei "der freie Wille des Einzelnen“, rechtlich Vertrag oder Verschulden, Ansprüche, die „im herrschenden Willen des Staates ihren Rechtsgrund" haben, müßten daher öffentlichrechtlicher Natur $\operatorname{sein}^{21}$ ). Bezüglich des sozialpolitischen, also öffentlichen Interesses hinter dem Sozialversicherungsrecht sagt er, es könne ebenso durch Änderung oder Fortbildung des Privatrechts verfolgt werden $\left.{ }^{22}\right)$. Richard Weyl, Vertreter der öffentlichrechtlichen Einordnung des Sozialversicherungsrechts, vertrat insoweit dieselbe Auffassung, indem er auf die gesetzlichen Eigentumsbeschränkungen, Unterhalts-, Erb- und Schadensersatzansprüche des Privatrechts und auf bestehende gesetzliche Verfügungsbeschränkungen für eindeutig privatrechtliche Ansprüche hinwies $\left.{ }^{23}\right)$. Er hielt bereits die öffentlichrechtliche Organisation der Versicherungsträger für das entscheidende Argument $\left.{ }^{24}\right)$. Die Trennungslinie zwischen privatem und öffentlichem Recht hat sich also verschoben. Die Grenze zwischen Privatautonomie und Staatswille, die mit dieser Trennungslinie einmal zusammenfiel, liegt jetzt weit jenseits, mitten im bürgerlichen Recht. Nicht mehr wo der Staat an Stelle der privaten Bürger und ihrer Verträge über das Recht durch Gesetzgebung im öffentlichen Interesse disponiert, beginnt heute der Bereich des öffentlichen Rechts, sondern erst wo ein Rechtssubjekt mit öffentlichem Status Angelegenheiten in öffentliche Verwaltung nimmt ${ }^{25}$ ).

Eine Auflösung der vorhin gezeigten Verflochtenheit der beiden Rechtsbereiche mag für Rechtswegfragen manchmal notwendig sein, sie wird von der tatsächlichen und praktischen

20) aaO., S. 329 f.

21) aaO., S. 333 mit Bezug auf Rosin, Das Recht der öffentlichen Genossenschaft, S. 175.

22) aaO., S. 331 .

2s) aaO., S. $914 \mathrm{f}$.

24) aaO., S. 917, $921 \mathrm{f}$.

25) Vgl. z. B. BGH, U. v. 15. 6. 1967, DVBl. 1967, 883 (884 re. Sp.): Immissionsschäden aus Autobahnbau sind privatrechtlich zu beurteilen ( $\$ 906 \mathrm{BGB}$ ), wenn sie von einer Privatfirma durchgeführt werden, öffentlichrechtlich (enteignungsgleicher Eingriff), wenn bzw. soweit die Privatfirma nur Werkzeug der verantwortlichen Behörde ist. 
Zusammengehörigkeit der Sozialverwaltung immer wieder überspielt werden. Auch hat der Blick in die Geschichte gezeigt, $\mathrm{da} \beta$ die Unterscheidung nur relative Bedeutung besitzt. Es spricht vieles dafür, im öffentlichen und privaten Recht nicht zwei geschlossene Rechtssysteme zu sehen; Bullinger hat das in seiner Schrift über "Offentliches Recht und Privatrecht" von 1968 ausführlich begründet. Hier geht es jedoch nicht um die Rückgewinnung gemeinrechtlicher Institute für die Bedürfnisse der Verwaltung, ein gewiß erstrebenswertes Ziel, sondern um den Sinn der Unterscheidung von privatem und öffentlichem Recht.

Ich glaube, daß in der Unterscheidung - nicht Scheidung von Privatautonomie und Staatswille als zweierlei Grundlagen des Rechts etwas Wesentliches, nämlich für die Freiheit Wesentliches liegt. Diese beiden Positionen sind nicht nur Hervorbringungen theoretischer Spekulation oder politischer Ideologie. In der Rechtsgeschichte ist erkennbar, wie die Privatautonomie als individuelle Freiheit der Rechtsetzung und Rechtsgestaltung aus der religiös oder metaphysisch geschlossenen Rechtsordnung herauswächst, vom römischen Konsensualkontrakt über die Testierfreiheit, die freie Verfügung über Grundeigentum u. a. bis zur Privatautonomie des BGB. Es ist andererseits erkennbar, wie die staatliche oder sonst hoheitliche Rechtsetzung und Rechtsgestaltung an die Stelle der religiösen oder metaphysischen Bindungen staatliche oder soziale Bindungen setzt, von der Gerichtsbarkeit anstelle von Rache, Selbsthilfe und Schiedsgericht über zwingendes Gesetzesrecht bis zur Ubernahme in staatliche oder sonst öffentliche Verwaltung.

Nicht nur historisch, auch gegenwärtig gibt es diese Reihe der Möglichkeiten eines mehr oder weniger privaten, mehr oder weniger öffentlichen Rechts. Versicherungen gegen Krankheit, Unfall, Arbeitsunfähigkeit u. a. könnten frei durch Vertrag von Versicherern mit Einzelnen zu individuellen Bedingungen vereinbart werden wie heute Kauf- und Werkverträge. Oder Gesetze könnten einen bestimmten Mindestinhalt der Verträge festsetzen, dispositiv wie beim Darlehensrecht des BGB oder zwingend wie beim Abzahlungsgeschäft. Sie könnten eine allgemeine Verpflichtung zum Vertragsschluß vorschreiben wie bei der Kraftfahrzeug-Haftpflicht-Versicherung ${ }^{26}$ ), oder einen beiderseitigen Kontrahierungszwang wie bei der Energielieferung ${ }^{27}$ ) oder in der Milchmarktordnung ${ }^{29}$ ), oder sie könnten das Rechtsverhältnis ohne Vertrag bei Erfüllung bestimmter Vor-

20) Gesetz über Pflichtversicherung . . . vom 7.11. 1939.

27) \$6 EnWG.

29) \$1 Abs. 1 und 4 MFettG. 
aussetzungen beginnen lassen wie im Sozialversicherungsgesetz $\left.{ }^{20}\right)$. Die Verwaltung kann ins Spiel gebracht werden durch eine Genehmigungspflicht für Unternehmen oder für ihre Tarife oder für alle ihre Verträge, ferner durch eine lockere oder strengere Aufsicht, wie im Privatversicherungsrecht ${ }^{30}$ ) oder im Bankwesen"1), oder auch durch Bildung von Versicherungsträgern als Einrichtungen der Selbstverwaltung wie im Sozialversicherungsrecht. Schließlich kann das Prinzip der Versicherung verlassen und eine allgemeine Staatsbürgerversorgung in unmittelbarer staatlicher Verwaltung eingeführt werden. Das Fortschreiten in dieser Reihe bedeutet ein Fortschreiten von der Privatautonomie zum staatlich bestimmten Recht.

Nehmen wir den Gedanken ernst, daß Privatautonomie das Prinzip des Privatrechts, staatliche Bestimmung des Rechts das Prinzip des öffentlichen Rechts ist, dann stehen diese beiden Prinzipien an den beiden Enden einer Reihe von Möglichkeiten, in der in einem bestimmten Sachbereich - Versicherung, abhängige Arbeit, Wohnungsmiete u. a. m. - staatliche Rechtsetzung und Rechtsgestaltung private Bestimmung des Rechts Stück für Stück ersetzen kann. Bei einer solchen Konzeption durchdringen sich privates und öffentliches Recht auf das engste. Für bestimmte Zwecke, heute für die Zuständigkeitsabgrenzung der Gerichtszweige, den Rechtsunterricht und die Systematik, muß an einer Stelle die Grenze gezogen werden. 1880 lag sie noch dort, wo das Gesetz an die Stelle des Vertrages und der freien Disposition über Rechte tritt, heute liegt sie dort, wo die Exekutive eine Angelegenheit selbst in Verwaltung nimmt ${ }^{32}$ ). Unabhängig von dieser mehr pragmatischen Grenzziehung sollte aber die durchgängige Unterscheidung der Prinzipien erhalten bleiben, denn ein Fortschreiten in jener Reihe der Verstaatlichung des Rechts ist ein Fortschreiten von der Freiheit des Einzelnen.

Rein privates Recht im eigentlichen Wortsinn gibt es heute nicht. Darum ist es besser von bürgerlichem Recht statt von Privatrecht zu sprechen, denn der Bürger ist dem öffentlichen Bereich zugewandt und eingegliedert, er ist nicht "privatus“; und von Amtsrecht statt von öffentlichem Recht, denn auch das bürgerliche Recht, nicht nur das Recht der Ämter und Behörden, ist im öffentlichen Interesse durch die öffentliche Gewalt geordnet. Aber das bürgerliche Recht und selbst das Amtsrecht, wo es Anträge oder Verträge oder andere Mitwirkungen des

20) $\$ \$ 306,537,1227$ RVO.

so) VersAufsG v. 6. 6. 1931 .

s1) KreditwG v. 10. 7. 1961.

39) Vgl. die oben (N. 15) Genannten. 
Bürgers vorsieht, enthält echt privatrechtliche Elemente, nämlich solche der Privatautonomie. Sie sind Elemente der Freiheit. Freilich geschah und geschieht die Einwirkung des Staates auf das Recht - durch Gesetzgebung bis hin zur Einbeziehung in die Staatsverwaltung - auch um der Freiheit willen, aber sie setzt an die Stelle der privaten, der großen Freiheit vom Staat und von der Gesellschaft die sozialisierte, die kleine Freiheit vom Arbeitgeber, vom Vermieter, von den Wechselfällen des Lebens. Das mag weithin wünschenswert sein. Auf dem Gebiet der Sozialversicherung haben wir das Recht in der Reihe der Möglichkeiten weit ins öffentliche Recht bis ins Amtsrecht hinausgeschoben, ohne es bisher zu bereuen. Aber wir sollten uns der Bedeutung der zweierlei Elemente überall in unserem Recht bewußt bleiben, sollten die privatrechtlichen Elemente als Zeichen erhaltener privater Freiheit und die öffentlichrechtlichen als Zeichen fortschreitender Sozialisierung der Freiheit ernst nehmen und bei Entscheidungen über die rechtliche Gestaltung eines Sachbereichs beide auf die Waagschale legen. Das gilt z. B. für die Alternative einer sozialrechtlichen, d. h. mehr öffentlichrechtlichen, oder arbeitsrechtlichen, d. h. mehr privatrechtlichen Konstruktion der Lohnfortzahlung im Krankheitsfall. Es kann vor allem als Warnzeichen bei der Entscheidung solcher Alternativen dienen. Die Versorgung mit Lebensmitteln, mit Energie, mit Verkehrsleistungen u. a. m. ließe sich schließlich ebenso organisieren wie die der Sozialversicherten mit ärztlichen Leistungen, mit der Folge, daB die Partner sich dort wie hier nicht unmittelbar privatrechtlich und personal sondern nur noch mittelbar als die letzten Ausläufer zweier großer, irgendwo weit entfernt miteinander verkoppelter administrativer Systeme, d. h. als Marionetten gegenüberständen.

\section{Gewaltverhältnis und Rechtsverhältnis}

Diese Vereinigung diskutierte 1926 den „Einfluß desSteuerrechts auf die Begriffsbildung des öffentlichen Rechts" ${ }^{\text {(3s)}}$, ein dem heutigen verwandtes Thema. Hensel vertrat damals die Ansicht, das Steuerverhältnis sei kein Gewaltverhältnis, sondern ein gesetzliches Schuldverhältnis öffentlichen Rechts, weil es durch das Gesetz begründet werde, das Behörde und Bürger gleichermaßen binde, von der Verwaltung aber nur gemäß dem Gesetz durchgeführt werde ${ }^{2}$ ). Nawiasky trat dem bei, weil ein Gewaltverhältnis dort bestehe, wo der Berechtigte bestimme, was der Verpflichtete $z u$ tun hat, weil dies aber im Steuerrecht nicht

93) VVDStRL 3 (1927) S. $63 \mathrm{ff}$.

2) aaO., S. 77-87. 
der Fall sei $\left.{ }^{85}\right)$. Bühler, Apelt, Walter Jellinek u. a. ${ }^{30}$ ) widersprachen, weil es nicht auf die gesetzliche Regelung, sondern auf deren Vollzug ankomme, den die Behörde als Berechtigter selbst anordne und durchführe.

Der Vorstoß Hensels blieb ohne Wirkung. Auf der Tagung von 1956 unternahm Herbert Krüger einen Angriff auf das besondere Gewaltverhältnis ${ }^{37}$ ). Weil es ein Rest oder ein illegitimes Gewächs ursprünglicher, unverfaßter, persönlicher Gewalt sei, stehe es im Widerspruch zur Herrschaft des Gesetzes und müsse durch eine Intensivierung des allgemeinen Gewaltverhältnisses ersetzt werden. Dem wurde vor allem von Werner Weber widersprochen, weil die Gewaltverhältnisse heute durchaus rechtlich verfaßt seien und weil die in ihnen ausgebildeten sachbezogenen Ordnungen und Institutionen vor einebnender Egalisierung bewahrt werden müßten ${ }^{88}$ ).

Heute ist die Gewalt im besonderen Gewaltverhältnis in starkem Maße rechtlich gebunden, vor allem durch Erstreckung des Instituts des Verwaltungsakts, der Grundrechtsgeltung und eines entsprechenden Rechtsschutzes in das Innere dieser Verhältnisse, der wiederum zur Ausbildung von Rechtsgrundsätzen und Ermessensschranken in der Verwaltungsrechtsprechung geführt hat. Die weit fortgeschrittene Normierung des Verwaltungshandelns und die wachsenden Zweifel an der zentralen Stellung des Verwaltungsakts im Verhältnis zwischen Bürger und Behörde werfen die seinerzeit von Hensel gestellte Frage erneut und nachdrücklich auf, nämlich ob der Begriff des Gewaltverhältnisses dem gegenwärtigen Verhältnis zwischen Verwaltung und Bürger überall angemessen ist.

Kein Rechtsgebiet ist geeigneter, diese Frage immer neu ins Bewußtsein zu bringen, als das Sozialversicherungsrecht. Das Versicherungsverhältnis entsteht kraft Gesetzes ohne Verwaltungsakt $t^{\text {so }}$, wie die Steuerpflicht, an die Hensel anknüpfte. Beitragspflicht und Leistungsansprüche sind bis ins letzte durch Gesetz oder Satzung geregelt. Obwohl der Versicherte Mitglied einer Körperschaft öffentlichen Rechts ist und dieses Verhältnis im allgemeinen als Gewaltverhältnis gilt $^{40}$ ), kann von einer

$\left.{ }^{25}\right)$ aaO. S. 124 f.; vgl. derselbe, Forderungs- und Gewaltverhältnis, Festschrift Zitelmann, 1913.

${ }^{20)}$ aaO., S. 106-109 (Bühler als Zweitreferent); 118 (Koellreutter), 121 f. (Apelt); 129 (Jellinek).

37) VVDStRL 15 (1957) S. $109 \mathrm{ff}$.

s8) aaO., $186 \mathrm{ff}$. , bes. S. $191 \mathrm{f}$.

s9) Vgl. zum Versicherungsverhältnis Brackmann, Hdb. S. $80 \mathrm{~b}$, 666 p; Wannagat, Lehrbuch, S. 299 ff.

s0) Vgl. H. Krüger, aaO., S. 110. 
Unterworfenheit unter hoheitliche Verfügungsgewalt nicht gut die Rede sein. Vor allem ist dabei zu berücksichtigen, daß sich über den bloßen Inhalt der Gesetze hinaus in Lehre und Rechtsprechung eine Fülle beiderseitiger Rechte und Pflichten ausgebildet hat, in deren Gesamtheit auch die Verwaltungsakte, die im Versicherungsverhältnis ergehen, eingebettet sind. Das gilt auch und wegen der geringeren Normierung sogar verstärkt für das Versorgungs- und Sozialhilferecht. Das Verhältnis verschiedener Sozialleistungen zueinander, die Pflicht sich einer Operation zu unterziehen, die Verweisung auf private Hilfe oder Selbsthilfe, die Behandlung Arbeitsunwilliger, die Pflicht der Behörde zu rascher Entscheidung oder zur Änderung einer Entscheidung von Amts wegen, ein Betreuungsverhältnis mit gegenseitigen Rechten und Pflichten, Pflichten der Behörde zu Informierung, Aufklärung, Rechtsbelehrung, Zusammenwirken mit anderen Stellen, Treu und Glauben, Vertrauensschutz, Pflicht zu besonderer Sorgfalt bei Anrechnungen usw., alle diese und viele andere Gegenstände sind in der Rechtsprechung zum Sozialrecht entwickelt worden ${ }^{41}$ ) und ergänzen die ohnehin minutiösen Regelungen der Gesetze.

Ein Verhältnis, in dem auf beiden Seiten derart ausgearbeitete materielle Rechte und Pflichten bestehen, kann mit dem Schema Rechtsbefehl und Rechtspflicht zum Gehorsam bzw. Abwehrrecht allein nicht angemessen erfaßt werden. Das war anders, solange die Polizeigewalt als paradigmatisch für das Verhältnis zwischen Verwaltung und Bürger gelten konnte. Sie war prinzipiell eine dem Bürger fernstehende Gewalt, die in außerordentlichen Fällen für einen bestimmten und begrenzten Zweck einen Befehl erteilte. Der Forderung nach Recht und Gerechtigkeit wurde Genüge getan, wenn diese Befehlsgewalt an eine gesetzliche Ermächtigung und in ein Netz von Amtspflichten gebunden und einer unabhängigen Kontrolle unterworfen wurde. Alles andere an Rechtsbeziehungen mußte als justizstaatliches Relikt erscheinen. Das alles gilt auch heute, aber es ist denjenigen Bereichen der Verwaltung, die nach Art des sozialrechtlichen Bereichs gestaltet sind, nicht angemessen. Hier tritt der Bürger mit einem Teil seines Daseins in ein längerdauerndes und intensiveres Verhältnis zur Verwaltung. Sie befiehlt ihm, oder bestimmt, was für ihn rechtens ist, aber er wirkt durch Anträge, Meldungen, Auskünfte, Verhandlungen, Erklärungen oder auch nur durch Verwirklichung der gesetz-

4) Vgl. die Ubersicht bei $U$. Eckhardt, Die Sozialverwaltung in der Rechtsprechung des BVerwG, DVBl. 1968, 866 ff. Die viel weitläufigere Rechtsprechung der Sozialgerichte füllt die Kommentare zu den Sozialversicherungsgesetzen. 
lichen Tatbestände an der Entstehung seiner Pflichten und seiner Rechte mit, er gibt und empfängt Leistungen, die miteinander in Zusammenhang stehen, er nimmt und fordert Rücksichten aller Art im Rahmen eines komplexen Lebensverhältnisses. Recht und Gerechtigkeit fordern hier nicht nur interne Bindungen und Kontrollen der Behörde und Abwehrrechte des Betroffenen, sondern rechtliche Relevanz des gesamten Verhältnisses zwischen Behörde und Bürger mit allen darin umschlossenen beiderseitigen Rechten und Pflichten. Dabei kommt es nicht nur auf die Entstehung und Erfüllung der Rechte und Pflichten, sondern vor allem auch auf das dazwischen liegende Verpflichtungsstadium an. Das alles wird umfaßt von dem heute noch ganz im Schatten des Verwaltungsakts und der Verwaltungskontrolle liegenden Rechtsverhältnis zwischen Behörde und Bürger ${ }^{42}$ ).

Von einem Rechtsverhältnis ist in der Verwaltungsrechtslehre nur andeutungsweise und meist nur als der Grundlage für Verwaltungsakte die Rede ${ }^{43}$ ). Der Verwaltungsakt als „einseitige Emanation der hoheitlichen Gewalt" (Forsthoff) ${ }^{44}$ ) steht

42) Vgl. hierzu für das Privatrecht J.Esser, SchuldR I, 3. Aufl., S. 4: Das Verpflichtungsstadium des Schuldverhältnisses ist „nicht nur notwendiges Vorstadium des Bewirkens und Erlangens der geschuldeten Leistung, sondern auch als bestimmte regelungsbedürftige Zeitspanne für die persönliche oder geschäftliche Vorausplanung und Abwicklung des Geschäfts. Schuldrechtliche Tatbestände sind letztlich dafür maßgebend, ob zur richtigen Zeit, in der rechten Dauer, ob überhaupt nicht oder mangelhaft erfüllt worden ist und wie der Gläubiger gegebenenfalls zu entschädigen ist; ferner dafür, ob und wann jemand von seiner Leistungspflicht befreit wird, für welche Risiken er einzustehen hat, welche Handlungen und Umstände er als haftbarmachende zu vertreten hat". Hier finden sich manche Anknüpfungspunkte für den Inhalt von Verwaltungsrechtsverhältnissen.

43) Vgl. O. Mayer, VerwR I, 3. Aufl., S. 103: Rechtsverhältnis als Grundlage subjektiver Rechte, die aber am Status orientiert sind; W. Jellinek, VerwR, 3. Aufl., S. 49: Rechtsverhältnisse öffentlichen Rechts sind solche, „kraft deren Verwaltungsakte vorgenommen werden sollen oder können“; Fleiner, VerwR, 8. Aufl., S. 47 f.: Im öffentlichen Recht gibt es „herrschaftliche Rechtsverhältnisse“, im übrigen bestimmen einseitiger Befehl und Zwangsgewalt das Verhältnis zwischen Verwaltung und Bürger; H.J.Wolf, VerwR I, §32 V: Rechtsverhältnisse werden mehr beiläuflg in kurzem Anhang zur Behandlung des Status und als Folge von Verwaltungsakten erörtert (vgl. § $40 \mathrm{I}$ ); ebenda §44: „Verwaltungsrechtliche Schuldund Ausgleichsverhältnisse" werden für den Bereich vermögenswerter Leistungen anerkannt und in der Richtung des hier Gesagten erörtert.

4) Forsthoff, Lb. 9. Aufl., S. 200 unter Ablehnung eines „dem bürgerlichen Recht vergleichbaren Rechtsverhältnisses zwischen Verwaltung und einzelnem". Unter dem Titel "Verwaltungsrechtsver- 
nach wie vor allein im Mittelpunkt der Verwaltungsrechtslehre. Gewiß kann der Verwaltungsakt im Verwaltungsrecht nicht entbehrt werden, und wenn "einseitig“ bedeutet, daß die behördliche Bestimmung dessen, was für den Bürger rechtens ist, nur als Ausspruch der Behörde ohne Zustimmung des Bürgers Geltung erlangt - im Gegensatz zum Vertrag -, so ist dagegen nichts einzuwenden. Es kann aber, wie die am Beispiel des Sozialrechts aufgezählten Rücksichten zeigen, nicht bedeuten: Emanation eines objektiven Staatswillens, der an und für sich und ohne Ansehen der Person richtig und gerecht und darum für die Rechtsstellung des Bürgers allein maßgebend ist. Die Anwendung des Gesetzes und das Ermessen, die den Verwaltungsakt tragen, geschehen nicht einseitig im Sinne von: ohne Bezug auf den Betroffenen. Es wird meist nicht genügend beachtet, $d a B$ der Verwaltungsakt einen materiellen und einen formellen Aspekt hat. Er ist, wie das Urteil, abschließender Bestandteil eines Verwaltungsverfahrens und insofern ebenso streng einseitig wie das gerichtliche Urteil, nämlich Ausdruck der staatlichen Dispositionsbefugnis über das Recht der Bürger. Sofern er aber materiell bestimmt, was für den Bürger rechtens ist, ist er eingebettet in ein System von Rücksichten, juristisch: von Rechten und Pflichten - Grundrechten, Amtspflichten, Ermessensbindungen, Rechtsgrundsätzen, Mitwirkungsrechten oder -pflichten u. a. - und ergeht nicht einseitig, sondern in dem zweiseitigen gesetzlichen Rechtsverhältnis zwischen Verwaltung und Bürger und in seinem Inhalt durch dieses Verhältnis bestimmt. Das gilt auch und grade für die besonderen Gewaltverhältnisse. Es ist einfach nicht wahr, daß das Verhältnis zwischen Gefängnisleitung und Gefangenem, Vorgesetztem und Beamten usw. hors la loi wäre. Es ist durch Grundrechte, Amtspflichten und Ermessensgrenzen bestimmt, auch da, wo es Entscheidungsspielräume einer Seite enthält, vergleichbar dem $\mathrm{Ar}$ beitsverhältnis mit seinen allgemeinen Weisungsrechten und Gehorsamspflichten, das ohne Zweifel ein Rechtsverhältnis ist.

Die genannten Einwände gegen Hensel - nicht das Gesetz, sondern die Verwaltung bestimme konstitutiv, was für den Bürger rechtens ist - beruhen auf der Alternativfrage: Setzt das Gesetz das Recht zwischen Verwaltung und Bürger, das

hältnis", aaO., $\$ 10$, behandelt er einige allgemeine Rechtsinstitute wie Geschäftsfähigkeit, Vertretung, Ersitzung, subjektive öffentliche Rechte u. a.m. Hier geht es demgegenüber um die besonderen Verwaltungsrechtsverhältnisse. Im Anstaltsbenutzungsrecht, aaO., § 21, S. 393, will Forsthoff für „besondere, engere Verhältnisse zur Verwaltung" und Fälle mit „Parallelen zur privatrechtlichen Vertragslage“ schuldrechtliche Bestimmungen sinngemäß heranziehen. 
von der Behörde nur ausgeführt wird, oder setzt es die Verwaltung, die dazu vom Gesetz nur intern ermächtigt wird? Ein Rechtsverhältnis scheint nur im Fall der ersten Alternative möglich. In Wirklichkeit setzt das Gesetz - einschließlich Verfassung und Rechtsgrundsätzen - das Rechtsverhältnis als einen Rahmen, innerhalb dessen, nicht nur kraft dessen die Verwaltung zur abgeleiteten oder selbständigen Rechtsbestimmung und -durchsetzung befugt ist ${ }^{45}$.

Das Verwaltungsrechtsverhältnis ist weder auf den Bereich des Verwaltungsvertrages noch auf die Leistungsverwaltung beschränkt, obwohl es hier am wichtigsten ist. Das Sozialrecht zeigt, daß der öffentlichrechtliche Vertrag nicht das Kardinalproblem der Leistungsverwaltung ist und daß Leistungs- und Eingriffsverwaltung nicht so getrennt und einander entgegengesetzt werden können, wie es oft geschieht. Eingriff, nämlich Zwangsmitgliedschaft und Auferlegung von Abgaben, und Leistungen sind in einem Rechtsverhältnis miteinander verknüpft. Der Vertrag spielt angesichts der zwingenden gesetzlichen Regelung aller Einzelheiten des Versicherungsverhältnisses keine Rolle. Es kann also nicht der Verwaltungsakt der Eingriffsverwaltung, der Vertrag der Leistungsverwaltung zugeordnet werden. Es muß oder kann auch nicht ein besonderes Recht der Leistungsverwaltung neben dem der Eingriffsverwaltung entwickelt werden, sondern es müssen den einzelnen Sachbereichen angemessene Verwaltungsrechtsverhältnisse ausgearbeitet werden, in denen Eingriffe wie Leistungen, Verwaltungsakte als einseitige Rechtsgestaltungen der Behörde wie Verträge ihren Platz haben.

45) Strickrodt bei Bühler-Strickrodt, aaO., S. 360, weist sehr zu Recht darauf hin, daß die zwangsweise durchgeführte Vollziehung als verfahrensrechtliche Erscheinung von dem materiellen Rechtsverhältnis und seiner normalen Abwicklung als ein rechtliches aliud zu unterscheiden sei. - Freilich bleibt die Anwendung hoheitlicher Gewalt in der behördlichen Entscheidung über das, was für den Bürger rechtens ist, und ihre Durchsetzung zu beachten. Hierin unterscheidet sich das öffentlichrechtliche von dem privatrechtlichen Rechtsverhältnis. In diesem entscheiden nur beide Partner gemeinsam - durch Vertrag - oder Dritte - der Gesetzgeber generell, der Richter individuell - was rechtens ist, in jenem auch ein Partner einseitig: die Behörde. Es ist jedoch ein entscheidender Unterschied, ob das Gesetz und die Rechtsgrundsätze als Ermächtigung der $\mathrm{Be}$ hörde zu einseitigem Handeln und Entscheiden und deren Einschränkung gesehen werden oder als Regelung eines zweiseitigen Rechtsverhältnisses, in dem die Behörde Entscheidungsbefugnisse besitzt. Das Verhältnis des Bürgers zum Gesetzgeber ist ein Gewaltverhältnis. Formelle und materielle Normen der Verfassung reichen nicht aus, ein rechtliches Rahmenverhältnis zu bilden, in dem sich Gesetzgebung abspielt. Gesetzgebung ist einseitige Ausübung von Staatsgewalt. 
Die Verwaltungsrechtslehre befindet sich vor dieser Aufgabe in einer ähnlichen Lage wie die Pandektistik des 19. Jh. Paradigmatisch für das Privatrecht war bis dahin das Eigentum gewesen, Schuldverhältnisse waren bloß die Titel abgeleiteten Eigentumserwerbs ${ }^{40}$ ) oder die Folgen der Eigentumsverletzung, also sekundär, entsprechend einer primär statischen Rechtsordnung. Da aber an die Stelle von Eigentum und Herrschaft im 19. Jh. der Austausch von Gütern und Leistungen trat, mußte das Obligationenrecht an die erste Stelle treten, was im BGB auch räumlich geschah, und zu diesem Zweck teils ausgebaut teils neu geschaffen und seitdem ständig fortentwickelt wer$\operatorname{den}^{47}$ ). Ebenso und aus entsprechenden Gründen muß im öffentlichen Recht neben das Verhältnis von hoheitlicher Gewalt und statusförmigen Abwehrrechten das Verwaltungsrechtsverhältnis treten ${ }^{48}$ ). Auch zwischen Staat und Bürger sind weithin nicht mehr statische Herrschaftsgewalt und ebenso statische Grundrechte bestimmend, sondern eine Fülle dynamischer Beziehungen und Abhängigkeiten, die in einem differenzierenden und zugleich beweglichen System von gesetzlichen Rechtsverhältnissen geordnet werden müssen ${ }^{40}$ ).

Ausgearbeitete Rechtsverhältnisse gibt es außer im Sozialversicherungsrecht in den Teilen des heutigen Verwaltungsrechts, die ehemals als privatrechtlich oder fiskalisch galten, vor allem im Beamtenrecht und im Steuerrecht ${ }^{50}$ ), die beide erst nachträg-

10) Vgl. J. Esser, SchuldR I, 3. Aufl., S. $1 \mathrm{f}$.

47) Vgl. J. Esser, aaO., S. 1 1. m. Nachw., zum Erfolg s. ebenda \$ 6.

18) Vgl. meine Schrift Das subjektive öffentliche Recht, 1967, S. 99 ff., auch S. 50 ff., 54 ff. Dort ergab sich, daß ein subjektives öffentliches Recht ohne gesetzliches Rechtsverhältnis zwischen Bürger und Verwaltung überhaupt nicht denkbar ist.

10) Dagegen spricht Hesse, Grundzüge des Verfassungsrechts, 3. Aufl. 1969, S. 111 f., allerdings nicht für das Verwaltungsrecht, vom Status des Staatsbürgers als Alternative zum Gewaltverhältnis. Rupp, Grundfragen der heutigen Verwaltungsrechtslehre, 1965, S. $153 \mathrm{ff}$., baut die Rechtsposition des Bürgers gegenüber der Verwaltung noch auf dem Status auf, wie es G. Jellinek, System der subj. öff. Rechte, 1905 , bereits tat.

so) Vgl. Bühler-Strickrodt, SteuerR I, 3. Aufl., S. 347 ff.: „Steuerrechtsverhältnisse", S. 361 ff.: "Steuerschuldverhältnis". Diese Abschnitte enthalten für das Steuerrecht ganz das, was hier für das ganze Verwaltungsrecht gefordert wird. Vgl. z. B. S. 350: Rechtsverhältnissen öffentlichen Rechts könne ebenfalls „jene Feinstruktur und Realisierungspräzision gegeben werden, die im Privatrecht durch die Fülle der vertraglichen und prozessualen Einzelgestaltungen üblich oder doch möglich ist", auch und grade da, wo sie nicht auf Vertrag, sondern auf Gesetz beruhen; S. 351: Steuerrechtsverhältnisse sind „die Gesamtheit der aktuellen Beziehungen zwischen dem Steuerpflichtigen und der Steuerbehörde umfassende, dabei aber im Einzelfall genau individualisierte Rechtsverhältnisse"; es herrsche 
lich dem Schema des öffentlichen Gewaltverhältnisses eingeordnet wurden. In anderen Teilen, wie im Subventionsrecht ${ }^{51}$ ), sind sie in der Ausbildung begriffen, am wenigsten noch im Anstaltsbenutzungsrecht ${ }^{52}$ ).

Hier und in sonstigen Bereichen des Verwaltungsrechts liegt ein weites Feld für sammelnde und ordnende Arbeit. Mit ihr wird eine neue, den gegenwärtigen Verhältnissen und Bedürfnissen angemessene, systematische Durchgestaltung des Verwaltungsrechts und damit eine entsprechende systematische Auslegung möglich sein, die einem Vergleich mit der des Privatrechts standhält. Nur in einem den sachlichen Besonderheiten und den Verhältnissen der Beteiligten angemessenen Verwaltungsrechtsverhältnis kann sich eine Billigkeitsrechtsprechung entfalten, die sich nicht in bodenlosen Grundrechts- und Wertspekulationen verliert; dabei könnte Art. 3 GG durchaus zum $\$ 242$ des Verwaltungsrechts werden. Schließlich könnte das formale verfahrensrechtliche, teils noch immer aktionenrechtliche Denken auch im Verwaltungsrecht überwunden werden und einem Denken in materiellrechtlichen Rechtsinstituten und Ansprüchen Platz machen. Das Verwaltungsprozeßrecht hat mit seiner Leistungs- bzw. Unterlassungsklage Raum genug für Rechte und Ansprüche aller Art, und der unscharf gewordene Verwaltungsakt könnte in seine ursprünglichen Konturen als behördliche, förmliche Entscheidung darüber, was für den Bürger rechtens ist, zurückgeführt werden.

\section{Staatsverwaltung und Selbstverwaltung}

Der organisatorische Bereich des Sozialverwaltungsrechts ist in dessen gewichtigstem Teil, dem Sozialversicherungsrecht, durch die Selbstverwaltung charakterisiert ${ }^{53}$ ). Das Recht der

jedoch noch die Vorstellung von einem Abgabengewaltverhältnis als Unterwerfungsverhältnis auf Grund obrigkeitlichen Befehls; S. 353: Dementsprechend zerreißen „ein punktuelles Denken und ein entsprechendes kasuistisches Verhalten die sowohl von der staatlichen Gesetzgebung her als auch auf seiten der einzelwirtschaftlichen und perönlichen Belastungen und vorsorgenden Planung begründeten Wirkens- und Verantwortungszusammenhänge".

51) Vgl. Götz, Das Recht der Wirtschaftssubventionen, 1966, bes. S. 32 f.: zum „Subventionsverhältnis“, sowie L. Simons, Leistungsstörungen verwaltungsrechtlicher Schuldverhältnisse, 1967.

52) Es wird z. B. bei $H . J$. Wolff, VerwR II, \$99, im Organisationsrecht behandelt und bleibt kasuistisch und enumerativ.

53) Vgl. SVwG v. 22.2.1951 i.d. F. v. 23. 8. 1967; Th. Siebeck, Das Recht der Selbstverwaltung in der Sozialversicherung, (Losebl.); Maunz-Schraft, Die Sozialversicherung und ihre Selbstverwaltung (Losebl.); Brackmann, Hdb. S. 154 b IV ff.; Werner Weber und J. Salzwedel, Die Selbstverwaltung in der Sozialversicherung, Schr.- 
Selbstverwaltung ist auch Teil des Allgemeinen Verwaltungsrechts $^{54}$ ). Es soll auch hier die Frage gestellt werden, was die Selbstverwaltung im Sozialrecht für die Selbstverwaltung als Institut und Lehrbereich des Allgemeinen Verwaltungsrechts bedeutet oder bedeuten könnte. Lange galt die kommunale Selbstverwaltung als paradigmatisch für Selbstverwaltung überhaupt ${ }^{\mathrm{ts}}$ ). Sie kann es nicht mehr sein. Es war von Anfang an zweifelhaft, ob die neue Selbständigkeit der Städte zu Beginn des 19. Jh. die Wiedererweckung alter autonomer Zellen der öffentlichen Ordnung oder ob sie die vorsichtig abscheidende Verselbständigung eines Bestandteils der einheitlichen Staatsverwaltung $\left.\mathrm{war}^{56}\right)$. Auch sind die Unterschiede zwischen Kommunal- und Staatsverwaltung eingeebnet: die kommunalen Körperschaften werden nicht von Bürger-Honoratioren, sondern wie die Länder von Parteien und Fachbeamten verwaltet, und die lokale Durchführung staatlicher Aufgaben überwiegt die wirklich eigenen Angelegenheiten ${ }^{57}$ ).

Die Selbstverwaltung der Städte wurde im 19. Jh. vom Bürgertum als ihre politische Organisationsform betrachtet und als gesellschaftliche Eigenverwaltung der staatlichen Verwaltung entgegengesetzt ${ }^{58}$ ). Dieses oppositionelle Prinzip aus der Zeit des großen Konflikts zwischen Bürgertum und Monarch besitzt keine Gültigkeit mehr. Es geht heute um den Anteil des Staates einerseits und der Kräfte der Gesellschaft, dargestellt in den Verbänden und ihrem Management, andererseits an der Verwaltung. Deshalb ist Kommunalverwaltung heute dezentralisierte Staatsverwaltung. Wenn es darum geht, das Institut einer eigenständigen Selbstverwaltung im Allgemeinen Verwaltungsrecht neu zu etablieren und auszubauen, so kann eher die Sozialversicherung in ihrer heutigen Ausgestaltung ${ }^{50}$ ) als paradigmatisch gelten. Hier hat Selbstverwaltung sich als „soziale

reihe d. Dt. Sozialgerichtsverb. Bd. 1 (1966) S. $27 \mathrm{ff}$.; Wertenbruch, Sozialrecht und allgemeines Verwaltungsrecht, DOV 1969, $593 \mathrm{ff}$. (600 f.).

54) Vgl. Forsthof, VerwR, § 24; H.J. Wolf, VerwR II, \$§ 80, 84 ff.; Werner Weber, Der nicht staatsunmittelbare öffentliche Organisationsbereich, Juristen-Jahrbuch Bd. 8 (1967/68) $137 \mathrm{ff}$.

85) Vgl. z. B. Otto Mayer, VerwR 3. Aufl, Bd. 2, S. 357 mit N. 11; Fritz Fleiner, Inst. d. Dt. VerwR, 8. Aufl. 1928, S. 105, der auch schon Sozialversicherungsträger nennt; Forsthoff, aaO., S. 438 ff., schildert die Entwicklung des Selbstverwaltungsbegriffs.

s6) Vgl. Forsthoff, aaO., S. 438 ff. einerseits und etwa $E$. Becker in Hdb. d. komm. Wissensch. u. Praxis, Bd. 1 1956, S. 118 ff.; E. R. Huber, Selbstverw. d. Wirtsch., 1958, S. 7 andererseits.

si) Vgl. Forsthoff, aaO., S. $439 \mathrm{f}$.

58) Forsthoff, aaO., S. 438 f.; Wolff, aaO., II, $\$ 80$ IV c.

s9) Nach dem SVwG v. 22. 2. 1951 i. d. F. v. 23. 8. 1967. 
Selbstverwaltung" herausgebildet, getragen von den sozialen Kräften, die das liberale Bürgertum abgelöst haben, und von einer Bewegung der Zusammenarbeit der Sozialpartner, die nach 1918 begann, in Verfassungsplänen des Widerstandes fortgeführt wurde ${ }^{80}$ ) und nach 1945 etwa in der "Gesellschaft für sozialen Fortschritt" gepflegt wurde ${ }^{61}$ ). Sie ist heute ein wesentlicher und, richtig verstanden, ausbaufähiger Teil unserer öffentliche Ordnung.

Sozialversicherung gilt heute meist als mittelbare Staatsverwaltung ${ }^{62}$ ). Dahinter steht die für das Verständnis von Selbstverwaltung scheinbar entscheidende Alternative von mittelbarer, d.h. relativ verselbständigter, Staatsverwaltung und Verwaltung eigener Angelegenheiten durch nichtstaatliche Einheiten der Gesellschaft.

Tatsächlich handelte 1881 der Staat - die Reichsregierung und der Reichstag - an Stelle der dazu nicht fähigen oder nicht bereiten sozialen Mächte, und zwar in ausdrücklicher Betonung seiner Aufgabe, nicht nur defensiv das Recht zu schützen, sondern das Wohlergehen aller, besonders der Schwachen, positiv zu fördern ${ }^{\text {(5) }}$ ) Andererseits beschränkte er sich auf die Anordnung der Zwangsmitgliedschaft, die Regelung der Beiträge und Leistungen und die Zahlung von Staatszuschüssen, überließ - oder übertrug - aber die Verwaltung der "genossenschaftlichen Selbstverwaltung", indem er, wie es in der kaiserlichen Botschaft hieß, „die realen Kräfte des Volkslebens . . . in der Form korporativer Genossenschaften unter staatlichem Schutz und staatlicher Förderung " zusammenfaßte, weil „die Staatsgewalt allein“ dieser Aufgabe nicht gewachsen sein würde ${ }^{64}$ ). Der Staat handelte also nicht selbst, wie bei Polizei, Verteidigung, Straßenbau, Eisenbahn, aber es handelten auch nicht autonome Gruppen aus eigener Initiative und Finanzkraft wie in Handelsgesellschaften, Wirtschaftsvereinigungen, Gewerkschaften, Wohlfahrtsverbänden. Die Frage, ob Selbstverwaltung wie die der Sozialversicherung mittelbare Staatsverwaltung oder gesellschaftliche Eigenverwaltung ist, ist also auf diese Weise nicht zu beantworten. Sie hängt von den Be-

80) Vgl. meinen Art. „Widerstandsbewegung“ im Evangelischen Staatslexikon, 1966, m. Nachw.

B1) Vgl. G. Erdmann, Die soziale Selbstverwaltung . . ., E. Bïhrig, Soziale Selbstverwaltung ..., H.-A. Bischoff, Staatsaufsicht und Selbstverwaltung . . ., alle in Festschrift für Fr. Sitzler, 1956.

62) Vgl. insbes. Brackmann, Hdb. S. 154 c mit zahlr. Nachw.; a. A. z. B. E. R. Huber, aaO., S. $40 ;$ H. Peters, Offentliche und staatliche Aufgaben, Festschr. H. C. Nipperdey, 1966, S. 877 ff. (889 f.).

o9) G. Wannagat, Lb. d. Soz.Vers. R., Bd. 1, 1965, S. 61.

4) Zitiert nach Wannagat, aaO., S. $63 \mathrm{f}$. 
griffen Staat, Gesellschaft, öffentlich und privat und ihrem Verhältnis zueinander $a b^{65}$ ).

Ich halte die Unterscheidung von Staat und Gesellschaft nicht für eine vorübergehende Erscheinung des bürgerlichen Zeitalters, sondern für eine Einsicht von bleibender Bedeutung für die Freiheit. Unterscheidung bedeutet allerdings hier ebensowenig wie im Verhältnis von öffentlichem und privatem Recht Scheidung, Trennung. Die Unterscheidung wird heute besonders von einer Sozialstaatslehre abgelehnt, die die Gesellschaft als den Inbegriff alles Offentlichen ansieht, in der es als reaktionäre Anmaßung erscheint, aus dem universalen Zusammenhang von Leistung und Verteilung einen spezifisch staatlichen Bereich als übergeordnet herauszuheben $\left.{ }^{68}\right)$. Daran ist soviel richtig, daß Offentlichkeit, öffentliches Interesse, Gemeinwohl nicht Domänen der verfaßten staatlichen Amtsgewalt sind. Wären sie das, dann müßte sich der Staat als Amtsgewalt in diesem Sinne in alle Bereiche des Gemeinwesens erstrecken, in denen öffentliche Angelegenheiten wahrzunehmen sind, und die staatsfreie Gesellschaft wäre zu privater Tätigkeit und zu privatem Nutzen reduziert und disqualifiziert, was ganz einfach den tatsächlichen Verhältnissen widerspräche oder zum totalen Staat führen müßte, wenn man die Verhältnisse dem anpassen wollte. Es läßt sich nicht leugnen, daß in und zwischen den Verbänden ein hohes $M a ß$ an öffentlichem Interesse und Gemeinwohl verwirklicht wird ${ }^{\mathrm{Q} 7}$ ). Andererseits geht es nicht an, die Sonderstellung der verfaßten staatlichen Amtsgewalt zu leugnen. Diese Sonderstellung beruht wie gesagt nicht auf einem Monopol des Offentlichen und auch nicht auf einem Monopol des Politischen als eines Bereiches des Öffentlichen. Politik ist die Uberwindung öffentlich relevanter Konflikte. Solche Konflikte werden in unendlicher Zahl ohne Staat überwunden, nämlich durch Kooperation und Kompromiß, auch durch Verbandsdisziplin. $\mathrm{Zu}$ einem Teil aber bleiben sie unüberwindbar. Ist das der Fall, und geht es um Leben, Freiheit, Eigentum und ein Mindestmaß an Gerechtigkeit, so gehen solche

o5) Hierauf weist Forsthoff, aaO., S. 441 hin.

60) So Ulrich K. Preuss, Zum staatsrechtlichen Begriff des Offentlichen, 1969, unter Verarbeitung der einschlägigen neueren Literatur. Sein Angriff auf die Identifikation von Staat und öffentlichem Bereich scheint mir berechtigt, wenn auch in vielem übertrieben.

o7) Vgl. hierzu bes. E. R. Huber, aaO., passim, und H.Peters, aaO., Doch verfließt bei Huber der Selbstverwaltungsbegriff. Peters' Unterscheidung von öffentlichen und staatlichen Aufgaben scheint mir überzeugend, allerdings ohne die Begründung mit dem sog. Subsidiaritätsprinzip. 
Konflikte aus der gesellschaftlich-politischen in die staatlichpolitische Sphäre über.

Da solche Konflikte nicht durch Kooperation, Kompromiß und Verbandsdisziplin überwunden werden können, aber überwunden werden müssen, werden sie mit verbindlicher Wirkung für die Beteiligten und bewehrt mit der Androhung von Zwang entschieden, wobei die Entscheidung u. U. weit in das Vorfeld drohender Konflikte hineingreifen muB. Eine solche Entscheidung steht nach Verfassung und Vernuft nur der verfaßten staatlichen Amtsgewalt zu. Sie ist ihr eigener Bereich und ihre spezifische Aufgabe. Deren Erfüllung ist nicht eine Leistung unter anderen, sondern wegen des akuten oder latenten Zwangs und weil jeder gesellschaftlich relevante Konflikt zum staatlich relevanten Konflikt werden kann, übergeordnetes, hoheitliches Handeln. Damit ist nur gesagt, was jedenfalls und ausschließlich Staatsaufgabe ist, nicht, daß der Staat auf Gefahrenabwehr beschränkt sei. Zwischen reinen Staatsaufgaben und rein gesellschaftlichen Aufgaben liegt eine tiefe Zone öffentlicher Aufgaben, zu deren Erfüllung die Beteiligung des Staates nicht entbehrt werden kann, ohne daß sie ganz in staatliche Verwaltung genommen werden müßten.

Sie bildet den Bereich möglicher Selbstverwaltung. Er umfaßt einen breiten Fächer von Möglichkeiten zwischen den beiden Extremen reiner Staatsverwaltung und rein gesellschaftlicher Erfüllung öffentlicher Aufgaben $\left.{ }^{68}\right)$. Das Sozialrecht als

68) Ich glaube, daß eine solche Vorstellung von Selbstverwaltung das Verfließen der begrifflichen Konturen vermeidet, das Werner Weber, Selbstverwaltung der Wirtschaft im Staat der Gegenwart, in: Staats- und Selbstverwaltung in der Gegenwart, 2. Aufl. 1967, S. 142 ff., gegen den Selbstverwaltungsbegriff E. R. Hubers (vgl. diesen, aaO.) geltend gemacht hat, andererseits aber auch Erscheinungen gerecht werden könnte, die vom klassischen Selbstverwaltungsbegriff (W. Weber, aaO., S. 151 ff.: kommunale, berufsständische, akademische, wasser- und bodenwirtschaftliche, sozialversicherungsrechtliche Selbstverwaltung und die der wirtschaftlichen Kammern) nicht erfaßt werden, vgl. dazu das Folgende.

$\mathrm{Zu}$ der hier gewählten Art der Begriffsbildung vgl. Nawiasky, Forderungs- und Gewaltverhältnis, Festschrift Zitelmann, 1913, S. 30 f.: „Zwei voneinander verschiedene Begriffe müssen sich nicht im Verhältnis von Position und Negation befinden, sie können auch die beiden Endpunkte einer geschlossenen Reihe bilden, deren Verbindung durch ein Mehr an Maß oder Grad hergestellt wird. Der Qualitätsunterschied beruht hier auf einem Unterschied der Quantität. Es ist das Prinzip der Typenbildung, das uns da entgegentritt. Eigentümlicherweise macht die juristische Begriffsbildung von dieser Konstruktionsmöglichkeit in der Regel keinen Gebrauch, obwohl doch das Leben, das in seinen formalen Beziehungen gemeistert werden soll, die stufenweisen Ubergänge den unvermittelten Gegensätzen vorzieht, obwohl doch nur diese Denkform die Umbildung 
modernes Rechtsgebiet läßt diesen Fächer für ein modernes Allgemeines Verwaltungsrecht in exemplarischer Weise erkennen. Zwischen reiner Staatsverwaltung, d. h. Ämter- und Behördenverwaltung des Bundes und der Länder, wie sie im Versorgungswesen besteht - z. B. Versorgungsämter als Sonderbehörden - und der rein gesellschaftlichen staatsfreien Tätigkeit, z. B. der Wohlfahrtsverbände, liegt eine Reihe von Organisationsformen der Selbstverwaltung. Die Bundesanstalt für Arbeit ist keine Einrichtung der Staatsverwaltung, weil sie als juristische Person mit eigenen Organen unter bloßer Rechtsaufsicht des Bundes aus der Staatsverwaltung ausgegliedert ist ${ }^{60}$ ). DaB sie juristische Person öffentlichen Rechts ist und unter Staatsaufsicht steht - einschließlich der Genehmigungspflicht für Satzung und Haushalt ${ }^{70}$ ) und sonstiger Genehmigungsvorbehalte - hält sie in der Nähe der Staatsverwaltung, ebenso die Ernennung der Präsidenten und Stellvertreter und die Berufung des Vorstandes und des Verwaltungsrates durch den Staat ${ }^{71}$ ). Die Bundesanstalt ist andererseits eine Einrichtung der Selbstverwaltung, weil und sofern ihre Organe aus Vertretern der Gewerkschaften und der Arbeitgeberverbände, neben Vertretern der öffentlichen Körperschaften, bestehen und die Mitglieder der unteren Organe durch die höheren Organe berufen werden ${ }^{72}$ ), ferner weil sie keiner Dienst- und Fachaufsicht unterliegt ${ }^{73}$ ) und aus Beiträgen der Versicherten und ihrer Arbeitgeber finanziert wird ${ }^{74}$ ). Entsprechendes gilt für die übrigen Sozialversicherungsträger, doch ist dem Prinzip der gesellschaftlichen Eigenverwaltung hier mehr Raum gegeben, indem alle Organe von den Versicherten und ihren Arbeitgebern nach Vorschlagslisten der Gewerkschaften und der Arbeitgeberverbände gewählt werden ${ }^{75}$ ). Eingeschränkt ist der Selbstverwaltungscharakter dieses Bereiches wiederum dadurch, daß eine nach staatlichen Gesetzen handelnde Bürokratie die eigentliche Substanz der Sozialversiche-

und damit die Entwicklung voll erfassen läßt. Es ist vielleicht nicht zu gewagt, wenn behauptet wird, daß durch die Nutzbarmachung dieses Prinzips manches bisher unbefriedigend gelöste Problem der rechtlichen Begriffsbestimmung geklärt werden kann, wenn auch selbstverständlich dabei mit juristischem Takt verfahren werden muß."

(9) $\S \S 189,190,224$ ArbeitsförderungsG v. 25.6.1969 (AFG)

70) $\$ 214,216$ AFG.

71) $\$ \S 197,211$ AFG.

72) $\S 192,195,197$ AFG.

73) \$224 AFG.

71) \$167 AFG.

75) § 7 SVwG. 
rungsträger ausmacht, die den Verbänden nur zur personellen Disposition überlassen worden ist.

Die Sozialhilfe ist, soweit sie von Kommunalkörperschaften getragen wird, wie gesagt nur dezentralisierte Staatsverwaltung. Ein Anteil gesellschaftlicher Eigenverwaltung besteht hier insoweit, als die Träger der Sozialhilfe den Verbänden der freien Wohlfahrtspflege einen Teil ihrer Aufgaben übertragen können ${ }^{76}$ ). Hier ragt die Selbstverwaltung in den Bereich der sogenannten Beliehenen hinein ${ }^{77}$ ). Die Beleihung kann eine Form der Selbstverwaltung sein, sofern auf ihrer Grundlage Glieder der Gesellschaft öffentliche Aufgaben unter Mitwirkung der Staatsverwaltung - in Gestalt der Ubertragung, der Aufsicht, eventuell der Finanzierung - erfüllen.

Der Streit um die Subsidiarität der kommunalen Jugendund Wohlfahrtspflege gegenüber derjenigen der freien Verbände gehört nicht in den Bereich der Selbstverwaltung, ist aber für deren Abgrenzung nach der Seite der rein gesellschaftlichen Eigenverwaltung von Bedeutung ${ }^{79}$ ).

Sozialverwaltungsrecht ist paradigmatisch für eine moderne Selbstverwaltung, aber keineswegs die einzige Möglichkeit der Teilung einer öffentlichen Aufgabe zwischen staatlichem Ämterwesen und gesellschaftlichen Kräften. In den angedeuteten Fächer können viele Erscheinungen der öffentlichen Verwaltung eingeordnet und je nach dem Gewicht beider Seiten systematisch lokalisiert werden.

Zur Abgrenzung ist zunächst darauf hinzuweisen, daß auf beiden Seiten administratives Handeln erforderlich ist, damit von Selbstverwaltung die Rede sein kann. Einwirkung oder Mitwirkung des Gesetzgebers oder der Gerichte auf gesellschaftliches Handeln macht es nicht zur Selbstverwaltung. Darum ist der Abschluß von Lohntarifverträgen nach dem Tarifvertragsgesetz keine Selbstverwaltung, wohl aber die Festsetzung der Güterkraftverkehrstarife durch die Tarifkommissionen der beteiligten Verbände, die vom Bundesminister für Verkehr als Verordnungen verkündet werden ${ }^{20}$ ).

Ferner schaffen Konzessionierung, Erlaubnis, z. B. im Gewerberecht, Uberwachung. z. B. der gewerblichen Anlagen, und Sonderaufsicht, z. B. im Kredit- und Versicherungswesen, keine Selbstverwaltung, weil es sich nicht um spezifisch öffentliche, politisch relevante Tätigkeiten handelt, sondern nur um rein

76) $\$ 10$ Abs. 5 BSHG.

77) Vgl. H.J. Wolf, VerwR II § 104.

i8) Vgl. H.J. Wolff, aaO.; VerwR III § 147 II; BVerfGE 22, 180.

79) $\$ \$ 20 \mathrm{ff}$. GüKG. 
staatliche Gefahrenabwehrmaßnahmen gegen Gefahren aus privater und primär privatnütziger Tätigkeit. Dasselbe gilt für die Heranziehung Privater für die Erfüllung staatlicher Verwaltungsaufgaben - Vorratshaltung, sachverständige Beratung u. a. m. - weil sie den Privaten zum bloßen Gehilfen der Verwaltung macht. Staatliche Zuschüsse begründen dann Selbstverwaltung, wenn nicht nur mittelbar, wie bei Subventionen, sondern unmittelbar wie bei der Sozialversicherung oder etwa der Deutschen Forschungsgemeinschaft öffentliche Aufgaben erfüllt werden, was dann mit staatlicher Rechnungsprüfung verbunden ist $\left.{ }^{80}\right)$.

Schließlich wären Erscheinungen wie die von manchen erstrebte Selbstverwaltung der Gerichte nur Verselbständigung von Teilen der Staatsverwaltung, nicht Selbstverwaltung.

In dem verbleibenden Bereich spezifisch öffentlicher, aber nicht notwendig rein staatlicher Aufgaben liegt der Fächer möglicher Formen von Selbstverwaltung. Seine Gestaltung liegt, unbeschadet der Verfassung und des Gesetzesvorbehaltes, im Ermessen des Staates. Dabei muß jedoch das Prinzip der gesellschaftlichen Eigenverwaltung gegenüber dem der Staatsverwaltung den Vorrang haben. Das folgt nicht aus dem Subsidiaritätsprinzip, weil es keine Allgemeinverbindlichkeit beanspruchen kann. Es folgt aus der Einsicht, daß der Staat kein Monopol für die Regelung aller relevanten überindividuellen Angelegenheiten, für öffentliches Wohl und öffentliche Interessen hat, daß der souveränen Staatsanstalt keine atomisierte Menge freier Individuen, sondern eine tätige und lebendige Gesellschaft gegenübersteht, deren Befreiung zuerst von ständischer Bindung und Enge, später von landesherrlicher Vormundschaft und schließlich von schrankenloser Wirtschaftsmacht nicht rückgängig gemacht werden soll. Auf der anderen Seite ist nicht zu vergessen, daß ohne die Entmachtung der intermediären Gewalten, ohne die Konzentration der politischen Entscheidungsbefugnis auf das verfaßte staatliche Ämterwesen die Gesellschaft nicht befreit worden, d. h. nicht entstanden wäre. Auch die Sozialversicherung ist vom Staat geschaffen worden. Dieser auf die politische Entscheidungsbefugnis konzentrierte Staat ist im Begriff auszuufern. Seine Souveränität ist ihm für den Bereich der staatspolitischen Entscheidungen gegeben, nicht für die Besorgung aller öffentlichen Angelegenheiten. An ihnen kann und soll er sich in zweckmäßiger Weise beteiligen, soweit es notwendig ist, aber er soll sie nicht in eigene Verwaltung nehmen, solange und soweit sie von den gesellschaftlichen

80) Vgl. \$31 Abs. 1 RVO; H. Peters, aaO., S. 883. 
Kräften in Kooperation und Kompromiß wahrgenommen werden können. Das braucht nicht zur weiteren Auflösung des Staates zu führen, es kann und soll vielmehr seine politische Gewalt stärken, indem es ihn auf seine spezifische Staatlichkeit konzentriert, damit er nicht zum Verband der Verbände verfließt und vor anderen politischen Herrschaftsansprüchen weichen muß, die niemals ausbleiben und sich von rechts und links schon abzeichnen.

Für die Beteiligung von Gesellschaft und Staat an der Erfüllung öffentlicher Aufgaben gibt es eine Fülle verschiedener Gesichtspunkte. Ich muß darauf verzichten, sie hier auszubreiten. Abgestufte Organisationsformen mit abgestufter Beteiligung Privater, abgestufte staatliche Aufsicht präventiver oder repressiver Art, staatliche oder eigene Finanzierung, mehr öffentlichrechtliche oder mehr privatrechtliche Gestalt der Rechtsverhältnisse können je nach dem Anteil möglicher kooperativer oder notwendiger entscheidender Bewältigung der betreffenden Aufgabe die Verfassung und den Status einer Selbstverwaltungseinrichtung bestimmen ${ }^{81}$ ). Als Beispiel mag noch das Gesetz über die Errichtung eines Zentralen Fonds zur Absatzförderung der deutschen Land-, Forst- und Ernährungswirtschaft vom 26. Juli 1969 angeführt werden ${ }^{82}$ ). Staatlich ist die Verwaltung nach diesem Gesetz, sofern der Fonds Anstalt öffentlichen Rechts ist, sein Verwaltungsrat vom Bundesminister berufen wird, Vorstandswahl, Satzung, Geschäftsordnung und Haushalt der ministeriellen Genehmigung bedürfen, die Staatsaufsicht sich auf Verletzung der Gesetze und des öffentlichen Wohls erstreckt und strenge Aufsichtsmittel besitzt, staatliche Zuschüsse geleistet werden und das Verfahren der Beitragserhebung sowie Meldepflichten durch ministerielle Verordnung bestimmt werden. Gesellschaftlich wird die Aufgabe erfüllt, sofern die Verbände der Beteiligten die Verwaltungsratsmitglieder vorschlagen, diese den Vorstand wählen, die Mitglieder ehrenamtlich tätig sind, die beteiligten Betriebe durch Beiträge den Fonds finanzieren und dieser sich einer „Zentralen Einrichtung der Wirtschaft" zur Erfüllung seiner Aufgaben bedient.

$\mathrm{DaB}$ es sich um eine öffentliche Aufgabe handelt, ist nicht zweifelhaft. Es scheint mir ein müßiger Streit zu sein, ob diese Einrichtung mittelbare Staatsverwaltung ist oder nicht. Worauf es mir ankam, war, den Begriff der Selbstverwaltung aus der Fatalität des Entweder-Oder in dem Streit um die „mittel-

81) Vgl. auch BVerfGE 25, 236 über die Entwicklung des Zahntechnikerberufsverbandes bis zur Teilhabe an den Sozialversicherungsleistungen und damit an der sozialen Selbstverwaltung.

82) BGBl. I S. 635. 
bare Staatsverwaltung " zu befreien und ihn entsprechend der realen Teilung administrativer öffentlicher Aufgaben zwischen Staat und Gesellschaft theoretisch als einen Fächer von Möglichkeiten der Kombination zweier Prinzipien der Erfüllung öffentlicher Aufgaben - Staatsverwaltung und gesellschaftliche Eigenverwaltung - darzustellen. Es scheint mir sinnvoller, den Begriff zwischen zwei deutlich unterschiedenen Prinzipien anzusiedeln, als ihn auf einem Prinzip aufzubauen, weil dadurch ein breites Feld mannigfacher Erscheinungen systematisch geordnet werden kann, ohne dab die notwendigen Differenzierungen abgeschnitten werden. Vor allem scheint es mir unumgänglich zu sein, der Selbstverwaltung eine neue Grundlage zu geben, nachdem die Steinsche ebenso wie die Gneistsche Konzeption in der gegenwärtigen Gesellschaft keine reale Grundlage mehr hat. Dafür kann es keinen geeigneteren Ausgangspunkt geben als die Sozialverwaltung, die von Anfang an keine oppositionelle sondern eine zwischen Staat und Gesellschaft geteilte Verwaltung war.

\section{Offentlichrechtliche Entschädigung}

Das sogenannte System der staatlichen Ersatzleistungen ${ }^{83}$ ) ist kein System. Es gibt zwei Institute mit je systematisch fest umrissenem Kern: die Enteignung und die Amtshaftung. Martin Heidenhain hat in seiner Schrift über diesen Gegenstand nachgewiesen, daß von einer Lücke zwischen beiden nicht gesprochen werden kann, weil sie nicht Ausprägungen desselben Prinzips sind $\left.{ }^{84}\right)$. Der sogenannte enteignungsgleiche Eingriff, der bekanntlich weithin weder Eingriff noch enteignungsgleich ist, ist daher nicht die natürliche Vervollständigung eines einheitlichen, aber zunächst nur an den Flügeln aufgeführten Bauwerkes. Die bestehende Reihe rechtmäßig - rechtswidrig schuldlos rechtswidrig schuldhaft ist unter dem Gesichtspunkt der Haftung keine Reihe, denn rechtmäßiges Handeln löst normalerweise keine Haftung aus und rechtswidrig schuldloses ebenfalls nicht, rechtswidrig schuldhaftes die Deliktshaftung.

In der gesamten Rechtsordnung hat sich gezeigt, daß die Verschuldenshaftung allein nicht ausreicht, jedoch nicht als Lückenproblem. Das Privatrecht hat das Problem durch die Annahme von Sorgfaltspflichten und einen objektiven Schuldbegriff im Rahmen des Deliktsrechts zu lösen gesucht ${ }^{85}$ ). Das wäre auch

83) Vgl. Forsthoff, Lb. 9 Aufl., 4. Abschnitt; H.J. Wolf, VerwR I $\$ 60$ IVe.

84) Amtshaftung und Entschädigung aus enteignungsgleichem Eingriff, 1965, S. $65 \mathrm{ff}$.

85) Vgl. Reinhardt, Gutachten z. 41. Dt. Juristentag, Verhandlungen Bd. I, 1, 1955, S. 269; Esser, Schuldrecht I, 3. Aufl., 1968, S. 50 ff., 70 ff. 
im Verhältnis zwischen Staat und Bürger möglich gewesen ${ }^{80}$ ), doch wurde ein anderer Weg gewählt. Die Haftung des Staates ist stets zögernd dem Wandel der Verhältnisse gefolgt. Solange seine vermögensrechtlich relevanten Konflikte mit dem Bürger auf die Entziehung oder Beschränkung von iura quaesita kraft ius eminens im Notfall beschränkt waren, schuldete er Entschädigung kraft Naturrechts ( $\$ 75$ Einl. ARL) ${ }^{87}$ ). Der Eisenbahnbau brachte das Institut der entschädigungspflichtigen Enteignung hervor ${ }^{\text {89 }}$ ). Die Einsicht in die Unhaltbarkeit einer bloßen Beamtenhaftung für Amtsdelikte führte zu Anfang des Jahrhunderts zur Amtshaftung des Staates ${ }^{\mathrm{B}}$ ). Das alles geschah vor dem Hintergrund des Prinzips der Verschuldenshaftung, das eine Ersatzplicht nur bei rechtswidrig-schuldhafter Schädigung begründete, es wurde ihm sozusagen unter dem Zwang der sich verändernden Verhältnisse und der Forderung nach Gerechtigkeit abgerungen.

Das gleiche gilt nun für die Entwicklung der Rechtsprechung zu Aufopferung und enteignungsgleichem Eingriff. Die Aufopferung kann hier als Ubergangserscheinung zurücktreten. Sie hat keinen eigenen Bereich mehr (Körperschäden sind haftungsrechtlich auch nur als Vermögensschäden relevant) ${ }^{20}$ ). Die Rechtsprechung mußte dem Bedürfnis nach Entschädigung für die zahllosen neuartigen Vermögensbeeinträchtigungen des modernen Verwaltungsstaates Rechnung tragen. Sie wählte nicht den Weg des Privatrechts über Sorgfaltspflichten und Deliktsrecht - außer im Bereich der Wegeunterhaltung - sondern knüpfte an die Enteignung an. Das Reichsgericht erweiterte das Gebäude der Enteignung auf gesetzliche Maßnahmen, auf vermögenswerte Rechte aller Art, auf bloße Beschränkungen usw., und der Bundesgerichtshof errichtete den Anbau des enteig-

80) Vgl. B. Mondry, Die öffentlich-rechtliche Gefährdungshaftung ..., 1964, S. 7 f.; Leisner VVDStRL 20 (1963), S. 194 ff. schlug diesen Weg vor. Scheuner sucht eine Lösung über Art. 34 GG, s. Jellinek-Gedächtnisschrift, 1955, S. $345 \mathrm{zu}$ g.

87) Vgl. Forsthoff, aaO., S. 302 f.

88) aaO., S. 304.

89) Heidenhain, aaO., S. 33 ff. H. geht den Gründen für die Einführung der Amtshaftung nicht nach (S. 35 f.). Sie dürften zeigen, daß es die für die Staatshaftung (in seinem Sinn) vorgebrachten waren, so daß der Gegensatz von Staats- und Amtshaftung, auf dem $\mathrm{H}$. alles weitere aufbaut, nicht so kraB erscheint. Mit Art. 131 WRV hat die alte Staatshaftung sich durchgesezt, aber, da mit ihrer Einführung stets die Sorge ihrer Begrenzung verbunden ist, nur in Anknüpfung an das Beamtendelikt. Im übrigen verdanke ich $H$. die wesentlichsten Einsichten dieses Kapitels.

oo) Vgl. Forsthoff, Lb., 9. Aufl., S. $327 \mathrm{f}$. 
nungsgleichen Eingriffs ${ }^{01}$ ). Das geschah, und darauf kommt es hier an, ohne eigentlich neue Begründung der Haftung, sondern durchweg mit dem Argument "wenn ..., dann erst recht" (womit verborgen blieb, daß sowohl a minore ad maius, als auch a maiore ad minus geschlossen wurde ${ }^{\text {2z }}$. Vereinzelte Bemühungen um eine besondere Begründung, besonders für die unter keinem Gesichtspunkt mehr enteignungsgleichen Fälle, blieben ohne Auswirkung. Auch die Gefährdungshaftung Forsthoffs $s^{93}$ ), die Kosten-Nutzen-Theorie Rudolf Reinhardts ${ }^{\text {94 }}$ ), der Rückgriff Schacks auf den klassischen Aufopferungsgrundsatz ${ }^{95}$ ) u. a. lassen den eigentlichen Haftungsgrund für die Staatshaftung, wie er für den heutigen Staat Geltung beanspruchen könnte, offen. Die Anlehnung an die Enteignung ersetzte für die Rechtsprechung einen solchen Grund, weil eine positivistische Rechtswissenschaft einen Haftungsgrund ohne Anlehnung an gesetztes Recht nicht suchen, geschweige denn finden konnte.

Der Zusammenhang dieser Frage mit dem Sozialrecht liegt nun darin, daß im Sozialrecht Verbindlichkeiten des gegenwärtigen Staates Ausprägung gefunden haben und dadurch sichtbar und greifbar geworden sind, die auch für die Entschädigung von Staatsbürgern Bedeutung haben könnten.

Das Wort Sozialstaat bedeutet, für sich genommen, alles und nichts. Das Sozialrecht in Versicherung, Versorgung und Fürsorge ist jedenfalls ein Stück Sozialstaatlichkeit. Die Sozialversorgung insbesondere läßt für den Zusammenhang unserer Frage erkennen, was das Sozialstaatsprinzip bedeutet.

Sozialrecht im allgemeinen soll dem Bürger eine Sicherung seiner Existenz gegen schicksalhafte Bedrohungen geben $\left.{ }^{\circ 8}\right)$. Die Sozialversorgung soll die Folgen des Krieges und seiner Begleiterscheinungen beseitigen oder mildern ${ }^{97}$ ). Ein Zusammenhang zwischen Sozialrecht und Eigentum liegt darin, daß ein voll ausgebautes sozialrechtliches Anspruchssystem die exi-

11) Vgl. die Darstellung bei Forsthoff, aaO., S. 305 ff. und Werner Weber, Eigentum und Enteignung in : Die Grundrechte Bd. II, 1954, S. 331 ff. (338-345).

02) Vgl. Heidenhain. aaO., S. 72 m. N. 34; vgl. auch die Aufzählung der Formulierungen aaO., S. 70 f. Vgl. insbes. BGHZ 6, 270, 290 und RGZ 140, 283.

98) aaO., S. $332 \mathrm{ff}$.

94) 41. Dt. Juristentag, aaO., S. $276 \mathrm{ff}$.

o5) 41 Dt. Juristentag, aaO., S. 54 i. V. m. S. 18-24.

*) Wertenbruch in: Bes. VerwR, hrsg. von v. Münch, 1969, S. 296 f.; 303 f.; ders., Begriff und Bedeutung des Sozialrechts, Ztschr. f. SozialR 1968, 385 ff., 388; K. Jantz, Strukturprinzipien der sozialen Sicherung in: Soziale Sicherung in Dtschld., hrsg. v. BM f. Arb. u. SozO, 6. Aufl. 1967, S. 1-5; H. J. Wolff, VerwR III, S. $144 \mathrm{ff}$.

i7) Vgl. H. J. Wolff, VerwR III, S. $149 \mathrm{f}$. 
stenz- und freiheitssichernde Wirkung ersetzen könnte und vielleicht einmal ersetzen wird, die das Eigentum in der Vergangenheit besa ${ }^{08}$ ). Die Sozialversicherung zeigt eine Anzahl wesentlicher Merkmale, die es rechtfertigen, sie mit der öffentlichrechtlichen Entschädigung in Verbindung zu bringen. Sie knüpft an bestimmte schädigende Ereignisse an; sie gewährt Ansprüche auf Leistungen aus allgemeinen Staatsmitteln im Prinzip ohne Rücksicht auf individuelle Bedürftigkeit; neben sozialpolitischen Zielen ist der Gesichtspunkt der Entschädigung - nicht voller Schadensersatz - für die erlittene Einbuße bestimmend; auch wird der Begriff des Sonderopfers, das einen Ausgleich verlangt, in diesem Zusammenhang gebraucht $\left.{ }^{09}\right)$. In der gesetzlichen Unfallversicherung verwirklichte sich das Prinzip der Gefährdungshaftung $\left.{ }^{100}\right)$. Dahinter steht der soziale Gedanke des Ausgleichs der Risiken und der Verantwortung des Staates für diesen Ausgleich. Die Art der Risiken ist freilich im Sozialrecht eine andere als in den Fällen der öffentlichrechtlichen Entschädigungen. Dort sind es schicksalhafte Gefahren für Gesundheit, Arbeitskraft, Arbeitsplatz und materielle Lebensgrunglage, für die niemand verantwortlich gemacht werden kann; hier sind es Gefahren für das Vermögen, die aus staatlichen Planungen, Veranstaltungen, Unternehmungen und Maßnahmen entstehen. Aber es wäre zu überlegen, ob nicht auch hier mit fortschreitender Sozialisierung des Daseins eine Annäherung festzustellen ist. Krieg und Verfolgung liegen schon auf der Grenze zwischen Schicksal und staatlicher Veranstaltung. Die Aktivität des Staates hat sich auf innere Kolonisation - die Umgestaltung der Gesellschaft in Stadt und Land - verlagert. Viele Umstände und Ereignisse, die früher als schicksalhaft galten, Krankheit, Unfall, Arbeitslosigkeit, wirtschaftlicher Verfall, Armut, Abhängigkeit, fehlende Bildungsmöglichkeiten, nimmt heute der Staat, gerufen oder ungerufen, in seine Verantwortung. Schicksal und Staatshandeln nähern sich einander an. Das Schicksal wird sozialisiert. Das bedeutet aber nicht, daß es für alle zum guten Geschick würde. Auch das verwaltete Schicksal enthält Risiken und Gefahren. Die Lebensumstände materieller Art stehen fast sämtlich zur Disposition des Staates. Von der Konjunkturpolitik über die Struktur- und Einkommenspolitik und die Bebauungsplanung bis zum Straßenbau zerstört oder durchkreuzt der Staat unzählige Dispositionen und eröffnet unzählige

${ }^{98}$ ) Vgl. Wertenbruch, Sozialrecht und allgemeines Verwaltungsrecht, DOV 1969, 593 ff. (594).

${ }^{\circ 9)}$ Vgl. H. J. Wolff, aaO., S. 148 f. m. w. Nachw.; Haueisen in: Staatsbürger und Staatsgewalt (Jubiläumsschrift) 1963, Bd. 1, S. 255 ff. (158).

100) Vgl. Wannagat, NJW 1960, 1579. 
Dispositionen, meist für andere. Soll er die Geschicke der Bürger in Verwaltung nehmen, ohne auch für die damit verbundenen Risiken aufzukommen? Leben, Gesundheit, Wohlstand und Zukunft, sonst dem Schicksal unterworfen, gewinnen den Charakter von öffentlichen Veranstaltungen mit kalkulierbarem und manipulierbarem Risiko. Gesundheits- und Bildungsvorsorge, Raumordnung, Bauplanung, Konjunkturplanung und andere öffentliche Veranstaltungen machen andererseits einen Teil des Geschicks für den heutigen Staatsbürger aus. Gehört es nicht zum Wesen oder wenigstens zum Begriff dieses Staates, daß er die mit seinem Handeln verbundenen Risiken trägt, $d . h$. ausgleicht, weil Sozialisierung des Schicksals Ausgleich bedeutet? Mit der Versorgung der Opfer von Krieg und Verfolgung hat er eine Last, die früher als Schicksalsschlag galt, zur öffentlichen Last und Aufgabe gemacht, mit der Sozialversicherung für eine andere solche Last die Verantwortung der Gesellschaft begründet. Muß er nicht aus den gleichen Gründen das Risiko seines eigenen für viele schicksalhaften Handelns übernehmen? Und liegt hier nicht der Grund für die Haftung des Staates in allen Fällen, in denen seine Verwaltung einzelne Bürger schädigt? Ist dies nicht die Gestalt, die Billigkeit und Gerechtigkeit in der Gegenwart für den Bereich unserer Frage angenommen haben? ${ }^{101}$ )

101) Der Gedanke des sozialen Ausgleichs als eigentlicher Grund für die Haftung des Staates im Bereich der sog. enteignungsgleichen Eingriffe taucht gelegentlich auch in der Literatur auf, so bei Schack, 41. Dt. Juristentag, aaO., S. 7, 58, bei Reinhardt, ebenda, S. $283 \mathrm{ff}$., bei Jaenicke, VVDStRL 20, 1963, S. 180, Leits. 3, u. S. $142 \mathrm{ff}$. Forsthoff sieht die öffentlichrechtliche Entschädigung als Korrelat des staatlichen Verfügungsrechts über die soziale Güterwelt, deren Strukturwandel sie darum folgen müsse, Lb., 9. Aufl., S. 301. Seine Begründung der Gefährdungshaftung, aaO., S. $334 \mathrm{f}$., entspricht ebenfalls dem hier gemachten Vorschlag, doch scheint mir der Begriff der Gefährdung nicht das Wesentliche zu treffen. Er nennt den Anlaß, aber nicht den Grund der Haftung.

In dem Urteil wegen eines Schulturnunfalls stellt der BGH auf die Frage $a b$, ob das Risiko des Unfalls vom Staat zu übernehmen sei, weil es in seinen Verwaltungsbereich fällt, und verneint sie, weil der Unfall - in diesem Fall - zum allgemeinen Lebensrisiko gehöre. Merkwürdigerweise spricht er sich dann jedoch für eine gesetzliche Begründung der Haftung für solche Fälle aus (BGH, DVBl. 1967, 236 f.). - Auch die Rolle, die der Gleichheitssatz bei der Begründung der Haftung für sog. enteignungsgleiche Eingriffe spielt (BGHZ 6, 270), deutet auf den Ausgleich als Prinzip dieser Haftung hin. Die klassischen Begründungen einer allgemeinen Staatshaftung sind durchaus mit heranzuziehen, bedürfen jedoch der Anpassung an das heutige Verhältnis zwischen Staat und Bürger, vgl. die Darstellung bei Otto Mayer, VerwR II, 3. Aufl. S. $295 \mathrm{ff}$. und Heidenhain, aaO., S. $22 \mathrm{ff}$., $168 \mathrm{ff}$. - Das Buch von N.Luhmann, Offentlichrechtliche Entschädigung rechtspolitisch betrachtet, 1965, habe ich nicht verstanden. - 
Ein solcher Haftungsgrund ist keine Anspruchsgrundlage. Eine rechtschaffene Verwaltungsrechtslehre braucht festeren und fruchtbareren Boden, nachdem sie über den Untergrund Klarheit gewonnen hat. Aus einem solchen Prinzip läßt sich auch nichts "ableiten", wie man es heute so gern tut. Es geht hier nicht um ein neues Staatshaftungssystem, sondern nur um eine selbständige Begründung der Staatshaftung in einem bestimmten Bereich, in dem sie bisher mit der Anlehnung an die Enteignung nur scheinbar begründet wurde. Dieser Bereich, der des sogenannten enteignungsgleichen Eingriffs, muß zunächst von der Enteignung abgelöst werden, zu der er nie eine innere Beziehung gehabt hat ${ }^{102}$ ). Enteignung war und ist in ihrem eigentlichen Bereich ein Rechtsinstitut mit eigener Sachlogik und scharfen Konturen ${ }^{109}$ ). Ihrer Sachlogik nach ist sie die planmäßige Beschränkung oder Entziehung privaten Vermögens, die durch überwiegende Gründe des Gemeinwohls ausnahmsweise gerechtfertigt ist. Juristisch ist sie die verfassungsrechtlich ausnahmsweise gestattete Umwandlung der Eigentums-, d.h. heute Vermögensgarantie in eine Eigentumswertgarantie; der Gegenstand des Eingriffs muß weichen, sein Wert bleibt erhalten. Mit Unglück, Zufall, Risiko, Gefahr und mit Ersatz für rechtswidrige Schädigungen hat das nichts zu tun. Die Konturen der Enteignung sind nur in Richtung der Eigentumsbindung nach der Natur der Sache unsicher, in Richtung der Gefahr und des Risikos, der unrechtmäßigen und zufälligen Schäden sind die Konturen nur durch die sinnwidrige Verwendung des Instituts der Enteignung für ihm fremde Fälle unsicher geworden. Die Enteignung kann und sollte also durch Loslösung der Fälle sogenannter enteignungsgleicher Eingriffe als fest umrissenes Rechtsinstituts im Bereich planmäßigen, auch verfahrensrechtlich geordneten Staatshandelns wiederhergestellt werden ${ }^{104}$ ).

Den „Schadensersatzanspruch wegen rechtswidriger Grundrechtsverletzungen", den Konow, Eigentumsschutz gegen Eingriffe der öffentlichen Hand, 1968, S. 24 f. gefunden zu haben meint, halte ich nicht für begründet. „Eindeutig“, „klar“ und „zwingend“ (S. 25) ist im Bereich der Grundrechte bislang nichts.

${ }^{102}$ ) Vgl. schon die Kritik Otto Mayers, VerwR II 3. Aufl., S. 302, N. 13. Für Lösung der "Staatshaftung" von Enteignung und Eigentumsbegriff auch Heidenhain, aaO., S. 171 f. $H$. J. Wolff, VerwR I, \$ 60 I c 3 a. E., spricht von dem "unnötigen und irreführenden Umweg über das Enteignungsrecht".

${ }^{103}$ ) Das ist der Grund, dessentwegen Forsthoff eine besondere Gefährdungshaftung des Staates annimmt, vgl. aaO., S. 332, 335. Für eine Wiederherstellung der Enteignung - nicht der klassischen auch Schack, 41. Dt. Juristentag, aaO., S. $53 \mathrm{f}$. und Janssen, Der Anspruch auf Entschädigung ..., 1961, passim, vgl. bes. S. 207, sowie ders., DVBI. 1967, 797 (Buchbespr.).

104) Der Ubergang von der Entschädigung für rechtmäßige zur Ent- 
Auch die Amtshaftung muß ein besonderes Rechtsinstitut bleiben. Es beruht auf dem Prinzip der Deliktshaftung, das mit Gefahr, Risiko und Zufall ebensowenig zu tun hat, wie die Enteignung ${ }^{103}$ ).

Der Raum der Schädigungen, die nicht Enteignung im eigentlichen Sinne und nicht Amtsdelikte sind, muß durch einen anderen Anspruch abgedeckt werden, der Ausgleichsanspruch aus Verwaltungsrisiko heißen könnte (in Anlehnung an den französischen risque social ${ }^{108}$ ). Das wäre freilich ein Name, kein Prin-

schädigung für rechtswidrige Maßnahmen ist das eigentlich AnstöBige an der Rechtsprechung, vgl. RGZ 140, 276 (283) und BGHZ 6, 270 $(278,290)$. Die Rechtmäßigkeit gehört so sehr zum Wesen der Enteignung, daß rechtswidriges Handeln niemals enteignungsgleich sein kann. Eben weil eine rechtswidrige Maßnahme keine Enteignung ist, mußte für sie eine Haftungsgrundlage gefunden werden (vgl. Heidenhain, aaO., S. 99 ff.). - Löst man die Staatshaftung, wie hier vorgeschlagen, von der Enteignung und begründet man sie mit der sozialen Risikohaftung des Staates, dann kommt es auf Rechtmäßigkeit oder Rechtswidrigkeit nicht mehr an. Diese Frage ist ohnehin häufig schwer zu entscheiden, z. B. bei $\S 906$ BGB (vgl. Reinhardt, 41. Dt. Juristentag, aaO., S. $256 \mathrm{~m}$. N. 95), und war es auch im Bereich des alten Aufopferungsanspruchs: wird das Schießen über die Grenzen des Ubungsplatzes rechtmäßig, weil der Bürger es dulden muß (§ 1004 Abs. 2 BGB)? Diese Schwierigkeit hängt mit der Zweispurigkeit des BGB-Deliktsrechts und des durch es bestimmten Begriffs der Rechtswidrigkeit überhaupt zusammen: Rechtswidrigkeit nach $\$ 823$ Abs. 1 ist Verletzung subjektiver Rechte, nach $\S \mathbf{8 2 3}$ Abs. 2 Gesetzesverletzung. Für den enteignungsgleichen Eingriff machte die Unterscheidung ebenfalls immer Schwierigkeiten (vgl. Bachof, Vornahmeklage, 2. Aufl. 1968, S. 117 N. 10a: der Eingriff kann rechtswidrig oder rechtmäßig sein; ders. aaO., S. 127: er kann beides zugleich sein). Der BGH hat die Entschädigung für rechtmäßige Eingriffe auf rechtswidrige als enteignungsgleiche erstreckt (s. oben) und die für enteignungsgleiche wiederum auf rechtmäßige (vgl. Heidenhain, aaO., S. 88, Nr. 5 m. Nachw.; Konow, Eigentumsschutz, 1968, S. 28 f., 41 ff., 194 ff., 188 f.). Für Immissionen läßt er die Frage der Rechtswidrigkeit offen (BGH v. 15. 6. 1967, DVBl. 1967, 883 unter 1., 2. Absatz). Die Gefährdungshaftung wird teils als Haftung für rechtmäßige, teils als Haftung für rechtswidrige Schädigung angesehen (vgl. Schack, 41. Dt. Juristentag, aaO., S. 26 m. N. 100). Die hier vorgeschlagene Haftung gilt für rechtmäßige Schädigungen, die keine Enteignung sind, wie für rechtswidrige, die keine Amtsdelikte sind. Bei ihr stellt sich nicht die Frage der Rechtswidrigkeit, weil diese nicht Haftungs- und nicht Haftungsausschlußgrund ist, sondern nur die Frage, wie Verwaltungsschäden gerecht zu verteilen sind.

105) Vgl. zur Amtshaftung Schack, 41. Dt. Juristentag, aaO., S. 28 ff., Jaenicke, VVDStRL 20, 1963, S. $144 \mathrm{f}$. und bes. Heidenhain, aaO.; das von $H$. gezeigte Problem der heutigen Amtshaftung dürfte ihren prinzipiell deliktsrechtlichen Charakter nicht aufheben. Zur beabsichtigten Novellierung des $\$ 839$ BGB vgl. Dietzel, JZ 1969, $48 \mathrm{ff}$.

106) Vgl. Münch, 41. Dt. Juristentag, aaO., S. 61 ff. (76), Scheuner, DOV 1954, 587 ff.; B. Mondry, Die öffentlich-rechtliche Gefährdungshaftung in Frankreich ..., 1964. 
zip für Ableitungen, die wiederum ohne Konturen bleiben müßten. Es wäre nach Voraussetzungen, Inhalt und Umfang eben der Anspruch, den die Rechtsprechung als Anspruch aus enteignungsgleichem Eingriff entwickelt hat ${ }^{107}$ ). Er kann an keiner Stelle wirklich aus dem Enteignungsrecht begründet werden und wurde auch nicht wirklich aus ihr begründet. Den einschlägigen Entscheidungen liegen keine enteignungsrechtlichen $\mathrm{Er}-$ wägungen zugrunde, sondern nur die Frage, ob es billig und gerecht ist, den Betroffenen seinen Schaden selbst tragen zu lassen oder ihn aus Mitteln der Allgemeinheit zu ersetzen. Nicht bewußte Uberordnung des Gemeinwohls über das Vermögen des Bürgers und planmäßiger Austausch der Eigentumsgarantie in eine Vermögenswertgarantie, sondern sozialer Ausgleich von Risiken öffentlichen Handelns steht überall hinter den Entscheidungen, die eine Entschädigung zubilligen. Der richtiger benannte Haftungsgrund hätte also keine größere Unsicherheit zur Folge als sie jetzt besteht. Die Unsicherheit wäre freilich auch nicht behoben, aber sie wäre wenigstens nicht verschleiert. Die Kunst des Richters, der ein Rechtsinstitut von Fall zu Fall Schritt für Schritt in Entwurf und Korrektur ausarbeitet, würde sich bei einem Anspruch aus sozialer Risikohaftung ebenso bewähren und besser zeigen als unter dem falschen Titel „enteignungsgleicher Eingriff“. Sie hätte, statt Ähnlichkeiten mit der Enteignung zu suchen, die sie, wie Eingriff und Rechtmäßigkeit, dann wieder überwinden muß, die Gefahren, die in die Verantwortung des Staates fallen, von denen, die der Bürger selbst tragen muß, zu sondern. Sie würde in Fällen wie den Schäden nach nur empfohlener Impfung oder den problematischen Turnunfällen oder den Schädigungen durch Straßen- oder U-Bahnbau von unangemessenen Beschränkungen frei $\left.{ }^{108}\right)$. Richterrecht wird das Gebiet der öffent-

107) Vgl. W. Rüfner, Zum gegenwärtigen Stand des deutschen Staatshaftungsrechts, BB 1968, 881 (882 unter 2.).

108) Die Arten und Fälle von Schädigungen sind im übrigen sehr vielfältig, z. B. Impfschäden: BGHZ 24,$45 ; 31,187 ; 34,23$; DƠ 1964, 815. Turnunfälle: Jaenicke, VVDStRL 20, 1963, S. 144 N. 23; BGH v. 16. 1. 1967, DOV 1967, 236; vgl. JZ 1968, 285 ff.; 1969, 7 ff. Immissionen u. a. Schädigungen durch öffentliche Bauvorhaben: Konow, Eigentumsschutz gegen Eingriffe der öffentlichen Hand, 1968, mit Rspr.Nachweisen; ferner Döbereiner, NJW 1968, 1916 ff.; Schack, NJW 1968, $1914 \mathrm{f}$.; ders., Betrieb 1968, 2115 ff.; OLG Hamm MDR 1968, 321. Planungsschäden: Burmeister, Die Verwaltung, 1969, 21; Kriele, DOVV 1967, 531 ff. Tumultschäden: W. Henrichs, NJW 1968, 973. Unrichtige Ladungen und Benachrichtigungen: $R$. Mayer, Justizverw. Bl. 1967, 245 ff.; Spruchrichterliche Maßnahmen: Konow, JR 1969, 6 ff.; BGH DOV 1968, 358; vgl. Verw. Arch. 1959, 386. Opfer von Gewaltverbrechen: Romberg, Z. f. Rechtspolitik 1968, 57 f. Viele Fälle sind gesetzlich geregelt, z. B. unschuldig erlittene Untersuchungs- 
lichrechtlichen Entschädigung noch lange, wenn nicht immer bleiben $\left.{ }^{100}\right)$. Angesichts der bisher gewonnenen Umrisse des Anspruchs wäre nicht zu befürchten, daß die Rechtsprechung haltlos würde. Was sie bisher in Grenzen gehalten hat, war jedenfalls nicht die Anlehnung an die Enteignung.

Das Sozialstaatsprinzip gewänne ein neues Sachgebiet konkreter Ausprägung. Es würde ihm nicht künstlich unterstellt. Vielmehr würde eine Element dieses Prinzips, das im Sozialrecht bereits Gestalt gewonnen hat, nämlich die Verantwortung des Staates für Daseinsrisiken der Bürger im Wirkungsbereich der öffentlichen Verwaltung, für eine drängende Frage des öffentlichen Rechts fruchtbar gemacht. Daß der Staat für die Daseinsrisiken der Bürger verantwortlich ist, soweit sie in den Bereich seiner Verwaltung fallen, weil er insoweit für ihr Dasein selbst die Verantwortung übernommen hat, ist die Gestalt, die die alte Forderung nach Billigkeit und Gerechtigkeit zwischen Verwaltung und Bürger unter den gegenwärtigen Verhältnissen angenommen hat.

\section{Das soziale Prinzip und die Freiheit}

Das Thema wäre einseitig behandelt, wenn nicht auch die Gefahr gezeigt würde, die vom Sozialrecht her dem Allgemeinen Verwaltungsrecht droht, nämlich die Sozialisierung des Verwaltungsrechts.

Das Sozialrecht bewahrt die Bürger vor Not und vor menschenunwürdigem Dasein in Krankheit und Elend. Nach dem Wegfall der patriarchalischen Formen der Daseinsvorsorge trägt die Genossenschaft der mündigen Staatsbürger die Lebensrisiken gemeinsam. Dieses soziale Prinzip ist duch den Begriff „sozialer Rechtsstaat“ zum Verfassungsgrundsatz geworden. Es wirkt von da aus zurück auf die ganze Rechtsordnung, besonders auf das Verwaltungsrecht. Hier stößt es auf das Prinzip, auf dem das herkömmliche Verwaltungsrecht aufgebaut ist.

oder Strafhaft; Nothelferentschädigung ( $\$ 539$ Nr. 9 RVO); polizeiliche Inanspruchnahme des Nichtstörers ( $870 \mathrm{pr}$. PVG); Tierseuchenmaßnahmen u. a. m. Der Hinweis im BGH, DVBl. 1967, 236 f., Schulturnunfälle bedürften gesetzlicher Regelung wie in Hamburg (\$ 7 SchulG v. 16. 4. 1957) überzeugt nicht. Die soziale Risikohaftung ist seit jeher Sache der Rechtsprechung. - Eine systematische Zusammenstellung der möglichen Fallgruppen, die von Amtshaftung und Enteignung nicht gedeckt werden, versucht Jaenicke, VVDStRL 20, 1963, S. $146 \mathrm{ff}$., 180. Vgl. zu den noch vorhandenen Lücken der allgemeinen Staatshaftung $W$. Rüfner, BB 1968, $881 \mathrm{ff}$. (884 f. zu 3.).

100) Ebenso Sellmann, NJW 1965, 1689 ff. (1690); Esser, Schuldrecht I, 3. Aufl., S. 266. 
Das Polizeirecht und mit ihm die wichtigsten Institute des allgemeinen Verwaltungsrechts beruhen auf der kunstvollen Verbindung des Schutzes der Bürger vor Gefahren mit ihrem Schutz vor dem Staat, der sie vor Gefahren schützt, auf der Verbindung der Eingriffsermächtigung zum Zweck der Gefahrenabwehr mit der rechtlichen Sicherung des Störers. Sie beruhen auf der Einsicht, daß Schutz vor Gefahren nur auf Kosten der Freiheit zu haben ist. Recht und Gerechtigkeit sind hier die Lösung der Aufgabe, Sicherheit und Freiheit in jedem einzelnen Fall im Gleichgewicht zu halten.

Man hat das liberal und formal genannt und gesagt, das soziale Prinzip habe dem Rechtsstaat einen neuen materialen Gehalt gegeben, nämlich die soziale Gerechtigkeit ${ }^{10}$ ). Das Sozialrecht als die wichtigste Konkretisierung des sozialen Prinzips kennt keinen Gegensatz von Sicherheit und Freiheit. Freiheit ist hier Freiheit von Not, Schicksal, Existenzrisiko. "Die Entfaltungsfreiheit der Persönlichkeit des einzelnen ist erst dann gewährleistet, wenn auch seine ökonomische Daseinssicherung gegeben ist" heißt es bei einem der führenden Sozialrechtspraktiker $\left.^{111}\right)$. Recht und Gerechtigkeit sind hier Ausgleich bis zur Chancengleichheit und korrekter Vollzug der gesetzlich geregelten Umverteilung.

Das soziale Prinzip droht auf dem Wege über das Sozialstaatsprinzip zum Prinzip des ganzen Verwaltungsrechts zu werden. Schon ist die Meinung vertreten worden, alle Verwaltungsaufgaben, auch die der Gefahrenabwehr, seien Leistungsaufgaben zur Verwirklichung der Sozialordnung. Ihre Erfüllung, nicht das Streitverhältnis zwischen Staat und Individuum, stehe im Mittelpunkt der Verwaltungstätigkeit ${ }^{112}$ ). Ist das richtig, dann tritt an die Stelle des genannten Gegensatzes von Sicherheit und Freiheit der Ausgleich der sozialen Lagen, z. B. des Störers und des Gefährdeten im Polizeirecht, oder die Verwirklichung übergeordneter sozialer Gerechtigkeit, dergegenüber jedes Beharren auf individuellen Rechten als sozial dysfunktional und damit im Bereich des sozialen Prinzips als illegitim erscheint.

Davor gilt es, das Verwaltungsrecht zu bewahren. Daß das soziale Prinzip in ihm einen legitimen Raum beanspruchen kann, steht außer Zweifel. Die in langer Erfahrung bewährten

110) z. B. Wertenbruch in Bes. VerwR, hrsg. von v. Münch, S. 299.

111) Wannagat, Das Sozialrecht im sozialen Rechtsstaat, Festschrift Jantz, 1968, S. 55 ff. (59).

112) E. Becker, VVDStRI 14, 1956, S. 98; vgl. auch Beinhardt, Das Recht der öffentlichen Sicherheit und Ordnung im Verhältnis zur Eingriffs- und Leistungsverwaltung, DVBl. 1961, $108 \mathrm{ff}$. 
Institutionen des liberalen Verwaltungsrechts müssen aber um der Freiheit willen vor einer sozialen Uberschwemmung und Umdeutung, die ihre Zerstörung wäre, bewahrt werden. In ihnen geht es nicht um die Freiheit, die der allgemeine und gleiche Wohlstand verleiht, sondern um die Freiheit der menschlichen Existenz, die das eigene Schicksal der sozialen Sicherung vorzieht. 
Leitsätze des Berichterstatters über:

\section{Die Rechtsformen der sozialen Sicherung und das Allgemeine Verwaltungsrecht}

I.

Offentliches und privates Recht sind nicht zwei gegeneinander abgeschlossene Gebiete, müssen aber nach ihren Prinzipien unterschieden werden.

1. Das Sozialrecht zeigt, daß öffentliches und privates Recht nicht durch eine feste Grenze geschieden werden können, denn sie sind im gleichen Maße verflochten wie amtliches und privates Handeln, und in der Geschichte hat sich die Grenze verschoben.

2. Dennoch können öffentliches und privates Recht unterschieden werden, denn ihnen liegen je verschiedene Prinzipien zugrunde: Rechtsetzung und Rechtsgestaltung sind entweder staatlich oder privat. In den meisten Rechtsgebieten und -instituten sind Elemente beider Art verbunden. Aus praktischen Gründen muß zwischen öffentlichem und privatem Recht eine scharfe Grenze gezogen werden. Doch sollten beiderseits dieser Grenze die öffentlichrechtlichen Elemente als Zeichen fortschreitender Sozialisierung von Gerechtigkeit und Freiheit von den privatrechtlichen Elementen als Zeichen erhaltener privater Gerechtigkeit und Freiheit unterschieden werden.

II.

Das Gewaltverhältnis als Grundform des Verwaltungsrechts sollte durch das Verwaltungsrechtsverhältnis ergänzt, vielleicht sogar ersetzt werden.

1. Das Sozialrecht zeigt, daß der Begriff des Gewaltverhältnisses dem gegenwärtigen Verhältnis zwischen Verwaltung und Bürger in einem großen Bereich nicht mehr angemessen ist.

2. In diesem Bereich bestehen Verwaltungsrechtsverhältnisse, deren Inhalt durch Gesetz, Verfassung und Rechtsgrundsätze in einem System von beiderseitigen Rechten und Pfichten festgelegt ist.

3. Der Verwaltungsakt als einseitige behördliche Bestimmung dessen, was für den Bürger rechtens ist, ist seinem Inhalt nach 
in dieses Verhältnis eingebettet und durch es bestimmt, auch im sogenannten besonderen Gewaltverhältnis.

4. Es ist Aufgabe der Verwaltungsrechtslehre, für alle geeigneten Bereiche der Verwaltung aus Gesetzen, Rechtsprechung und Wissenschaft besondere Verwaltungsrechtsverhältnisse auszuarbeiten, um der Auslegung des Verwaltungsrechts, der Billigkeitsrechtsprechung und dem Ausbau eines Systems sachgemäßer materiellrechtlicher Institutionen und Ansprüche eine der Gegenwart angemessene systematische Grundlage zu geben.

III.

Selbstverwaltung ist heute Verwaltung öffentlicher Angelegenheiten durch Staat und Gesellschaft im Zusammenwirken ihrer spezifischen Mittel.

1. Paradigmatisch für die Selbstverwaltung ist heute nicht mehr das Kommunalrecht, sondern eher das Sozialversicherungsrecht.

2. Staat und Gesellschaft können nicht getrennt werden, müssen aber um der Freiheit willen auch heute unterschieden werden.

3. An der Wahrnehmung öffentlicher Angelegenheiten haben sowohl die gesellschaftlichen Kräfte, nämlich durch Kooperation, Kompromiß und Verbandsdisziplin, als auch die verfaßte staatliche Amtsgewalt, nämlich durch verbindliche und erzwingbare Entscheidung, Anteil.

4. Zwischen reiner Staatsverwaltung und rein gesellschaftlicher Eigenverwaltung liegt ein breiter Fächer von Möglichkeiten der Selbstverwaltung als Kombination staatlicher und gesellschaftlicher Wahrnehmung öffentlicher Aufgaben mit stärkerem oder schwächerem Anteil des Staates, der den Streit um die mittelbare Staatsverwaltung absolet macht.

5. Aus dem Vorrang der Freiheit folgt der Vorrang des Prinzips der gesellschaftlichen Eigenverwaltung im Bereich der Selbstverwaltung.

IV.

Im Bereich der öffentlichrechtlichen Entschädigung sollte der Anspruch aus sogenanntem enteignungsgleichem Eingriff durch einen Ausgleichsanspruch aus Verwaltungsrisiko ersetzt werden. 
1. Die Haftung des Staates für rechtswidrig-schuldlose und zufällige Schäden wurde zu Unrecht an das Institut der Enteignung angelehnt. Eine eigene Begründung für sie fehlt.

2. Im Sozialrecht hat eine Verantwortung des Staates für das Dasein der Bürger Ausdruck gefunden, die sich auch auf alle Bereiche dieses Daseins erstrecken muß, die von der Staatsverwaltung betroffen werden. Es gehört zum Wesen des gegenwärtigen Staates, daß er die mit seinem Handeln verbundenen Risiken trägt, $d$. $h$. ausgleicht.

3. Die Enteignung kann so wieder auf die planmäßige Beschränkung oder Entziehung privaten Vermögens, die durch überwiegende Gründe des Gemeinwohls ausnahmsweise gerechtfertigt ist, begrenzt werden. Der Bereich des sogen. enteignungsgleichen Eingriffs wird durch einen Ausgleichsanspruch aus Verwaltungsrisiko gedeckt, der jenem nach Voraussetzungen, Inhalt und Umfang voll entspricht. Er kann auf der Grundlage des zu 2) gesagten durch die Rechtsprechung frei von unangemessenen Bindungen fortentwickelt werden.

V.

Die bewährten Institutionen des liberalen Verwaltungsrechts müssen vor der Zerstörung durch eine soziale Umdeutung um der Freiheit willen bewahrt werden. 



\title{
Die Rechtsformen der sozialen Sicherung und das Allgemeine Verwaltungsrecht
}

\author{
- Einordnung des Rechts der sozialen Sicherung \\ in das (allgemeine) Verwaltungsrecht -
}

\section{Mitbericht von Professor Dr. Wolfgang Rüfner, Kiel}

Nachdem Herr Henke die Ausstrahlungen des Sozialrechts in das Allgemeine Verwaltungsrecht behandelt hat, möchte ich mich damit beschäftigen, wie das Recht der sozialen Sicherung in das Verwaltungsrecht einzuordnen ist, wie insbesondere die Grundsätze des allgemeinen Verwaltungsrechts in ihm wirksam werden. Von vornherein bitte ich um Verständnis dafür, daß ich mein Thema nicht erschöpfen kann, wenn ich eine angemessene Redezeit einhalten will ${ }^{1}$ ).

\section{A Grundlagen}

Lange Zeit schien das Sozialrecht nur wenige Beziehungen zum übrigen Verwaltungsrecht zu haben, ein Spezialrecht zu sein, mit dem sich der normale Jurist kaum abzugeben brauchte ${ }^{2}$ ). Und doch ist es, wie das BVerfG kürzlich sagte, für den Einzelnen, für die Gesellschaft, für die öffentliche Ordnung und das Gemeinwohl von derselben fundamentalen Bedeutung wie das Allgemeine Verwaltungsrecht ${ }^{3}$ ).

(1) Die soziale Sicherheit wurde vor der Industrialisierung nicht als Problem empfunden, obwohl es Armut und Not auch damals gab. Es existierten sogar Vorformen unserer heutigen Sozialversicherungen, die allerdings nur einen kleinen Teil der Bevölkerung erfaßten').

1) Zur Abgrenzung des Sozialrechts vgl. Wertenbruch, DOV 1969, S. 595 ff. und kritisch zur überkommenen Begriffsbildung Rode, ZSR 1969, S. 641 ff., 724 ff. Das Referat beschränkt sich bewußt auf die drei überkommenen Typen des Rechts der sozialen Sicherung, nämlich auf Sozialversicherung, Versorgung und Sozialhilfe (Fürsorge), geht aber über den engen Begriff der sozialen Sicherheit hinaus, den Friederichs, JZ 1967, S. $278 \mathrm{ff}$., postuliert.

2) Vgl. z. B. O. Mayer, Deutsches Verwaltungsrecht $I^{2}, 1917$, S. 494, Anm. 34; Bogs, Festgabe Roehrbein 1962, S. 17.

a) BVerfGE 26, S. 100 (110 f.).

4) Vgl. Dietrich Schäfer, Die Rolle der Fürsorge im System sozialer Sicherung, 1966, der zu Beginn seines Buches die geschichtlichen 
Die Sicherheit des Menschen beruhte im wesentlichen auf der Hausgemeinschaft, die über die engere Familie hinaus auch das Gesinde und dessen Anhang einschloß. Im übrigen kümmerte sich um die Armen neben privater oder kirchlicher Mildtätigkeit die vorwiegend örtliche Armenpflege. Sie hatte es mit einer vielleicht bedeutenden, zu großen und lästigen, aber immerhin nur mit einer Minderheit der Bevölkerung zu tun, die vom Normalen durch ihre Armut abwich.

(2) Für die Mehrheit ist die "soziale Sicherung" erst seit der Industrialisierung zur Notwendigkeit geworden. Das Ausmaß der Probleme, die sich dabei stellten, wurde zunächst nicht erkannt: Die Fabrikarbeiter, denen die oft noch schlechter gestellten Landarbeiter nur sehr zögernd gleichgestellt wurden'), wurden als Arme im überkommenen Sinn angesehen. Ansätze, ihre Lage zu bessern, galten bis zu den ersten Sozialversicherungsgesetzen, ja bis ins 20. Jahrhundert hinein als Maßregeln der Armenpflege, also als Fortsetzung der überkommenen Fürsorge mit anderen Mitteln'). Das war verständlich, denn die Industriearbeiter waren zunächst wie die Armen der älteren Zeit wiederum nur eine Minorität, die durch ihre Bedürftigkeit aus dem Rahmen fiel. Sie machten 1846 im Deutschen Zollverein erst 4,44\% der Bevölkerung aus, die selbständigen Gewerbetreibenden dagegen 7,25\% ${ }^{7}$ ). So war es vielleicht nicht von Anfang an erkennbar, da $\beta$ es nicht darum ging, die Armenpflege zu verbessern, sondern darum, Umstellungsschwierigkeiten auf dem Weg zu einer neuen sozialen Ordnung zu meistern. Immerhin belehrt uns L. v. Stein schon 1850 über den ungeheuren Unterschied zwischen der früheren Armut und dem Pauperismus des Industriearbeiters ${ }^{8}$ ).

Heute können wir jedenfalls die soziale Sicherheit nicht mehr unter dem Blickwinkel des Armenwesens oder der Fürsorge für sozial schwächere Bevölkerungskreise sehen. Auf die soziale

Zusammenhänge eingehend darstellt; zu den Vorformen der Sozialversicherung vgl. insbes. S. 82 f.; dazu ferner J. Lingnau, Das System sozialer Hilfeleistungen, S. 42 ff.; Thielmann, Die Geschichte der Knappschaftsversicherung, 1960; $E$. Loening, Lehrbuch des Deutschen Verwaltungsrechts, 1884, S. 552; K. v. Stengel, Lehrbuch des Deutschen Verwaltungsrechts, 1886, S. $443 \mathrm{f}$.

5) Vgl. dazu Schäfer (wie vorst. Anm.), S. 40.

) Vgl. z. B. W. Roscher, System der Armenpflege und Armenpolitik ${ }^{3}, 1906$, S. $263 \mathrm{ff} ., 344 \mathrm{ff}$.

${ }^{7)} F$. Lütge, Deutsche Sozial- und Wirtschaftsgeschichtes, 1966, S. 487.

g) L. v. Stein, Die Geschichte der sozialen Bewegung in Frankreich, Ausgabe 1921, Bd. 2, S. 72 ff.; ähnlich R. v. Mohl, Die Polizeiwissenschaft nach den Grundsätzen des Rechtsstaats, 1. Bd. ${ }^{3}, 1866$, S. $352 \mathrm{ff}$. 
Sicherung ist vielmehr die gesamte Bevölkerung angewiesen, wenn wir von statistisch kaum mehr erfaßbaren Ausnahmen absehen ). Das ist selbst gegenüber älteren Bemerkungen des BVerfG mit Nachdruck zu betonen ${ }^{10}$ ).

Allerdings ist zwischen den einzelnen Arten der Sozialleistungen zu differenzieren: Ständige Hilfe für den Lebensunterhalt aus der Sozialhilfe bleibt Ausnahme. Private Vorsorge für Krankheit und Unfall wäre noch einem erheblichen Teil der Bevölkerung möglich, wenn die Sozialversicherung nicht Zwangsversicherung wäre. Eine eigenverantwortliche Invaliditäts- und Altersvorsorge ist jedoch nahezu für jeden ausgeschlossen. Kaum einer vermag sich ein so großes Vermögen zu schaffen, daß er auf ein gesichertes Alter rechnen kann. Der Grund dafür liegt einmal in der ständigen Inflation und sodann in den hohen Ansprüchen, die heute an die Altersversorgung gestellt werden. Nur eine im Umlageverfahren finanzierte Rente kann die Inflation überspielen und dazu noch eine ständige Anpassung an das Wirtschaftswachstum gewährleisten. So drängt die Entwicklung hier zu einer allgemeinen Volksversicherung. Sie ist in der Schweiz erreicht, auch die Bundesrepublik ist ihr sehr nahe, denn die gesetzliche Rentenversicherung erfaßte schon $85 \%$ der Erwerbstätigen, bevor die Pflichtgrenze für Angestellte entfiel ${ }^{11}$ ). Eine Ausdehnung auf die Selbständigen ist zu erwarten ${ }^{12}$ ).

B Grundsätzliches zur Einordnung des Rechts der sozialen Sicherung

\section{Fürsorge und Versorgung}

\section{Begriffliches}

(3) Da die Sozialversicherung, vor allem die Rentenversicherung, fast die gesamte Bevölkerung umfaßt, möchte man

9) Vgl. Jantz, in: Reuß-Jantz, Sozialstaatsprinzip und soziale Sicherheit, 1960, S. 33 ff.; Wertenbruch, ZSR 1968, S. 394. Die Sozialversicherungsbeiträge sind höher als die Lohn- und Einkommenssteuern (1958 12,5\% gegen 6,5\% des Volkseinkommens), vgl. Wannagat, Lehrbuch des Sozialversicherungsrechts I, 1965, S. 157.

10) Vgl. die Kritik von Rohwer-Kahlmann, in: Festschrift Bogs 1967, S. 112, $123 \mathrm{ff}$., insbes. gegen BVerfGE 10, S. 354 (365 f.) und 18, S. 257 (270 ff.); in: BVerfGE 11, S. 105 (113) ist dagegen schon anerkannt daß die Sozialversicherung nicht nur für die sozial Schwachen arbeitet.

11) Unter Einschluß der Selbständigen. Vgl. Joseph Schneider, Rechtsprobleme im Wandel der Rentenversicherung, Kleine Schriften zur Sozialpolitik und zum Arbeitsrecht, 4. Folge, Heft 9 (Vortrag vom 28. 11. 1962), S. 28.

12) Vgl. Entschließung des Dt. Bundestags vom 8. 12. 1967, Stenographische Berichte, S. 7343 und 7357 (Umdruck 323, Anlage 29). 
meinen, sie sei von allen Arten der Sozialleistungen am meisten in das System unseres Verwaltungsrechts eingebaut, viel mehr als Fürsorge und Versorgung, die nur für vergleichsweise kleine Kreise in Betracht kommen. Tatsächlich scheint das Gegenteil der Fall zu sein. Der durchschnittliche Jurist kann noch eher mit Fürsorge- und Versorgungsrecht etwas anfangen als mit dem Sozialversicherungsrecht.

Vielleicht hängt das damit zusammen, daß die Fürsorge oder neuerdings Sozialhilfe der älteste Zweig der Sozialleistungen ist. Es handelt sich um die direkte Weiterentwicklung der früheren Armenhilfe. Wir sprechen heute von Fürsorge, wenn die Verwaltung dem Bürger ohne Gegenleistung bei individuellem Bedarf hilft. Typisches Kennzeichen ist die Subsidiarität der Hilfe und ihre Abhängigkeit vom vorherigen Einsatz von Einkommen und Vermögen des Bedürftigen oder seiner unterhaltspflichtigen Angehörigen ${ }^{18}$ ).

Die Versorgung wird ebenfalls ohne Gegenleistung, aber für generellen typischen Bedarf gewährt, ohne daß die individuelle Bedürftigkeit zu prüfen ist $\left.{ }^{14}\right)$. Versorgung gab es in Deutschland bisher fast nur als Ausgleich für besondere Lasten des Krieges. Sie näherte sich damit einer typisierten Aufopferungsentschädigung ${ }^{15}$ ), wenn sich auch die Rechtsprechung entschieden dagegen wehrte, sie als solche $\mathrm{zu}$ bezeichnen ${ }^{16}$ ). Sonstige Versorgungsleistungen kennen wir in der Form des Kindergeldes und der Ausbildungsbeihilfen ${ }^{17}$ ).

Fürsorge und Versorgung sind Idealtypen, die in der Wirklichkeit oft ineinander übergehen ${ }^{18}$ ). Die Höhe der Kriegsopferversorgung richtet sich zum Teil nach dem sonstigen Einkommen des Beschädigten ${ }^{10}$ ), die Kriegsopferfürsorge zeigt schon in ihrer Bezeichnung die Vermengung der Begriffe. Das Kindergeld für das 2. Kind ist nach § 4 BKGG von einer Einkommensgrenze abhängig gemacht. Ähnliches gilt für die Ausbildungsförderung nach dem neuen Ausbildungsförderungsgesetz

18) Vgl. Wertenbruch, in: Besonderes Verwaltungsrecht, hsg. von I. v. Münch, 1969, S. 304 f.; H. J. Wolff, Verwaltungsrecht III², 1967, S. 191 f., \& 147 I; Wannagat, Lb. I (9), S. 6 f.

14) Vgl. dazu kritisch Wertenbruch, wie vorst. Anm. S. 303 f.; H. J. Wolff, Verwaltungsrecht III ${ }^{2}$, S. 128, $\S 137$ III $2 \beta$.

15) Vgl. dazu Obermayer, Die Rechtsnatur der Kriegsopferversorgung; Berg, Festschrift Bogs 1967, S. $19 \mathrm{ff}$.

16) Vgl. BGHZ 20, S. 61 (64).

17) Bogs, in: Festgabe Krohn 1954, S. 42, unterscheidet die Sonderversorgung zum Ausgleich bestimmter Schäden (z. B. der Kriegsopfer) und die allgemeine Staatsbürgerversorgung.

18) Vgl. Wertenbruch, DÖV 1969, S. 596; ders. ZSR 1968, S. 390.

10) Vgl. \$\$ 31-33 BVG zur Grund- und Ausgleichsrente. 
und für die Förderung nach dem Honnefer Modell $\left.{ }^{20}\right)$. Sie stehen im Schnittpunkt von Versorgung, Fürsorge, Bildungs- und Gesellschaftspolitik, gehören vielleicht im Sinn der Unterscheidung von Badura ${ }^{21}$ ) nicht einmal ganz eindeutig zur Leistungsverwaltung.

\section{Die Rechtsstellung des Bürgers}

(4) Die Rechtsstellung des Bürgers war ursprünglich im Fürsorgerecht sehr prekär. Die Hilfe wurde nicht um des Bedürftigen selbst willen gegeben, sondern um der öffentlichen Ordnung willen. Für einen Anspruch des Armen hatte das 19. Jahrhundert kein Verständnis. Die Fürsorge entsprach damit etwa dem Bild, das uns Otto Mayer von der öffentlichen Anstalt gab: Das Fürsorgerecht war nur Organisationsrecht. Ein Rechtsverhältnis zwischen Verwaltung und Leistungsempfänger konnte nicht entstehen. Die Hilfe wurde rein tatsächlich gewährt, als Almosen, wie man bewußt sagte. Als sich das nach dem 2. Weltkrieg änderte, war das Allgemeine Verwaltungsrecht bereits voll entwickelt. Das Sozialhilferecht konnte auf ihm aufbauen.

Für die Versorgung gilt Ähnliches. Als sie größeren Umfang annahm, konnte sie auf das ausgebildete Allgemeine Verwaltungsrecht zurückgreifen. So fügen sich Fürsorge- und Versorgungsrecht scheinbar unproblematisch in das Bild unseres Verwaltungsrechts ein. Ich sage bewußt: „scheinbar", denn es blieb wie überall in der Leistungsverwaltung nicht ohne Schwierigkeiten, den neuen Rechtsstoff in das gegebene wissenschaftliche System zu inkorporieren ${ }^{22}$ ).

Immerhin handelt es sich bei Fürsorge und Versorgung um typische Verwirklichungen der iustitia distributiva.

Der Staat gibt nach individuellem oder gruppentypischem Bedarf, nicht nach Gegenleistung. Er paktiert nicht mit dem Bürger, sondern bleibt in der Distanz, die seinem hoheitlichen Wesen entspricht. So fügen sich beide Zweige der Leistungsverwaltung in das sog. klassische Verwaltungsrechtsdenken ein, wenn auch heute die Stellung des Bürgers verfassungsrechtlich gesichert ist: Der Sozialstaat garantiert ihm das variable und mit der wirtschaftlichen Entwicklung nach oben tendierende

$\left.{ }^{20}\right)$ An diesem Beispiel zeigt Wertenbruch, ZSR 1968, S. 390, daB die überkommenen Gruppierungen nicht mehr zureichen. Sehr kritisch zur überkommenen Dreiteilung Rode, ZSR 1969, S. 729 ff.

21) Badura, DOV 1966, S. 630.

22) Vgl. $P$. Badura, Verwaltungsrecht im liberalen und im sozialen Rechtsstaat, 1966, S. 5 . 
Existenzminimum, der Gleichheitssatz das Recht auf gleiche Teilhabe an den Leistungen, die über das Minimum hinausgehen.

\section{Die Sozialversicherung}

\section{Grundsätzliches}

(5) In der Sozialversicherung ist vieles anders. Sie ist das Kernstück der nachliberalen Sozialpolitik und deckt gewöhnlich die Risiken des Alters, der Invalidität, der Krankheit, des Arbeitsunfalls und der Arbeitslosigkeit.

Als Zwangsversicherung entspricht sie zwar nicht liberalem Denken. Sie tastet aber die kapitalistische Wirtschaftsordnung nicht an, sondern fügt sich in sie ein und sucht Mißständen zu steuern. Der Idee nach müßte sie noch nicht einmal die sog. natürliche Einkommensverteilung ändern, wenn sie das auch in der Realität mehr oder minder stark tut: Die Leistungen sind nämlich den Beiträgen nicht durchweg versicherungsmathematisch äquivalent. Vor allem zugunsten der Familie gibt es beitragslose Leistungen. Insofern sind Elemente der Versorgung in ihr enthalten, während Gedanken der Fürsorge nur selten, vor allem in der schweizerischen außerordentlichen Rente ${ }^{23}$ ), verwirklicht wurden.

Für die Erfüllung der hier anfallenden Aufgaben stehen alle die Formen zur Verfügung, die der Staat hat, wenn er gewährleisten will, daß bestimmte Leistungen erbracht werden: Er kann selbst leisten, er kann sich einer speziell geschaffenen juristischen Person des öffentlichen Rechts bedienen, er kann die Aufgaben an Genossenschaften oder sonstige Private delegieren und vielleicht dabei die Figur des beliehenen Unternehmers ins Spiel bringen. Er kann sich endlich mit Normativbestimmungen begnügen.

Alles das ist für die gesamte Leistungsverwaltung typisch, weil es kein gewissermaßen natürliches Monopol des Staates zur Erbringung bestimmter Leistungen gibt. Wir kennen z. B. die staatliche oder kommunale und die private, aber durch scharfe Normativbestimmungen regulierte Energieversorgung. Ähnliches wäre auch in der Sozialversicherung denkbar und ist sogar, wenn wir über eine formale Betrachtung hinausgehen, zum Teil verwirklicht. Äußerlich überwiegt der Typ der öffentlichrechtlichen Genossenschaft, aber mit verschiedenen Graden der Selbstverwaltung von der Rentenversicherung bis zur

${ }^{23}$ ) Art. 42 Bundesgesetz über die Alters- und Hinterlassenenversicherung v. 20. 12 . 1946. 
Unfallversicherung. Ein Vergleich der Unfallversicherung mit der obligatorischen Haftpflichtversicherung des Kraftfahrzeughalters, die privatrechtlich nach Normativbestimmungen funktioniert, zeigt, daß vielleicht die Möglichkeiten nicht einmal ganz ausgeschöpft sind. Auch die Geschichte der Ersatzkassen zeigt, daß die Erfüllung mancher Aufgaben durch Private denkbar wäre: Sie sind erst seit 1937 Körperschaften des öffentlichen Rechts $\left.{ }^{24}\right)$. Vorher waren sie privatrechtliche Genossenschaften in der Form der Versicherungsvereine auf Gegenseitigkeit, die durch besondere gesetzliche Bestimmungen an Regeln der öffentlichrechtlichen Krankenkassen gebunden waren. Je nachdem, wie man den Begriff faßt, waren sie vielleicht in mancher Hinsicht auch beliehene Unternehmer, obwohl ich eher dazu neige, dafür wenigstens die Kompetenz zu fordern, Verwaltungsakte zu erlassen. Ubertragung von wichtigen öffentlichen Aufgaben genügt m. E. nicht.

\section{Die Rentenversicherung}

a) staatliche Aufgabe

(6) Die letztgenannten Rechtsformen sind freilich in der Rentenversicherung kaum diskutabel. Sie ist finanziell und politisch von so großer Bedeutung, daß eine Erfüllung ihrer Aufgaben durch private Versicherungsvereine oder beliehene Unternehmer ausscheidet. Betrugen die Gesamtausgaben der Sozialversicherung im Jahre 1967 59.262 Millionen DM, so beliefen sich die Ausgaben der Rentenversicherung allein auf 39.564 Millionen DM, also auf $2 / 3$ davon und etwa die Hälfte des Bundeshaushalts $\left.{ }^{25}\right)$. Politisch ist die gesetzliche Rentenversicherung deshalb so wichtig, weil sie die einzige Altersvorsorge ist wenn wir von den Ruhegehältern der Beamten absehen -, die nach Höhe und Sicherheit für die breite Masse der Bevölkerung in Betracht kommt. Eine ausreichende private Vorsorge für die Risiken des Alters und der Invalidität ist, wie schon gesagt, praktisch ausgeschlossen ${ }^{28}$ ) und eben deshalb ist die Rentenversicherung in Deutschland und, ich nehme an, auch in Osterreich, vielleicht nicht ganz so in der weniger inflationsgeprüften Schweiz, so sehr als Staatsaufgabe im Bewußtsein der

24) Vgl. 15. VO zum Aufbau der Sozialversicherung v. 1. 4. 1937, abgedruckt in: Die Ersatzkasse 1937, S. 126.

25) Der Anteil der gesamten Ausgaben der Sozialversicherung am Nettosozialprodukt belief sich auf $16,37 \%$. Vgl. zu den Zahlen Tietz, Zahlenwerk zur Sozialversicherung in der Bundesrepublik Deutschland, $U$ 49, 52 und 53.

$\left.{ }^{20}\right)$ Vgl. dazu - etwas weniger entschieden, aber in der Tendenz ähnlich: Sozialenquête, S. 124. 
Bevölkerung, daß eine Verweisung auf private Vorsorge ganz abgesehen von deren Irrealität - politisch ausgeschlossen ist. Verfassungsrechtlich gesehen, würde der Sozialstaat eine seiner wesentlichen Aufgaben verfehlen, würde er nicht der Bevölkerung eine ausreichende Altersversorgung bieten ${ }^{27}$ ).

Nur theoretisch wäre das mit geringerem Staatseinfluß denkbar, als ihn die heutige deutsche Rentenversicherung kennt. Angesichts der riesigen Finanzmassen können sich die Ausgaben der Rentenversicherung nicht ohne Rücksicht auf die Wirtschaftslage bewegen. Eine Aufsplitterung in verschiedene kleinere autonome Einrichtungen würde zwar vielleicht den wirtschaftlichen Effekt von Renten- und Beitragsänderungen mildern, müßte aber dann zu erheblichen Ungleichheiten für die Versicherten führen.

Dem sollte nicht entgegengehalten werden, daß die Rentenversicherung in Deutschland verschiedene Träger hat. Die Landesversicherungsanstalten der Arbeiter sind in einem finanziellen Verbund und tragen die Aufwendungen für Rentenzahlungen gemeinsam nach dem Verhältnis ihrer Beitragseinnah$\mathrm{men}^{28}$ ). Auch zwischen den einzelnen Zweigen: der Arbeiterrentenversicherung, der Angestelltenversicherung und der Bundesknappschaft, gibt es durch verschiedene Dosierung der Bundeszuschüsse ${ }^{29}$ ) und z. T. durch ad-hoc-Gesetze einen finanziellen Ausgleich ${ }^{30}$ ). Beiträge und Renten sind minutiös gesetzlich geregelt, für die Selbstverwaltung bleibt Spielraum nur im Randbereich der Gesundheitsvorsorge und Rehabilitation. Wenn irgendwo, dann ist bei der Rentenversicherung von mittelbarer Staatsverwaltung und nicht von gesellschaftlicher Selbstverwaltung zu sprechen ${ }^{31}$ ).

Das gilt, obwohl die Träger der Rentenversicherung für ihre Organisation und ihr Personal weitgehend freie Hand haben und von gewählten Vertretern der Versicherten und der Arbeitgeber verwaltet werden ${ }^{32}$ ). Es ist auch nicht entscheidend, daß sie, wie bei der Selbstverwaltung üblich, in der Regel nur

27) Vgl. zur Rentenversicherung als Staatsaufgabe BVerfGE 21, S. 362 (375 ff.); ferner allgemein zur Sozialversicherung Brackmann, Handbuch der Sozialversicherung, S. 154 b IV ff., bes. S. 154 d.

28) $\S \S 1390$ ff. RVO.

20) §1389 RVO; § 116 AVG.

so) Vgl. z. B. Ges. über die mehrjährige Finanzplanung des Bundes II. Teil - Finanzänderungsgesetz 1967 - v. 21. 12. 1967, BGBl I, S. 1259, Art. 2, \& 3 unter 9.

s1) Vgl. W. Weber, Die Selbstverwaltung in der Sozialversicherung, in: Schriftenreihe des Dt. Sozialgerichtsverbandes, Bd. I, 1966, S. 30 f.

32) Aus diesem Gesichtspunkt etwas anders Salzwedel, Die Selbstverwaltung usw. (wie vorst. Anm.), S. 50 ff.; auch Wertenbruch, DOV 1969, S. 601 ff. setzt den Wert der Selbstverwaltung zu hoch an. 
der Rechtsaufsicht, nicht der Zweckmäßigkeitsaufsicht unterstehen $^{\text {s5)}}$. Daraus kann keinesfalls geschlossen werden, der Staat habe die Rentenversicherung der gesellschaftlichen Selbstverwaltung der Beteiligten überlassen und sich von der Verantwortung zurückgezogen. Eine solche Betrachtung wäre rein formal und ließe unbeachtet, daß die politische Verantwortung vom Staat durch die Gesetzgebung übernommen wurde und zudem der Vollzug der Gesetze von den staatlichen Aufsichtsbehörden und den Sozialgerichten überwacht wird. Mit der kommunalen Selbstverwaltung und ihrem erheblichen politischen Entscheidungsspielraum ist jedenfalls die Selbstverwaltung der Rentenversicherung nicht vergleichbar. Sie ist im wesentlichen technischer Art, entlastet den Staatsapparat und ist - sit venia verbo - auch eine psychologische Konzession an die Beteiligten ${ }^{34}$ ).

Wir können die gesetzliche Rentenversicherung und ihre Selbstverwaltung nicht mit kleineren berufsständischen Versorgungseinrichtungen vergleichen: Eine Ärzteversorgung kann staatlich überwachte genossenschaftliche Selbsthilfe sein. Es kann ihr überlassen werden, Beiträge und Leistungen unter staatlicher Aufsicht selbst festzusetzen, zumal die gesamtwirtschaftlichen Auswirkungen eventueller Änderungen unbedeutend sind. Dafür ist auch die Sicherheit, die eine solche kleine Einrichtung gewähren kann, nur beschränkt: Sie muß, wenn sie nach dem allein möglichen Umlageverfahren arbeitet, alsbald in Schwierigkeiten kommen, wenn die Zahl der Berufsangehörigen einmal zurückgeht ${ }^{33}$ ). Zudem läßt sich die Frage, ob eine weitgehende gesellschaftliche Eigenverwaltung dem Prinzip der Freiheit besser entspricht als die staatlich gesteuerte Selbstverwaltung der gesetzlichen Rentenversicherung, kaum eindeutig positiv beantworten: Es besteht auch die Gefahr unangemessener Gruppenmacht ${ }^{36}$ ). Ein möglichst weitgehender

33) Vgl. Salzwedel, wie vorst. Anm., S. $55 \mathrm{ff}$.

34) Vgl. W. Weber (wie Anm. 31), S. 132 f.; auch Carganico und Spiecker, Festschrift Lauterbach 1961, S. 45 ff., die an sich die Selbstverwaltung höher einschätzen, als das hier geschehen ist, meinen am Ende (S. 57 f.), ohne finanzielle Eigenverantwortung könne es keine Selbstverwaltung geben. Dieser Zustand ist bei der Rentenversicherung weitgehend erreicht. Die Sozialenquête (S. $104 \mathrm{ff}$.) hütet sich, die Selbstverwaltung überzubewerten.

${ }^{35)}$ Vgl. dazu Liefmann-Keil, Soziale Sicherheit 1968, S. 165 ff. Sie gibt deshalb einer differenzierten Sozialversicherung den Vorrang vor Standesversicherungen.

96) Vgl. dazu die Bedenken bei $H$. P. Ipsen, Rechtsfragen berufsständischer Zwangsversicherung, 1954, S. $35 \mathrm{ff}$. Uberhaupt liegt in der genauen gesetzlichen Fixierung der Ansprüche aus der Sozialversicherung ein Element der Freiheit. Vgl. dazu Bogs, Das Problem 
Rückzug des Staates garantiert nicht ein Maximum an Freiheitlichkeit. Vielleicht ist das gegenwärtige deutsche System unter den derzeitigen Verhältnissen in dieser Hinsicht sogar optimal.

b) Staatsleistung oder erzwungene Selbsthilfe?

(7) Immerhin läßt sich noch fragen, ob wir es bei der gesetzlichen Rentenversicherung mit einer Staatsleistung oder mit einer staatlich regulierten und erzwungenen Selbsthilfe der Bürger zu tun haben. Das wird gewöhnlich unter dem Schlagwort „Versicherungs- oder Versorgungsprinzip“ diskutiert ${ }^{37}$ ).

Die gegenwärtige Struktur der deutschen und etwas abgeschwächt auch der österreichischen Rentenversicherung ${ }^{39}$ ) scheint mehr für die erzwungene Selbstvorsorge, also mehr für das Versicherungsprinzip zu sprechen ${ }^{39}$ ). Die Rente ist indes, was oft übersehen wird, lohn-, nicht beitragsproportional: Ein 14\%iger Beitrag vom Durchschnittslohn des Jahres 1957 zählt genauso viel wie ein vielleicht $18 \%$ iger von 1974 . Der Grundgedanke ist nicht, dem Versicherten das Äquivalent seiner Beiträge zu bieten, sondern eine seinem bisherigen Lebensstandard entsprechende Rente. Die gegenwärtige deutsche Rentenformel strebt weniger nach versicherungsmathematischer Gerechtigkeit als nach angemessener Versorgung $\left.{ }^{40}\right)$. Sie hütet sich allerdings vor Nivellierungen, die den Leistungswillen der Versicherten mindern und der Hinterziehung von Sozialabgaben Vorschub leisten.

Immerhin arbeitet die Rentenversicherung nach dem Austauschprinzip, das nach manchen dem modernen Staat zuwider ist $^{\text {t1) }}$ und eine Staatsleistung ausschließt. Das beruht indes auf

der Freiheit im sozialen Rechtsstaat, in: Festschrift für Fr. Lenz 1961 (hier nach: Rechtsstaatlichkeit und Sozialstaatlichkeit, S. 517 ff., zitiert). Unter diesem Gesichtspunkt ist auch die weitgehende Forderung nach Selbstverwaltung bei Rohwer-Kahlmann, ZfS 1960, S. 536, bedenklich. Auch eine allgemeine Volksversicherung oder Staatsbürgerversorgung ohne Selbstverwaltung wäre verfassungsrechtlich zulässig. zumal sich die deutsche Rentenversicherung ihr schon nähert. Vgl. Wannagat. Lb. I (Anm. 9), S. 224 ff.

37) Vgl. dazu schon Rosin, Die Rechtsnatur der Arbeiterversicherung, in: Festgabe f. P. Laband z. 50. Jahrestag der Doktorpromotion, 2. Bd., 1908, S. 41 ff.

38) Vgl. zur Rentenbemessung in Osterreich $\$ \S 238 \mathrm{f}$., 261 ASVG.

39) Dafür sehr dezidiert Weidner, ZVersWiss 1961, S. 141 ff., 225 f., $229 \mathrm{f}$.

10) Vgl. Jantz, in Reuß-Jantz (Anm. 9) S. 38, der betont, die Rente sei Gegenleistung für die Lebensarbeit, nicht für die Beiträge.

11) Vgl. Bullinger, Vertrag und Verwaltungsakt, 1962, S. 233; Stern, VVDStRL 21, S. 217 f.; Herbert Krïger, Allg. Staatslehre, 1964, 
einem Mißverständnis: Die Verwirklichung der iustitia commutativa durch eigene Leistungen im Austausch gegen Leistungen des Bürgers ist dem modernen interventionistischen Staat nicht fremd. Er vertraut nicht mehr darauf, daß die gesellschaftlichen Kräfte selbst für den gerechten Ausgleich der Interessen sorgen. Er kann sich auch in vielen Bereichen, die wir zur Leistungsverwaltung rechnen, nicht mit der nachträglichen Korrektur der Ergebnisse begnügen, sondern er erbringt selbst Leistungen, die auch Private erbringen könnten, und fordert dafür entsprechende Entgelte. Beispiele liefern etwa die gemeindlichen oder staatlichen Verkehrsunternehmen. Man könnte sie auch kostenlos arbeiten lassen, aber rechtlich läßt sich das weder aus dem Prinzip des angeblich unkaufmännischen modernen Staates noch aus einem extrem interpretierten Sozialstaatsgrundsatz ableiten.

Ist also das "do ut des" in der Rentenversicherung kein Argument gegen die Staatsleistung, so ist für sie zunächst auf weitere Abweichungen vom Versicherungsprinzip hinzuweisen: Es gibt beträchtliche Staatszuschüsse, die allerdings der Idee nach nicht für die Alterssicherung, die zentrale Aufgabe der Rentenversicherung, gedacht sind ${ }^{42}$ ) und auch gewisse Kriegsfolgen ausgleichen sollen $\left.{ }^{45}\right)$. Wichtiger noch ist der soziale Ausgleich unter den Versicherten: Leistungen für Kinder, Witwen und Waisen werden ohne besonderen Beitrag gewährt, Ausfall- und Ersatzzeiten werden angerechnet, obwohl in ihnen keine Beiträge geleistet wurden.

Darin liegt eine interpersonale Umverteilung ${ }^{44}$ ) unter den Beteiligten, die zum Teil Leistungen ohne Gegenleistungen erhalten. Insoweit gibt es in der Rentenversicherung Konzessionen an den Versorgungsgedanken, die - wie nebenbei bemerkt sei - nicht völlig unproblematisch sind. Gerechter wäre es, diese Zusatzleistungen ganz aus Steuermitteln aufzubringen. Es ist unter dem Gesichtspunkt des Gleichheitssatzes nicht unbedenklich, daß ein Teil des Volkes aus Solidaritätsgesichtspunkten gewisse Leistungen finanzieren muß, während andere, vielleicht Vermögendere, sich daran nicht beteiligen ${ }^{45}$ ). Eine allgemeine Volksversicherung, wie die schweizerische Alters-

S. 268 und 896; Köttgen, VVDStRL 6, S. 121; ders., Die Erwerbswirtschaftliche Betätigung der öffentlichen Hand und das öffentliche Recht, 1928, S. 14.

12) Vgl. dazu Jantz, Festschrift Bogs 1959, S. 161 ff.; ders. in: ReußJantz (Anm. 9), S. 46.

13) Vgl. Sozialenquête, S. $93 f$.

4) Vgl. dazu Schewe, Festschrift Bogs 1967, S. 147 ff.; Sozialenquête, S. $62,147 \mathrm{ff}$.

45) Vgl. Bogs, Festgabe Krohn 1954, S. 47. 
und Hinterlassenenversicherung kennt dieses Problem nicht; bei ihr ist der Beitrag ohnehin einer allgemeinen Steuer vergleichbar.

Deshalb ist es auch vertretbar, daß in der Schweiz der soziale Ausgleich unter den Versicherten und damit der Versorgungsgedanke wesentlich stärker ausgeprägt ist: Es gibt Mindestund verhältnismäßig geringe Höchstrenten, dagegen eine unbegrenzte prozentuale Beitragspflicht vom Erwerbseinkommen $\left.^{40}\right)$. Darüber hinaus wird im Fall der Bedürftigkeit sogar eine nicht aus Beiträgen gedeckte außerordentliche Rente gezahlt, so daß sogar das Fürsorgeprinzip in Einzelfällen verwirklicht wird ${ }^{47}$ ). Das ist vielleicht nicht systemgerecht, hat aber den Vorzug, daß die Leute nicht auf die Fürsorge verwiesen werden wie in Deutschland. Im Grunde ist das eine Frage der Nomenklatur, die aber psychologisch nicht unwichtig ist.

Ich würde die bisher geschilderten Abweichungen vom Versicherungsprinzip jedoch nicht allein für entscheidend halten, um die Leistungen der Rentenversicherung als Staatsleistungen anzusprechen: Wesentlicher ist vielmehr ein Umschlag von der Quantität in die Qualität: Von Eigenvorsorge in genossenschaftlicher Form ist nicht mehr zu sprechen, wenn nahezu das ganze Volk bei finanziell verbundenen Einrichtungen zwangsversichert ist und Beiträge wie Renten gesetzlich minutiös geregelt sind. Eine Genossenschaftsorganisation, der die überwältigende Mehrheit der Staatsbürger zwangsweise angehört, deren Etat vom Staat manipuliert wird und deren riesige Finanzmassen für Wirtschafts- und Währungspolitik von ähnlicher Bedeutung sind wie der Staatshaushalt, ist eine staatliche Einrichtung. Ihre Leistungen lassen sich nicht mit privaten Versicherungsleistungen vergleichen, die auf Grund individueller, wenn auch typisierter Versicherungsverträge erbracht werden. Wenn wir bei dem Bild der Trennung von Staat und Gesellschaft bleiben wollen: Es kann keine Leistungen der gesamten Gesellschaft an die gesamte Gesellschaft geben, die außerhalb des Staatlichen bliebe.

c) Konsequenzen

(8) Konsequenzen aus dieser Auffassung ergeben sich zunächst für das vielleicht mehr theoretisch als praktisch wichtige Problem des Eigentumsschutzes: In Ubereinstimmung mit vielen Außerungen in der Literatur ${ }^{48}$ ) hat das Bundessozialgericht

46) Vgl. Gysin, Schweiz. Ztschr. f. Sozialversicherung 1964, S. 9.

47) Art. 42 AHV (Anm. 23).

18) Vgl. Scheuner, Verhandlungen des 36. Deutschen Juristentags, Bd. II, S. 451; ders., DOV 1956, S. 575 f.; Ipsen, JZ 1953, S. 663; 
(BSG) die Rentenansprüche mehrfach als Eigentum bezeichnet, das den Schutz des Art. 14 GG genieße ${ }^{48}$ ). Ich möchte dem zwar nicht entgegentreten, aber darauf hinweisen, daß das BSG in allen praktisch gewordenen Fällen erklärt hat, es handele sich um eine zulässige Inhaltsbestimmung des Eigentums, nicht um eine Enteignung ${ }^{50}$ ). Art. 14 würde zwar einer Kürzung einer privaten Versicherungsrente entgegenstehen, aber kaum einen Umbau der gesetzlichen Rentenversicherung verhindern können, wenn er im Rahmen des Angemessenen die bisherigen Erwartungen der Versicherten berücksichtigte. Der Schutz des Bürgers liegt, wenn wir von gewissen Extremfällen absehen, z. B. dem völligen Entzug einer Rente, für die lange Zeit Beiträge gezahlt wurden, weniger in Art. 14 als in Art. 3 GG: Es geht nicht darum, ein erworbenes Vermögen gegen staatliche Eingriffe zu schützen, sondern darum, die Teilhabe an staatlichen Leistungen zu sichern ${ }^{51}$ ). Langfristig hat der Bürger dadurch besseren Schutz als durch Art. 14, der sich immer auf bestimmte geschuldete Summen beschränken müßte, die von der Inflation in kurzer Zeit überholt würden.

Grundsätzlich lassen sich die Ansprüche aus der Rentenversicherung eher mit beamtenrechtlichen Versorgungsansprüchen als mit privatrechtlichen Versicherungsansprüchen vergleichen $^{52}$ ). Auch der Beamte erhält sein Ruhegehalt nicht etwa ohne Gegenleistung aus einer Freigebigkeit des Staates. Er bekommt vielmehr einen in mancher Hinsicht modifizierten Lohn für seine Dienste, wie das BVerfG vor einiger Zeit unter Abrücken von der Alimentationstheorie mit Recht ausgeführt

Dürig, JZ 1954, S. 9, Anm. 27; Bogs, Referat auf dem 43. Dt. Juristentag, Sitzungsberichte, G S. 54 ff.; ders. ZSR 1962, S. 189 ff.; ders. ZSR 1968, S. 515 ff.; Rohwer-Kahlmann, ZSR 1956, S. 239 ff., 310, 343 (sehr weitgehend); Ule, ZSR 1956, S. 138 ff., $180 \mathrm{ff}$; $v$. Altrock, Festschrift Bogs 1959, S. 33; Berg, Festschrift Bogs 1967, S. $17 \mathrm{f}$; ablehnend Zimmer, BArbBl. 1959, S. 584 ff. und DOV 1963, S. $81 \mathrm{ff}$.

40) BSGE 9, S. $127(128)$; 13, S. 247 (250); 14, S. 133 (137); das BVerfG ist recht zurückhaltend: vgl. BVerfGE 14, S. 288; 20, S. 52; 22, S. 241 (253); auch E 11, S. 221 zum Sterbegeld der Krankenkassen; ferner E 21, S. 362.

s0) W. Weber, in: Rechtsschutz im Sozialrecht, 1965, S. $281 \mathrm{ff.;} v \mathrm{vgl}$. auch Bogs, ZSR 1968, S. $515 \mathrm{ff}$.

51) Insofern liegt der Fall anders als bei der Kassenpraxis des Arztes, vgl. dazu BSGE 5, S. $40=$ JZ 1958, S. 20 mit zust. Anm. Dürig; s. auch Dïrig, Festschrift Apelt, S. 33 ff. (44).

s2) Vgl. dazu Wannagat, Lb. I (Anm.9), S. 217; BSG v. 21.9. 1966, DVBl. 1968, S. 890 mit freilich insoweit abl. Anm. Janssen; unter diesem Gesichtspunkt wäre es sinnvoll, die Kumulierung von Sozialleistungen, insbes. von Sozialversicherungsleistungen auf ihre Berechtigung zu untersuchen. Vgl. dazu Haase, Festschrift Bogs 1959, S. $107 \mathrm{ff}$. 
hat $^{53}$ ). Modifiziert ist der Lohn des Staates vor allem dadurch, daß der Staat nicht schlechthin eine bestimmte Geldsumme schuldet, sondern angemessenen Unterhalt, auch nach dem Ausscheiden aus dem aktiven Dienst. Genau dasselbe will die gesetzliche Rentenversicherung in Deutschland und Osterreich $\left.{ }^{54}\right)$. In der Schweiz liegen die Verhältnisse etwas anders: Die AHV ist nur als Basissicherung gedacht ${ }^{55}$ ), im Prinzip muß sich dadurch an der Qualifizierung der Ansprüche aber nichts Wesentliches ändern.

Die Beiträge zur Rentenversicherung sind öffentlichen $\mathrm{Ab}$ gaben vergleichbar: Der volkswirtschaftlichen Wirkung nach entsprechen sie am ehesten den direkten Steuern, deutlicher: der Lohnsteuer ${ }^{\text {sb }}$ ). Aber sie stehen nicht wie die Steuern für die allgemeinen Staatsaufgaben zur Verfügung, sondern sind für spezielle Zwecke gedacht: Den Versicherten sollen aus den Beiträgen besondere Vorteile erwachsen. In den Kategorien des Abgabenrechts bleiben damit Gebühr und Beitrag diskutabel. Gebühren werden für die Benutzung von Einrichtungen erhoben. Dabei besteht ein unmittelbarer Zusammenhang zwischen der Inanspruchnahme der Leistung und der Gebührenpflicht. Gerade dieser Zusammenhang fehlt bei der Rentenversicherung: Wer Beiträge zahlt, hat keine Gewähr dafür, jemals Leistungen zu erhalten: Er kann vorher ausscheiden, er kann zu früh sterben. Deshalb ist nicht die Gebühr die richtige Kategorie, sondern - wie es auch der Bezeichnung entspricht - der Beitrag: Den Versicherten erwachsen besondere wirtschaftliche Vorteile, die Beiträge werden nach den Vorteilen bemessen. Es besteht zwar eine Beziehung von Leistung und Gegenleistung, aber sie ist nicht synallagmatisch wie beim privaten Versicherungsvertrag, ja sie ist sogar noch lockerer als bei der Gebühr. Die Höhe des Beitrags und die Höhe der Leistung stehen aber nicht ohne Beziehung nebeneinander.

In technischen Fragen kann es nützlich sein, Parallelen zwischen privater Versicherung und gesetzlicher Rentenversicherung zu ziehen ${ }^{57}$ ). Im Grundsätzlichen sollte aber der Vergleich

53) BVerfGE 21, S. 329 (340 ff. - Witwerpension); dagegen hat das BVerfG in E 17, S. 1 (17 ff.) die Einschränkung der Witwerrente in der Sozialversicherung gebilligt. Vgl. dazu kritisch Zacher, 47. Dt. Juristentag, Sitzungsberichte O, S. 26.

54) Vgl. die in Anm. 33 zitierte Bemerkung von Jantz.

55) Vgl. Gysin, Schweiz. Ztschr. f. Sozialversicherung 1964, S. 12.

s6) Vgl. Wannagat, Lb. I (Anm. 9), S. 225; Zacher, Festschrift Jantz 1968, S. 39, Anm. 53.

s7) Uberhaupt soll die Ahnlichkeit des sozialversicherungsrechtlichen Verwaltungsrechtsverhältnisses und des privatrechtlichen Versicherungsverhältnisses - vgl. Möller, Festgabe Roehrbein 1962, 
zum Verwaltungsrecht, insbesondere zum Beamtenversorgungsund Abgabenrecht gesucht werden, weil dort eher angemessene Lösungen für die Probleme zu finden sind ${ }^{\mathrm{s}}$ ).

\section{Die Arbeitslosenversicherung}

(9) Mit Staatsleistungen, nicht mit genossenschaftlicher Selbsthilfe haben wir es auch bei den Leistungen der Bundesanstalt für Arbeit zu tun, nach gesetzlicher Definition einer Körperschaft des öffentlichen Rechts ( $\$ \S 3,189$ AFG). Bei formaler Betrachtung ist die Tätigkeit dieser Anstalt weitestgehend den Sozialpartnern überantwortet. Im Vorstand und Verwaltungsrat, in den Verwaltungsausschüssen der Landesarbeitsämter und Arbeitsämter sitzen zu je $1 / 3$ Vertreter der Arbeitgeber, der Arbeitnehmer und öffentlicher Körperschaften.

Trotzdem hat der Staat hier ebensowenig wie bei der Rentenversicherung die Verantwortung aus der Hand gegeben. Alle wichtigen Entscheidungen sind bereits im Gesetz getroffen, überdies sind an vielen Stellen Rechtsverordnungen der Bundesregierung oder des Bundesarbeitsministers vorgesehen. Ein Vergleich mit den Möglichkeiten kommunaler Selbstverwaltung ist auch hier ausgeschlossen. Die Selbstverwaltung der Bundesanstalt hat mehr technische Bedeutung, entlastet den Staatsapparat und trägt vielleicht etwas dazu bei, die tägliche Arbeit zu entpolitisieren und zu versachlichen.

Um eine echte Versicherung handelt es sich bei der Arbeitslosenversicherung noch weniger als bei der Rentenversicherung ${ }^{50}$ ). Das kommt schon in der Diktion der Gesetze und teilweise auch der Literatur zum Ausdruck, wo man sich scheut, sie überhaupt zur Sozialversicherung zu zählen. Es fehlt überdies an einem kalkulierbaren Risiko. Weder das Umlageverfahren noch die Deckung durch Vermögensansammlung könnten eine ernsthafte Krise meistern: Die Umlagen sinken im Verhältnis zu den Ausgaben, wenn die Arbeitslosigkeit ansteigt, und die Liquidation von Vermögenswerten ist in der Flaute nur mit großen Verlusten und deflatorischen Effekten möglich, die die Krise verschlimmern.

Aus diesen Gründen ist die Arbeit der Bundesanstalt überhaupt nicht unter dem Versicherungsgedanken zu sehen. Lei-

S. 164 - ungeachtet der grundsätzlichen Unterschiede nicht geleugnet werden.

58) Anders Krohn, Festgabe Roehrbein 1962, S. 125 f., der im Zweifel nach Versicherungsprinzipien auslegen möchte.

s0) §51 Abs. 1 SGG rechnet sie überhaupt nicht zur Sozialversicherung, wie die besondere Anführung zeigt. 
stungen aus der Arbeitslosenversicherung oder der Arbeitslosenfürsorge sollen auch erst ihre letzten Mittel sein, wenn die Möglichkeiten, Arbeitsplätze zu schaffen oder zu erhalten, ausgeschöpft sind. Ihre erste Aufgabe ist die Sorge um die Vollbeschäftigung und den sinnvollen Einsatz der Arbeitskräfte. Das kommt im neuen Arbeitsförderungsgesetz besser als im alten AVAVG zum Ausdruck. Dahinter steht das Grundrecht auf Arbeit, das zwar im GG nicht positiviert ist ${ }^{60}$ ), aber in dem $\mathrm{Maße}$, in dem es überhaupt in einer freiheitlichen Wirtschaftsordnung realisierbar ist, im Grundsatz des Sozialstaats enthalten ist ${ }^{\text {(1) }}$.

\section{Die Kranken- und Unfallversicherung}

(10) Die beiden noch verbleibenden Zweige der Sozialversicherung, die Kranken- und die Unfallversicherung heben sich von dem bisher gezeichneten Bild deutlich ab. Obwohl sie am Anfang der Entwicklung des modernen Sozialversicherungsrechts standen, der Staat also ihre Arbeit für besonders dringlich hielt, stehen sie heute in größerer Distanz vom Staat als Renten- und Arbeitslosenversicherung.

Die Krankenkassen sind zwar Körperschaften des öffentlichen Rechts, aber mit einem relativ weitgehenden Recht zur Selbstorganisation nach genossenschaftlichen Prinzipien. Unter der Voraussetzung ausreichender Größe und Leistungsfähigkeit können sich Betriebs- oder Innungskrankenkassen bilden ${ }^{62}$ ), deren Risikostreuung oft günstiger ist als die der allgemeinen Orts- und Landeskrankenkassen. Auch können sich einzelne Versicherungspflichtige der automatischen Pflichtmitgliedschaft in der für sie zuständigen Krankenkasse durch Beitritt zu einer Ersatzkasse entziehen ${ }^{63}$ ), wenn auch jede Rücksicht auf das individuelle Risiko ausgeschlossen ist ${ }^{\text {t4 }}$ ).

In der Verwaltung haben die Krankenkassen auf der Einnahmenseite Spielraum: Sie setzen die Beiträge nach ihrem Bedarf fest, so daß ein Anreiz zur Sparsamkeit und wirtschaftlichem Verhalten auch bei den Versicherten besteht - jedenfalls wenn die Verhältnisse überschaubar sind. Für die Ausgaben ist die Kasse ebenfalls jenseits der Pflichtleistungen frei,

${ }^{80)}$ Vgl. dagegen Art. 163 II WeimRVerf.; auch Art. 23 der UN Menschenrechtsdeklaration.

11) Detaillierter in der Europ. Sozialcharta (BGBl. 1964 II, S. 1263).

Teil I Nr. 1 und Teil II, Art. 1.

o2) $\$ \S 245$ ff. RVO.

6s) $\$ 517$ RVO.

ه4) $\$ \S 505,511 \mathrm{RVO}$. 
allerdings ist ihre Entscheidungsfreiheit insoweit juristisch größer als faktisch, weil gewisse Mehrleistungen üblicherweise erbracht und von den Versicherten erwartet werden.

Erhebliche soziale Macht kommt den Krankenkassen als Tarifpartnern der Ärzte zu. Auch in diesem Bereich arbeiten sie bzw. ihre Verbände in eigener Verantwortung unter staatlicher Aufsicht ${ }^{65}$ ).

Gegenüber einer privaten Versicherung besteht der Hauptunterschied - abgesehen von der Pflichtmitgliedschaft - darin, $\mathrm{da} ß$ die Beiträge lohnproportional, grundsätzlich nicht risikogerecht sind. Alle Beitragszahler erhalten gleichmäßige Leistungen für sich und ihre Familienangehörigen, wenn wir von dem praktisch kaum noch bedeutenden Krankengeld ${ }^{68}$ ) absehen. Darin liegt ein erheblicher sozialer Ausgleich ${ }^{67}$ )

Trotzdem zögere ich, die Leistungen der Krankenkassen als Staatsleistungen zu bezeichnen oder von staatlicher Leistungsverwaltung zu sprechen. Der Akzent liegt wesentlich mehr als bei der Renten- und Arbeitslosenversicherung auf der genossenschaftlichen Selbsthilfe.

Für die Unfallversicherung gilt ähnliches, vielleicht ist die genossenschaftliche Selbsthilfe noch etwas stärker zu betonen ${ }^{68}$ ). Es gibt zwar formell kein Recht der Selbstorganisation, dafür aber noch größeren Spielraum der Selbstverwaltung. Beiträge und Leistungen enthalten geringere Abweichungen von der versicherungsmathematischen Äquivalenz als in allen anderen Zweigen der Sozialversicherung.

Krankenkassen und Berufsgenossenschaften als Träger der Unfallversicherung sind grundsätzlich finanziell selbständig und erhalten keine Staatszuschüsse ${ }^{60}$ ). Auch ein Ausgleich unter verschiedenen Versicherungsträgern findet im Prinzip nicht statt.

65) $\S 368$ ff. RVO; zur normativen Wirkung der Gesamtverträge zwischen kassenärztlichen Vereinigungen und Krankenkassen vgl. BSG v. 21. 10. 1958, Breithaupt 1959, S. 397, Nr. 143.

66) Vgl. Ges. über die Fortzahlung des Arbeitsentgelts im Krankheitsfalle und über Anderungen des Rechts der gesetzlichen Krankenversicherung v. 27. 7. 1969, BGBl. I, S. 946.

67) Vgl. Sozialenquête, S. 203 ff., 238.

68) Vgl. Hans Peters, Festschrift Nipperdey II 1965, Bd. II, S. 889, der die Aufgaben der Berufsgenossenschaften zu öffentlichen, aber nicht zu staatlichen erklärt; ähnlich W. Martens, Offentlich als Rechtsbegriff, 1969, S. 121.

o9) Vgl. Rengert, Festschrift Lauterbach 1961, S. 97, der besonders auf die finanzielle Selbständigkeit der Unfallversicherung hinweist; ähnlich Carganico und Spiecker, ebda., S. 58; Bogs, Grundfragen des Rechts der sozialen Sicherheit und seiner Reform, 1955, S. 54. Zur größeren Selbstverwaltung der Unfallversicherung vgl. $W$. Weber, Die Selbstverwaltung (Anm. 31), S. 30. 
Dieses System funktioniert vollkommen freilich nur, soweit keine Dauerleistungen zu erbringen sind. Für die Rentenlast der Unfallversicherung gibt es daher einen finanziellen Ausgleich nach besonderen gesetzlichen Bestimmungen ${ }^{70}$ ).

C Das Recht der sozialen Sicherung und die Handlungsformen des formellen Verwaltungsrechts

Insgesamt zeigt das System der sozialen Sicherung keinen einheitlichen Charakter. Wir finden die reine Staatsleistung bei Sozialhilfe und Versorgung, in der Sozialversicherung Nuancierungen von der Staatsleistung bis zur genossenschaftlichen Selbsthilfe. Nichtsdestoweniger ist das gesamte Rechtsgebiet formell dem öffentlichen Recht zugewiesen. Wo das zweifelhaft sein könnte und früher auch zweifelhaft war, in der Sozialversicherung, hat § 51 Abs. 2 SGG diese Zweifel behoben.

\section{Der Verwaltungsakt (VA)}

\section{Grundsätzliches}

(11) Damit hat die gesamte Sozialverwaltung die Möglichkeit, durch Verwaltungsakte zu handeln, denn der VA gilt als die gewöhnliche Handlungsform, in der ein Träger öffentlicher Verwaltung dem Bürger gegenübertritt. Das wirft in der Leistungsverwaltung grundsätzliche Probleme auf, deren wir uns im Alltag selten bewußt werden. Der VA ist aus Polizeibefehl und Steuerbescheid abstrahiert worden, an die Leistungsverwaltung hatte $O$. Mayer kaum gedacht ${ }^{71}$ ). Er ging deutlich von der polizeilichen Verfügung aus: Die Behörde dürfe nicht unmittelbar aus dem Gesetz heraus mit Zwangsmitteln gegen den Bürger vorgehen. Wie im Zivilrecht vor die Vollstreckung das Urteil gesetzt sei, so müsse im öffentlichen Recht vor die Vollziehung der VA als fester Punkt treten, der dem Einzelnen Halt gewähre und ihn darüber sicherstelle, wohin es gehe ${ }^{72}$ ).

Diese Konzeption ist an sich für die Leistungsverwaltung nicht brauchbar, und es ist kein Zufall, daß in diesem Bereich von VAen früher selten die Rede war. Erst nach dem zweiten Weltkrieg hat der VA sich hier ganz durchgesetzt.

Der Grund dafür war einmal die verwaltungsgerichtliche Generalklausel, die zunächst auf die Anfechtung von VAen be-

70) Vgl. Unfallversicherungsneuregelungsgesetz v. 30.4. 1963, BGBl. I, S. 241, dazu BVerfGE 23, S. 12; ferner Finanzänderungsgesetz 1967 v. 21. 12. 1967, BGBI. I, S. 1259, Art. 2, § 4.

71) Vgl. Badura (Anm. 22), S. 9, 11; kritisch zum Begriff des Verwaltungsakts auch ders., DOV 1968, S. 452.

72) O. Mayer, Dt. Verwaltungsrecht $I^{8}$, 1924, S. 92 f., auch S. 59. 
schränkt zu sein schien. Das verleitete dazu, überall VAe anzunehmen, um den Rechtsschutz zu ermöglichen. Dieser Grund ist heute in Deutschland weggefallen, da die allgemeine Leistungsklage anerkannt ist. In Osterreich ist die Lage freilich anders, da nach positiver gesetzlicher Vorschrift grundsätzlich Rechtsschutz nur gegen Bescheide möglich ist ${ }^{23}$ ).

Es gibt jedoch noch weitere Gesichtspunkte, die eine Utbertragung des VA in die Leistungsverwaltung rechtfertigen:

Wir kennen viele Leistungen, bei deren Bewilligung der Behörde ein Ermessen eingeräumt ist. Es ist sinnvoll, sogar notwendig, daß in solchen Fällen nicht einfach nach Belieben oder auch Ermessen ausgezahlt wird, sondern daß Art und Ausmaß der Leistung vorher verbindlich durch rechtsgestaltenden VA festgelegt werden ${ }^{74}$ ).

Wo Ansprüche nach Art und Umfang gesetzlich genau fixiert sind, muß dagegen nicht notwendig zwischen Anspruch und Erfüllung ein VA treten ${ }^{75}$ ). Die Behörde kann schlicht erfüllen; hält sie den Anspruch für ungerechtfertigt, kann sie eine Leistungsklage abwarten. Ein etwaiger ablehnender VA ist nicht mehr als die Erklärung eines Schuldners, er sei zur Leistung nicht bereit, eine Erklärung, die allerdings eine kurze Klagefrist in Lauf setzt ${ }^{76}$ ).

Einen Sinn hat der VA, wenn er nicht frei zurücknehmbar ist, sondern das Rechtsverhältnis stabilisiert. Dann ist er dem richterlichen Urteil über den erhobenen Anspruch vergleichbar, mag auch seine Bestandskraft hinter diesem zurückbleiben. Dabei sehe ich die wesentliche Funktion in der Stabilisierung für die Zukunft, also für die Gewährung künftiger Leistungen. Bei einmaligen Leistungen ist der VA im Grunde entbehrlich. Das zeigt etwa $\$ 1569$ a RVO, wo eine förmliche Rentenfeststellung in der Unfallversicherung dann nicht gefordert wird,

73) Vgl. $\$ 63$ ff. österr. VerwVerfG.

74) Vgl. Huber, Schweiz. Ztschr. f. Sozialversicherung 1957, S. 8 f.; BSG v. 23. 8. 1958, SozR SGG, §54, Bl. Da 11 Nr. 42 läßt bei Ablehnung von Ermessensleistungen zu Recht keine zusammengefaßte Anfechtungs- und Leistungsklage nach § 54 Abs. 4 SGG zu.

75) Vgl. Wertenbruch (Anm. 13), S. 352 f.; dagegen setzt sich Haueisen, DVBl. 1959, S. $793 \mathrm{ff}$., sehr dezidiert für die vorherige Entscheidung durch Verwaltungsakt ein; vgl. auch ders., Die Ortskrankenkasse 1965, S. 361 ff. und DVBl. 1969, S. 717. - Kritisch zum Verwaltungsakt in der Leistungsverwaltung überhaupt Menger, DOV 1955 S. 590; sehr hart äußert sich Zacher, Festschrift Jantz 1968, S. 38 zum Verwaltungsakt (nbegriffsjuristischer Popanz in der Mitte des Systems des Verwaltungshandelns").

70) Vgl. Götz, DVBl. 1961, S. 437, der mit Recht fordert, der Verwaltungsakt müsse mehr sein als das Schreiben eines Schuldners, der zu seiner Verbindlichkeit Stellung nehme. 
wenn die Rente nur für die Vergangenheit gewährt wird. Für einmalige Leistungen könnten überhaupt Regeln genügen, welche sich mit der Erstattung von Uberzahlungen befassen. Das übertriebene Denken in VAen hat indes sogar dazu geführt, daß solche Regeln, wo sie bestehen - wie im Beamtenrecht -, durch das Verbot der Rücknahme überspielt werden: Der rechtswidrige VA, auf dem die Leistung beruht, darf wegen des Vertrauensschutzes nicht zurückgenommen werden, daher läßt sich eine Uberzahlung nicht feststellen ${ }^{77}$ ).

Wir werden diesem Problem im Sozialrecht nachgehen müssen. Zu fragen ist in diesem Zusammenhang, ob jede Verwaltungsbehörde über jeden beliebigen gegen sie erhobenen öffentlichrechtlichen Anspruch potentiell verbindlich durch VA entscheiden kann oder sogar muß: Ersteres scheint communis opinio zu $\operatorname{sein}^{78}$ ), ist aber kürzlich mit guten Gründen bestritten worden $\left.{ }^{70}\right)$. Für das Sozialversicherungsrecht und das Recht der Kriegsopferversorgung hat der Gesetzgeber insoweit besondere Probleme geschaffen, da §77 SGG, der allen VAen Bestandskraft verleiht, nicht genügend durchdacht ist.

\section{Sozialhilfe und Versorgung}

(12) Im Fürsorgerecht spielte der VA anfänglich keine Rolle für das Verhältnis zum Hilfeempfänger: Er hatte keinen Rechtsanspruch, zwischen ihm und der Behörde entstand überhaupt kein Rechtsverhältnis, das durch VA rechtlich hätte gestaltet werden können. Als der Anspruch des Hilfsbedürftigen anerkannt wurde, hatte sich der VA bereits als Kernstück des Allgemeinen Verwaltungsrechts durchgesetzt. Es war darum keine Frage, daß im Fürsorgerecht mit dieser Handlungsform zu arbeiten sei. Das ist in aller Regel auch sachgerecht, denn das Bundessozialhilfegesetz gewährt nur selten Ansprüche auf ganz bestimmte Leistungen; grundsätzlich stellt es Form und Maß der Hilfe in das pflichtgemäße Ermessen der Behörde, gibt also nur einen Anspruch auf gesetzmäßige und sachgerechte Entschei-

77) Vgl. §87 II BBG, dazu BVerwG v. 24. 4. 1959, NJW 1960, S. $258 \mathrm{ff}$. und BVerwG v. 7. 6. 1962, DOV 1962, S. 823 (826).

78) Vgl. z. B. Götz, DVBl. 1961, S. 437; Weides, JuS 1964, S. 112 f.; berichtend, aber selbst kritisch Löwenberg, die Geltendmachung von Geldforderungen im Verwaltungsrecht, 1967, S. 31; BVerwGE 18, S. 283 (285 ff.); BVerwG v. 17. 9. 1964, DOVV 1965, S. 53; BVerwG v. 26. 2. 1965, DOV 1965, S. 710 (711); OVG Münster v. 19. 7. 1962, DVBl. 1963, S. 187 f. = DOV 1963, S. 27 f., sämtlich zu Forderungen des Staates gegen den Bürger.

79) Löwenberg, wie vorst. Anm.S. 19, 45 ff.; kritisch auch Rupp, DVBl. 1963, S. 579. 
dung. Eine schlichte Leistung ist in diesen Fällen ausgeschlossen. Anders liegt es dort, wo das Gesetz feste Summen auswirft, z. B. bei der Blindenhilfe ( $\$ 67$ Abs. 2 BSHG). Hier ist schlichte Leistung, bei Verweigerung Leistungsanklage mög$\operatorname{lich}^{80}$ ).

Die Frage der Rechts- oder Bestandskraft von VAen stellt sich im Sozialhilferecht in der Regel nicht, da Zusagen für die Dauer nicht gemacht werden. Jedenfalls bietet das Sozialhilferecht keinen Anlaß, diese Probleme aufzurollen.

Auch das Versorgungsrecht wuchs in das bereits vom Denken in VAen beherrschte Verwaltungsrecht hinein. Das Verwaltungsverfahrensgesetz zur Kriegsopferversorgung folgt nur der seit langem geltenden Ubung, wenn es in $\$ 22$ festlegt, daß Leistungen auf Grund eines Bescheides erbracht werden, der die Leistung festgesetzt hat. Das gilt generell, also auch dort, wo Ermessensentscheidungen nicht $\mathrm{zu}$ treffen sind. Zwischen den Anspruch und die Leistung ist also immer ein VA geschoben. Das Problem der Bestandskraft ist für Bescheide über Rechtsansprüche in $\S 41$ dahin geregelt, daß zuungunsten des Berechtigten ein neuer Bescheid ergehen kann, wenn außer Zweifel steht, daß der frühere Bescheid tatsächlich und rechtlich unrichtig war. Zugunsten des Berechtigten kann jederzeit ein neuer Bescheid erteilt werden. Er muß erlassen werden, wenn das BSG in ständiger Rechtsprechung eine andere Auffassung vertritt, als sie dem Bescheid zugrundelag. Utber die Bestandskraft von Ermessensentscheidungen ist nichts gesagt. Das BSG wendet hier trotz §77 SGG die Regel des Allgemeinen Verwaltungsrechts $\mathbf{a n}^{\mathbf{8 1}}$ ).

Das Kindergeld wird - anders als die Kriegsopferversorgung - grundsätzlich schlicht gewährt. Nur bei Ablehnung oder Entzug des Kindergeldes ist ein schriftlicher begründeter Bescheid zu erteilen ( $\$ 25$ BKGG).

\section{Sozialversicherung}

(13) Während Sozialhilfe und Versorgungsrecht in das Allgemeine Verwaltungsrecht hineinwachsen konnten, waren die Hauptgebiete des Sozialversicherungsrechts bereits ausgebildet,

80) Vgl. im einzelnen Wertenbruch (Anm. 13), S. 352 f.; ders., Festgabe Küchenhoff 1967, S. 343 ff., bes. S. 345 f.; Müller-Tochtermann, JuS 1962, S. 451; Jehle, Sozialhilferecht, §4, Anm. 6 b; ferner zur Konkretisierung durch Verwaltungsakt allgemein BVerwGE 28, S. 353 (355), wo der Verwaltungsakt sogar bei Ermessensschrumpfung für notwendig gehalten wird.

81) Vgl. BSGE 21, S. $35(36,38)$. S. auch Anm. 107. 
bevor sich Otto Mayers Allgemeines Verwaltungsrecht durchgesetzt hatte. Die RVO zeigte vor der Novellierung durch das SGG - und zeigt in ihrer Sprache $z$. T. heute noch ${ }^{82}$ ) - das Bild des älteren Verwaltungsrechts, wie wir es auch in den Lehrbüchern vor Otto Mayer finden. Der VA als genereller Begriff spielt keine Rolle; es gibt einzelne Entscheidungen, Verfügungen und Bescheide, über die jeweils gehörigen Orts das Nötige bestimmt ist. Im Streitfall gab es eine Art von Administrativjustiz mit rechtskraftfähigen Entscheidungen. Das gilt z. B. für die Leistungen der Krankenkassen, die an sich schlicht gewährt wurden ${ }^{83}$ ). Die Renten der Renten- und Unfallversicherung wurden stets durch Bescheid festgesetzt, der in seiner Wirkung einem rechtskräftigen Urteil gleichgestellt war ${ }^{84}$ ).

Das SGG hat das Denken in Verwaltungsakten für seinen Bereich, d. h. für den gesamten Bereich der Sozialversicherung und noch darüber hinaus, eingeführt ${ }^{85}$ ), die RVO wurde ihm angepaßt. Wir müssen also heute davon ausgehen, daß alle Entscheidungen, Verfügungen und Bescheide von Versicherungsträgern VAe sind, die den allgemeinen Regeln des Verwaltungsrechts unterliegen, soweit nicht etwas Besonderes bestimmt ist. Das SGG sollte aber an den früheren rechtskraftfähigen Leistungsbescheiden über Renten nichts ändern. Deshalb bestimmt $\$ 77$ SGG: Wird der gegen einen VA gegebene Rechtsbehelf nicht oder erfolglos eingelegt, so ist der VA für die Beteiligten in der Sache bindend, soweit durch Gesetz nichts anderes bestimmt ist. Daran, daß diese Bestimmung über die Leistungsbescheide weit hinausgreift, hat man nicht gedacht $t^{80}$ ). So ist es zu einer Regelung gekommen, die vom Rentenbescheid bis zum Bescheid über die Befreiung von der Versicherungspflicht alles undifferenziert über einen Leisten schlägt. Außerdem klagt die Praxis vielfach über die zu starre Bindung an unrichtige VAe, die es in anderen Bereichen nicht gibt.

Um Mißverständnisse zu vermeiden, ist zunächst klarzustellen, daß eine Änderung zugunsten des betroffenen Bürgers trotz § 77 SGG und anderer spezieller einschlägiger Bestimmungen immer zulässig ist $\left.{ }^{87}\right)$. Zu diskutieren ist lediglich, inwie-

82) Vg1. Wertenbruch, DÖ 1969, S. 604.

89) Vgl. $\$ \S 1551,1636$ ff. RVO a. F.

84) Vgl. \$§ 1583, 1631 RVO a. F.

85) Vgl. dazu grundsätzlich zustimmend Haueisen, DVBl. 1969, S. 717; kritisch v. Altrock, Festschrift Bogs 1959, S. 21.

89) Vgl. Bundestagsdrucksache I/4357 vom 19.5. 1953, § 26 Abs. 1, dazu Begründung des Regierungsentwurfs auf S. 26.

87) BSGE 10, S. 248 (249). 13, S. 86 (87 f.); 18, S. 22 (25, 29 m. w. N.); Haueisen, in: Staatsbürger und Staatsgewalt I, 1963 S. 264. 
weit z. B. nach $\S 1300$ RVO ein günstigerer Zweitbescheid erlassen werden $m u \beta^{88}$ ).

Hinsichtlich der allein problematischen Zuungunstenbescheide ist bezüglich der Rentenbescheide de lege lata an der starren Bindung kaum zu rütteln. Die Spezialbestimmung des $§ 1744$ RVO zählt erschöpfend auf, wann eine neue Prüfung zulässig ist, und beschränkt sie im wesentlichen auf die Gründe, die gewöhnlich zur Wiederaufnahme eines durch rechtskräftiges Urteil abgeschlossenen Verfahrens ausreichen. Man kann per analogiam zum Urteil noch einige weitere Berichtigungsgründe finden, z. B. den der offenbaren Unrichtigkeit ${ }^{89}$ ), aber im Prinzip bleibt der Bescheid unabänderlich ${ }^{00}$ ).

(14) Es sind also allenfalls Uberlegungen de lege ferenda möglich"1). Dabei wird oft auf die ärgerliche Diskrepanz zwischen der Kriegsopferversorgung und der Rentenversicherung hingewiesen ${ }^{\circ 2}$ ). Dafür gibt es in der Tat keine einleuchtenden Gründe. Wir können auch berücksichtigen, daß die Schweiz ${ }^{23}$ ) und Frankreich das Vertrauen des Rentners in den Bestand seiner Rente nicht schützen, sondern nur die Rückzahlungspflicht für Zuvielzahlungen beschränken. Ehe aber eine Revision des §1744 RVO als dringlich erklärt wird, sollte auch bedacht werden, daß nach der neueren Rechtsprechung des BSG eine eigentliche Dauerwirkung der fehlerhaft berechneten anders der zu Unrecht überhaupt bewilligten - Rente nicht mehr besteht: 1744 RVO verlangt nämlich danach, daß der Betrag der Rente ungekürzt bleibt, nicht, daß künftige Erhöhungen auf der falschen Basis weiterberechnet werden ${ }^{\text {of }}$ ). Nimmt man hinzu, daß grobe Fehlberechnungen eines Computers im Zweifel unter die offensichtlichen Rechenfehler fallen, die

88) Vgl. BSGE 19, S. 38 (43); 26, S. $89(90,92)$; 28, S. 141 (143 f.); BSG v. 31. 10. 1968, DVBl. 1969, S. 372 f.; vgl. dagegen BVerwG v. 19. 10. 1967, DVBl. 1968, S. 155 (156 f.), wo nach allgemeinem Verwaltungsrecht in einer Lastenausgleichssache entschieden wurde.

89) Vgl. Bogs, Festgabe Roehrbein 1962, S. 31; Haueisen (Anm. 87), S. 267; ders., NJW 1960, S. 1499 f.; BSGE 15, S. 96 (98); 24, S. 203 (204 m. w. N.).

Do) BSGE 11, S. 226 (229 f.); 14, S. 10 (mit Vorbehalt für arglistiges Erschleichen auf S. 17); 14, S. 154 (157 f.); 18, S. 84 (87 ff.); 24, 203 (204); ähnlich BSG v. 9.9. 1966, DVBl. 1967, S. $582 \mathrm{f}$.

11) Vgl. dazu die Lösung der Rentenanpassungsgesetze, z. B. 11. Rentenanpasungsgesetz v. 1.11. 1968, BGBI. I, S. 1189, §14.

92) Vgl. \$41 VerwVerfG KOV, dazu BSGE 24, S. 203 (207).

03) Vgl. Art. 47 AHV (Anm. 23), dazu Vollzugsverordnung vom 31. 1. 1947, Art. $78 \mathrm{f}$.

D4) Vgl. BSGE 24, S. 236 (239 ff.); schon vorgezeichnet in BSGE 14, S. 154 (159); vgl. aber auch BSGE 26, S. 98 (100 f.). 
korrigiert werden können ${ }^{95}$ ), erscheint $\S 1744$ RVO jedenfalls nicht mehr als dringend reformbedürftig $\left.{ }^{26}\right)$. Immerhin dürfte der Vertrauensschutz bei weitem übertrieben sein, wenn sogar betrügerisches Verhalten bis zu einem rechtskräftigen Strafurteil honoriert wird ${ }^{97}$ ).

Nicht zuletzt um der Bindungswirkung nach $\S 77$ SGG/1744 RVO zu entgehen, neigt das BSG einer Ausweitung der schlichten Erfüllung zu Lasten des VA zu. Es hat sich zwar nicht zu der Auffassung durchringen können, als bindende VAe im Sinne von §77 SGG und 1744 RVO seien nur besonders qualifizierte VAe, etwa nur förmliche Rentenbescheide anzusehen, die in einem besonders geordneten Verfahren ergangen sind ${ }^{\text {po }}$ ). Das mag in der Intention des Gesetzgebers gelegen haben, hat aber in der Formulierung des Gesetzes keinen Ausdruck gefunden. Das BSG geht darum mit beachtlicher Konsequenz den anderen Weg, den Begriff des VA einzuschränken ${ }^{09}$ ), eine Tendenz die im Prinzip zu begrüßen ist, weil nur so der VA wieder Konturen gewinnen kann. So sollen im Regelfall Leistungen der Krankenkassen schlicht gewährt werden, ohne daß ein VA erlassen wird. Der Auszahlungsschein, den der Kranke bei allen Leistungen vorzulegen hat und auf dem die Leistungen vermerkt werden, soll nur eine Unterlage für die technische Abwicklung der Leistung sein $\left.{ }^{100}\right)$. In einer anderen Sache, allerdings nicht aus dem Bereich der Sozialversicherung, meinte das BSG einmal sogar, die Ausstellung von Bundesbehandlungsscheinen, in denen die Versorgungsbehörde die Garantie für die Kosten der

95) Vgl. BSGE 24, S. 203 (204).

96) Vgl. dazu im einzelnen Thieme, 45. Dt. Juristentag 1964, Sitzungsberichte H, S. 23 ff., der sich für eine Neuregelung ausspricht, sie aber nicht zur Erzielung billiger Ergebnisse für dringend erforderlich hält.

${ }^{97)}$ Vgl. Salzwedel, in: Rechtsschutz im Sozialrecht, 1965, S. 218, der hier von der Bindung absehen möchte; BSGE 14, S. 10 (17).

98) In diesem Sinn Rohwer-Kahlmann, in: Wandlungen der rechtsstaatlichen Verwaltung, 1962, S. 69 ff.; Brackmann, Festschrift Lauterbach 1961, S. 90 f.; dahingestellt noch in BSGE 15, S. 118 (122).

90) Zustimmend dazu Bogs, Festgabe Roehrbein 1962, S. $32 \mathrm{f}$.

100) BSGE 25, S. 280 (282); auch die Beanstandung eines Beitrags ist nach BSGE 24, S. 13 (14) kein Verwaltungsakt. Vgl. dagegen die großzügige Annahme eines Verwaltungsakts in BSGE 19, S. 178 (Bescheinigung der Ersatzkasse nach \$ 518 RVO als feststellender Verwaltungsakt). - Kritisch zu BSGE 25, S. 280: Brackmann, Handbuch (27), S. 382 e; Schröder-Printzen, Festschrift Bogs 1967, S. 185 ff., bes. S. $192 \mathrm{ff}$., der den Schalterakt als Verwaltungsakt mit Widerrufsvorbehalt ansehen möchte - vielleicht ähnlich wie es BSGE 7, S. 226 (228) zur Benachrichtigung über einen Rentenvorschuß an einen Kriegsbeschädigten angenommen hat. 
Behandlung übernimmt, sei kein VA, da sie die Leistung selbst, nicht deren Regelung sei ${ }^{101}$ ).

Die letzte Konsequenz solcher Anschauungen wäre, daß es bei Krankenkassenleistungen überhaupt keine VAe gäbe ${ }^{102}$ ). Bei Ablehnung durch die Krankenkasse stünde dem Betroffenen dann die Leistungsklage zu. Das BSG ist jedoch zu dieser methodisch einwandfreien Folgerung nicht fortgeschritten: Es nimmt vielmehr an, daß im Streitfall ein VA erlassen wird, z. B. wenn der Versicherungsträger nach Utberprüfung an seiner Ablehnung festhält oder einen Abhilfebescheid im Widerspruchsverfahren erläßt. Das ist konstruktiv nicht ganz sauber, aber praktikabel, weil der strittige Einzelfall im Gegensatz zur Routinesache genauer geprüft werden kann. §54 Abs. 4 SGG scheint zudem die Meinung des BSG zu stützen, wenn dort eine Klage auf Aufhebung eines VA zugleich mit der Klage auf Leistung zugelassen wird. Uberdies findet sich in § 25 BKGG eine ausdrückliche Vorschrift, daß ein Bescheid nur bei negativer oder entziehender Entscheidung zu erlassen ist. Die österreichischen ${ }^{103}$ ) und schweizerischen ${ }^{104}$ ) Krankenkassen verfahren ähnlich. Die Beitragsangelegenheiten werden ebenso erledigt: Bescheide gibt es grundsätzlich nur in Streitfällen.

(15) Die Ausflucht des schlichten Verwaltungshandelns hilft freilich nicht weiter, wenn das Gesetz an vielen Stellen ausdrücklich VAe vorschreibt, z. B. bei den Befreiungsbescheiden in der Kranken- und Rentenversicherung ${ }^{105}$ ). Hierfür gibt es nicht einmal eine dem \$1744 RVO entsprechende Regelung für die gröbsten Fehler, vielmehr gilt nur \& 77 SGG, so daß jede Korrektur ausgeschlossen zu sein scheint. Dieses Ergebnis ist sicher untragbar, denn der VA kann in seiner Bestandskraft nicht noch über dem richterlichen Urteil stehen $\left.{ }^{106}\right)$.

Andererseits kann die Regel des $§ 77$ SGG nicht einfach durch das allgemeine Verwaltungsrecht überspielt werden, wie das

101) BSGE 25, S. 257 (258 f.); mit seiner Begründung setzt sich das BSG deutlich von sonst im Verwaltungsrecht üblichen Auffassungen ab.

102) Insofern könnte der kritische Einwand Salzwedels (Anm. 97), S. 206, der Kreis der sozialrechtlichen Verwaltungsakte sei geschlossen (gegen BSGE 6, S. 175), auch hier erhoben werden.

108) \$367 ASVG

104) Vgl. Gysin, Schweiz. Ztschr. f. Sozialversicherung 1964, S. 19.

105) Vgl. einen solchen Fall in BSGE 15, S. 252; v. Altrock, Festschrift Bogs 1959, S. 30 f., möchte deshalb die Beitragsbescheide genauso wie die Bewilligungsbescheide - der Kranken - und Unfallversicherung von den allgemeinen Lehren vom begünstigenden Verwaltungsakt verschonen.

106) Vgl. Kormann, System der rechtsgeschäftlichen Staatsakte, 1910, S. 369. 
die Kriegsopfersenate des BSG in ständiger Rechtsprechung allerdings nur für wenige Fälle, da gewöhnlich spezielle Regeln eingreifen - vertreten ${ }^{107}$ ). Wenn das SGG den VA für bindend erklärt, soweit durch Gesetz nichts anderes bestimmt ist, so will es gerade die Regel des Allgemeinen Verwaltungsrechts mit ihrer recht unbestimmten Güterabwägung ausschließen und dem Bürger die Gewähr größerer Beständigkeit geben ${ }^{108}$ ).

Aus dem Dilemma können nur Analogien zu spezielleren Normen führen $\left.{ }^{100}\right)$. So kommt für das Beitragsrecht eine Analogie zu \$96 RAbgO in Frage, wenn man nicht auf §1744 RVO mit seinen allerdings sehr beschränkten Möglichkeiten zurückgreifen will.

De lege ferenda wäre zu fordern, daß der Gesetzgeber Klarheit schafft, für welche VAe die strenge Bindung des $\$ 77$ SGG gelten soll, und so sein Versehen korrigiert. Muster könnte dafür methodisch die österreichische Lösung sein: Das Gesetz zählt in §367 ASVG erschöpfend auf, in welchen Fällen ein Bescheid zu erlassen ist ${ }^{110}$ ).

\section{Andere Handlungsformen}

\section{Die öffentlichrechtlichen Willenserklärungen Privater}

(16) Der VA ist nicht die einzige Handlungsform, die im Sozialrecht Bedeutung hat. Da das Sozialrecht, vor allem das Sozialversicherungsrecht, es mit zweiseitigen Verhältnissen des öffentlichen Rechts zu tun hat, gewinnt als Pendant zum VA das rechtsgeschäftliche Handeln Privater besondere Bedeutung ${ }^{111}$ ).

Das scheint eine Besonderheit des Sozialrechts zu sein, denn im Polizeirecht, dem sog. klassischen Bereich des öffentlichen Rechts, hat das private Handeln allenfalls als Verfahrensantrag

107) Vgl. BSGE 7, 8 (16); 7, 51 (52 f.); 8, 11 (14); 10, 72 (74); 15, 81; $21,35(36,38)$; BSG v. 20.8.1963, NJW 1963, S. 2093; außerdem 5 . Senat des BSG v. 1. 7. 1969, DVBl 1969, S. $744 \mathrm{f}$. Ebenso Haueisen vielfach, z. B. DVBl. 1969, S. 231; DVBl. 1960, S. 919 f.; wie Anm. 87, S. $266 \mathrm{f}$.

109) Zacher, 45. Dt. Juristentag, Sitzungsberichte H, S. 87 f.; Thieme, ebda., S. 22 f. (weniger dezidiert); Salzwedel (Anm. 97), S. 218; Bogs, in: Festgabe Roehrbein 1962, S. 23 ff.; Wertenbruch, DOV 1969, S. 606.

100) Vgl. dazu die methodisch saubere Entscheidung BSGE 17, S. 295 (wo S. 298 die Heranziehung von Grundsätzen des allgemeinen Verwaltungsrechts immerhin nicht ganz ausgeschlossen wird); BSGE 15, S. 96 (98) zur Heranziehung von $\$ 92$ Abs. 3 (jetzt Abs. 2) RAbgO.

110) Vgl. auch die erschöpfende Aufzählung der Rücknahmegründe in $\$ \$ 200,201$ BEG.

111) Vgl. dazu allgemein G. Küchenhof, Die öffentlichrechtliche Willenserklärung der Privatperson, in: Festschrift Laforet 1952, S. 317 ff. 
Bedeutung. Eine Mitgestaltung des Rechtsverhältnisses durch Private kommt nicht in Betracht. Von da aus kann leicht die Meinung aufkommen, es sei überhaupt der Natur eines öffentlichrechtlichen Verhältnisses zuwider, Privaten Mitgestaltungsrechte einzuräumen. Möglich sei nur, daß der Bürger durch einen Antrag den Anstoß zu behördlichem Handeln gebe $^{112}$ ). Diese Sicht verkennt, daß die Ausdehnung des öffentlichen Rechts über die Eingriffsverwaltung des 19. Jahrhunderts hinaus ihre Konsequenzen hat: Wenn der Staat zwischen sich und dem Bürger Rechtsverhältnisse schafft, die in ihrer Konstruktion bürgerlichrechtlichen Verhältnissen entsprechen, kann und muß er nicht mehr beim Dogma des rein einseitigen hoheitlichen Handelns stehen bleiben.

Ich möchte nicht zu sehr in die Details gehen. Das BSG sagt z. B., der Antrag auf vorgezogenes Altersruhegeld habe im Gegensatz zum normalen Rentenantrag materiellrechtliche ${ }^{113}$ ) - und das müßte wohl heißen: rechtsgeschäftliche - Bedeutung. Es begründet das etwas formal damit, daß der Antrag in $\$ 1248$ Abs. 2 und 3 RVO ausdrücklich genannt sei. Der tiefere Grund dürfte sein, daß durch die vorgezogene Altersrente das gesamte Rentenversicherungsverhältnis umgestaltet wird: Es können vor allem keine weiteren rentensteigernden Beiträge mehr geleistet werden. Der Rentenberechtigte gestaltet durch seinen Antrag selbst mit, er beantragt nicht nur ein hoheitliches Handeln. Ähnliches gilt für den freiwilligen Beitritt zu einer Sozialversicherung, soweit er gesetzlich möglich ist. Er ist einseitige rechtsgestaltende Willenserklärung des Bürgers, kein Antrag auf Aufnahme ${ }^{114}$ ). Für frei ausgehandelte Verträge zwischen Verwaltung und Bürger läßt das Sozialrecht im allgemeinen keinen Raum. Allerdings sollten wir nicht verkennen, daß die Versicherungsverhältnisse der Sozialversicherung privatrechtlichen Versicherungsverhältnissen teilweise recht ähnlich sind. Wären z. B. die Ersatzkassen nicht juristische Personen des öffentlichen Rechts, würde wohl auch heute niemand daran AnstoB nehmen, die Zulassung zu ihnen als Vertrag mit Abschlußzwang anzusehen. Zudem bestehen zwischen mitwirkungsbedürftigem VA und Vertrag nicht immer große sachliche

112) Vgl. O. Mayer, Deutsches Verwaltungsrecht $I^{3}, 1924$, S. 15, $108 \mathrm{f}$. - Schon in solchen Fällen kann das Fehlen des Antrags zur Nichtigkeit führen, vgl. BSGE 12, S. 265 (268).

113) BSGE 13, S. 79 (81); 20, S. 48 (49); vgl. auch 15, S. 157 (158 ff.); dagegen BSGE 16, S. 202 (203) und 20, S. 48 (49 ff.); gegen diese Rechtsprechung des BSG Barth, Die Sozialversicherung 1966, S. 1 ff.; allgemein zum Rentenantrag vgl. Röss, Die Sozialversicherung 1966, S. 6 ff., $40 \mathrm{ff}$.

114) BSGE 23, S. 248 (251); a. A. Wertenbruch (Anm. 13), S. 322. 
Unterschiede ${ }^{115}$ ). Das BSG hat das klarer als das BVerwG in seiner Rechtsprechung zum Prozeßvergleich herausgearbeitet $\left.{ }^{116}\right)$.

\section{Das schlichte Verwaltungshandeln}

(17) Auch für die Verwaltung ist der VA nicht die einzige Handlungsform. Besondere Bedeutung gewinnt im Bereich des Sozialrechts das sog. schlichte Verwaltungshandeln.

Wir hatten uns schon mit der schlichten Erfüllung beschäftigt, der ein Erfüllungsanspruch des Bürgers korrespondiert. Dagegen scheinen noch viele Reserven zu bestehen, die ähnliche Gründe haben wie die zögernde Anerkennung rechtsgeschäftlicher Mitwirkung des Privaten: Der Untertan muß die staatliche Entscheidung abwarten, die er allenfalls beantragen kann. Ein Automatismus, der staatliches Handeln irgendwelcher Art nur vom Bürger abhängig macht und ihm einklagbare Erfüllungsansprüche gibt, ist unerträglich. Allenfalls kann der Bürger einen rechtswidrigen Staatsakt anfechten und damit negativ beseitigen. Das wird selten so klar ausgesprochen, dürfte aber vielfach im Hintergrund stehen. Wer so denkt, verkennt - wie das vielfach im 19 . Jh. geschehen ist $^{117}$ ) - den Unterschied zwischen den freien Akten staatlicher Souveränität (z. B. der Gesetzgebung) und dem Handeln der gesetzlich gebundenen Verwaltung. Die Verwaltung ist eben nicht souverän und sie hat es nicht mit prinzipiell rechtlosen Untertanen zu tun. Ganz abgesehen davon ist die ältere Anschauung, die nur die Beseitigung rechtswidriger Staatsakte auf dem Verwaltungsrechtsweg zuließ, zu deutlich von der bloßen Eingriffsverwaltung geprägt, als daß sie heute noch brauchbar wäre.

Auch im übrigen bietet das Sozialversicherungsrecht - mehr noch als das sonstige Sozialrecht - viele Beispiele für das schlichte Verwaltungshandeln. Zu erwähnen ist etwa die Vermittlung von Arbeitsplätzen und die Berufsberatung durch die Arbeitsämter. Hinzuweisen ist auch auf die vielfachen Beratungen und Auskünfte in der Kranken- und Rentenversicherung sowie auf das Verfahren der Beitragseinziehung ${ }^{118}$ ). Die Auskünfte und Beratungen sind für den Bürger von großer Bedeu-

115) Vgl. Thieme, in Hamburger Festschrift für Fr. Schack, 1966, S. $159 \mathrm{f}$.

110) BSGE 26, S. 210 (211 f.); bestätigt in BSG v. 22.8.1967, NJW 1968, S. 176; vgl. dazu Haueisen, DVBl. 1968, S. 287 f.; ders., NJW 1969, S. 122 ff.; ders. NJW 1967, S. 590 f. - Siehe dazu auch BVerwGE 14, S. 103 (105); anders noch BSGE 16, S. 61 (62), dazu kritisch Salzwedel (97), S. $203 \mathrm{f}$.

117) Vgl. dazu Rüfner, Verwaltungsrechtsschutz in Preußen, 1962, S. 154; ders., DOV 1963, S. 720.

118) Vgl. dazu BSGE 17, S. 173 (175). 
tung, dennoch haben sie mit VAen, die das Rechtsverhältnis gestalten, nichts zu tun. Sie sind aber auch nicht rechtlich unerheblich, sondern können zumindest Schadensersatzansprüche der Versicherten auslösen ${ }^{110}$ ).

\section{Das Dauerverhältnis}

(18) Die relativ große Bedeutung des schlichten Verwaltungshandelns ist typisch für die verwaltungsrechtlichen Dauerverhältnisse, mit denen wir es im Bereich des Sozialrechts meist zu tun haben. Sie können nicht durch VAe gestaltet werden, weil der VA immer nur eingreift und sinnvoll ist, wenn ein fester Punkt für die Zunkunft geschaffen werden muß $\left.{ }^{120}\right)$. Dann allerdings hat er auch während eines laufenden Dauerverhältnisses seinen Platz.

Das Dauerverhältnis interessiert uns noch unter einem anderen Aspekt: Es muß sich veränderten Verhältnissen ständig anpassen und läßt sich darum nicht rein statisch betrachten und in starre gegeseitige Ansprüche auflösen. Wohl kann man die bestehenden Ansprüche zu jeder Zeit konkretisieren, aber es gibt keine Gewähr dafür, daß sie in alle Ewigkeit fortbestehen. Das ist relativ unproblematisch bei der Sozialhilfe, die immer unter dem Vorbehalt der Veränderung der Umstände gewährt wird. Es gilt nicht minder für die Sozialversicherung, soweit sie auf Dauer disponiert, vor allem Dauerleistungen gewährt. Seit der Rentenreform ist das für die Rentenversicherung augenfällig: Sie gewährt von vornherein keinen Anspruch auf eine bestimmte Geldsumme, sondern verheißt eine Rente nach einer bestimmten Rentenformel. Auch wenn wir das Versicherungsverhältnis als ein Rechtsverhältnis mit gegenseitiger Bindung ansehen, so ist doch eine spätere Veränderung möglich und im System bereits angelegt. Auch mit einer Veränderung der Rentenformel muß gerechnet werden. Formell gibt es dabei keine Hindernisse aus der zweiseitigen Bindung, weil der Gesetzgeber nicht wie eine Verwaltungsbehörde an Zusagen gebunden ist. Der Gesetzgeber ist jedoch nicht völlig frei: Er hat Erwartungen der Versicherten geweckt, die nicht ohne weiteres enttäuscht werden dürfen. Ein zureichender Schutz der Versicherten ist indes, wie schon erwähnt, nicht aus Art. 14 GG zu gewinnen. Das allfällige Eigentum der Rentenberechtigten steht unter dem Vorbehalt weitreichender Inhaltsveränderungen. Diese Änderungen dürfen nicht willkürlich sein, sondern müssen die bisherigen Dispositionen der Versicherten angemessen berücksichtigen. In diesem Rahmen darf der Gesetzgeber das

119) Dazu vgl. u. S. 216.

120) Vgl. dazu Scheuner, DOV 1957, S. 383. 
Rechtsverhältnis neuen Notwendigkeiten und sozialen Entwicklungen anpassen, wobei er im Fall der Not auch zu schmerzhaften Eingriffen befugt ist. Was im Einzelfall noch toleriert werden kann, ist abstrakt und generell nicht zu sagen. Als Richtmaß könnte etwa die schweizerische Willkürrechtsprechung zum Gleichheitssatz dienen ${ }^{121}$ ).

(19) Für das Sozialversicherungsverhältnis als Dauerverhältnis müssen schließlich die Regeln gelten, welche die Rechtsprechung zur Haftung wegen Verletzung von Schuldnerpflichten in vertragsähnlichen Verhältnissen des öffentlichen Rechts herausgearbeitet hat. Sie erkennt hier neben der Amtshaftung noch Ansprüche entsprechend den bürgerlichrechtlichen Regeln über die Verletzung von Schuldverpflichtungen an, die allerdings vor dem ordentlichen Gericht geltend zu machen sind. Das BSG hat mangels besonderer gesetzlicher Anknüpfungspunkte für solche Schadensersatzansprüche bisher keine Kompetenz der Sozialgerichte beansprucht und ist insoweit der Rechtsprechung des BVerwG zur Verletzung beamtenrechtlicher Fürsorgepflichten nicht gefolgt. Jedenfalls hat es Schadensersatzansprüche nicht zugesprochen ${ }^{122}$ ), allerdings einmal einem Versicherungsträger verwehrt, sich auf die verspätete Entrichtung eines Beitrags $\mathrm{zu}$ berufen, weil die Verspätung auf mangelnder Beratung des Versicherten beruhte ${ }^{125}$ ), und dabei Formulierungen gebraucht, die stark in die Richtung eines Schadensersatzanspruchs gehen ${ }^{124}$ ).

\section{$D$ Notwendigkeit und Zweckmäßigkeit öffentlichrechtlicher Handlungsformen}

(20) Am Ende bleibt uns noch die Frage, ob die Einordnung des Rechts der sozialen Sicherung in das Verwaltungsrecht notwendig und zweckmäßig ist. Darüber, daß wir es auf allen behandelten Gebieten mit öffentlichem Recht zu tun haben, ist in Deutschland nicht mehr zu diskutieren: Für Fürsorge und Versorgung war es nie im Streit, für die Sozialversicherung haben wir die positive Regel des $\S 51$ Abs. 2 SGG. Diskussionen, wie es sie bei uns in der Vergangenheit gegeben hat und in Frankreich heute noch gibt, sind de lege lata sinnlos.

121) Vgl. dazu die Nachweise bei Rüfner, Der Staat 1968, S. 45, Anm. 28.

122) BSGE 26, S. 129 (132 ff.) betrifft den Ausnahmefall des § 1436 RVO.

${ }^{123}$ ) BSG v. 14. 6. 1962, ZfS 1962, S. $240=$ MDR 1962, S. 1022; dazu kritisch Handtke, Sozialgerichtsbarkeit 1964, S. 68 und Röß, Sozialversicherung 1966, S. 42 f. Vgl. dazu neuestens BSG v. 18.11. 1969, DVBl. 1970, S. 293.

124) BSG v. 20.2. 1962, Sozialversicherung 1963, S. 62, betrifft einen Sonderfall. 
Ehe ich die Frage nach der Zweckmäßigkeit der öffentlichrechtlichen Abwicklung stelle, möchte ich daran erinnern, daß ich nicht nur für Fürsorge- und Versorgungsrecht, sondern auch für Renten- und Arbeitslosenversicherung sehr dezidiert den Standpunkt vertreten habe, es handele sich um Staatsleistungen an den Bürger, nicht um genossenschaftliche Selbsthilfe. Es geht daher um eine typische Staat-Bürger-Beziehung, nicht um das Verhältnis von Bürgern untereinander, an dem zufällig auch einmal der Staat beteiligt ist. Im Sinne der neueren Subjektstheorie, wie sie etwa von $\mathrm{H}$. J. Wolff vertreten wird $\left.{ }^{125}\right)$, gehören also Renten- und Arbeitslosenversicherung fraglos ins öffentliche Recht. Für die Kranken- und Unfallversicherung läßt sich das vielleicht nicht mit derselben Entschiedenheit und nicht für jede mögliche Ausgestaltung behaupten.

Die geschichtliche Entwicklung in Deutschland hat indes dazu geführt, daß die Grenzlinie des formellen öffentlichen Rechts nicht solchen theoretischen Uberlegungen entspricht. In weiten Bereichen hat der Staat die Wahl, ob er sich des öffentlichen oder des privaten Rechts bedient. Bevorzugt er das Privatrecht, so bleibt er zwar im sogenannten Verwaltungsprivatrecht mannigfachen Bindungen des öffentlichen Rechts unterworfen, aber für die Anwendung spezifisch verwaltungsrechtlicher Handlungsformen ist kein Raum.

$\mathrm{Ob}$ eine Aufgabe verwaltungsprivatrechtlich oder öffentlichrechtlich erfüllt werden soll, ist unter diesen Umständen eine Frage der Rechtstechnik, die zumeist keine grundsätzliche $\mathrm{Be}-$ deutung hat. Ihre Entscheidung hängt hauptsächlich davon $a b$, ob der VA ein zweckmäßiges Gestaltungsmittel ist. Ich möchte das für die Renten- und Arbeitslosenversicherung bejahen, ohne daraus eine Weltanschauungsfrage zu machen. Es gibt im Sozialversicherungsrecht von der Befreiung von der Versicherungspflicht über die Festsetzung des Beitrags bei freiwilliger Versicherung bis zum Leistungsbescheid eine Menge von Entscheidungen, die zweckmäßigerweise durch VA einseitig und nach den Maßstäben des Verwaltungsrechts getroffen werden müssen und denen eine gewisse Beständigkeit zukommen muß.

(21) Für die Kranken- und Unfallversicherung lassen sich ähnliche praktische Erwägungen anstellen. Zwar wäre hier eine privatrechtliche Abwicklung noch eher angemessen als in der Rentenversicherung, da besonders die Unfallversicherung deutlich Züge einer genossenschaftlichen Selbsthilfe zeigt. Der Privatautonomie könnte jedoch auch die Erfüllung dieser öffent-

${ }^{125}$ ) H. J. Wolf, AöR 76, S. 205 ff.; Schmidt-Rimpler, HdSW Bd. 12, S. 695 fif. 
lichen Aufgaben nicht überlassen bleiben. Denkbar wäre nur eine privatrechtliche Organisations- und Handlungsform mit eingehenden Normativbestimmungen, die sich von den bestehenden kaum $\mathrm{zu}$ unterscheiden brauchten.

Alles das bestätigt die in jüngster Zeit vielfach vorgetragene These, daß die Unterschiede zwischen dem formellen öffentlichen Recht und dem Privatrecht zunehmend relativiert werden. Wir sollten dies nicht als eine Denaturierung des öffentlichen Rechts empfinden, sondern uns darüber klar sein, daß unsere öffentlichrechtlichen Begriffe und Denkschemen aus einer vergangenen Zeit stammen und nur für die eng begrenzte Tätigkeit des liberalen Staates entwickelt worden waren. Thre Anpassung an die Erfordernisse der modernen Leistungsverwaltung muß notwendigerweise zur einer Annäherung an das Privatrecht führen. 
Leitsätze des Mitberichterstatters über:

\title{
Die Rechtsformen der sozialen Sicherung und das Allgemeine Verwaltungsrecht
}

\author{
- Einordnung des Rechts der sozialen Sicherung \\ in das (allgemeine) Verwaltungsrecht -
}

\section{A Grundlagen}

1. In der vorindustriellen Zeit beruhte die „soziale Sicherheit" im wesentlichen auf der Familien- und Hausgemeinschaft. Daneben gab es frühe Solidargemeinschaften und vor allem die örtliche Armenpflege.

2. Das heutige System der sozialen Sicherung, insbes. die Sozialversicherung als sein wichtigster Zweig, wurde zunächst als Fortentwicklung und Verbesserung der Armenpflege verstanden. Diese Sicht, die heute noch nachwirkt, verkennt, daß nach der Auflösung der alten Haus- und Familiengemeinschaften die gesamte Bevölkerung (von statistisch kaum ins Gewicht fallenden Ausnahmen abgesehen) auf die soziale Sicherung angewiesen ist. Insbesondere ist eine eigenverantwortliche Vorsorge für Alter und Invalidität in dem Umfang, wie sie gewünscht wird, weder Unselbständigen noch Selbständigen möglich (Inflation und Wirtschaftswachstum!). Insoweit ist heute die Gesamtbevölkerung und mit ihr der "Normalbürger" „sozial bedürftig".

B Grundsätzliches zur Einordnung des Rechts der sozialen Sicherung

\section{Fürsorge und Versorgung}

3. Durch die Fürsorge (Sozialhilfe) deckt der Staat oder ein anderer Träger öffentlicher Verwaltung ohne Gegenleistung individuellen Bedarf. Die Versorgung erfüllt ebenfalls ohne Gegenleistung gruppentypische Bedürfnisse. Das Recht der Versorgung ist bislang in Deutschland noch wenig ausgebildet und im wesentlichen - wichtigste Ausnahme: Kindergeld -auf den Ausgleich von Kriegsfolgen beschränkt.

4. Fürsorge und Versorgung lassen sich verhältnismäßig leicht in das „klassische“ Bild der Hoheitsverwaltung des ein- 
seitig handelnden Staates einfügen. Die Stellung des Bürgers ist heute verfassungsrechtlich gesichert durch einen Anspruch auf das - variable und mit der wirtschaftlichen Entwicklung nach oben tendierende - Existenzminimum. Im übrigen hat er einen Anspruch auf Gleichbehandlung, wenn Leistungen erbracht werden.

\section{Sozialversicherung}

5. Die Sozialversicherung ist das Kernstück der nachliberalen Sozialpolitik. Sie deckt wichtige Lebensrisiken durch eine Zwangsversicherung ab, zumeist, aber nicht notwendig, mit mehr oder weniger großen Umverteilungseffekten und unter Einschluß von Elementen der Versorgung, u.U. sogar der Fürsorge. Sie kann in Form einer Staatseinrichtung oder in Form obligatorischer genossenschaftlicher Selbsthilfe mit Normativbestimmungen organisiert sein.

6. Die Rentenversicherung (Alters- und Invalidenversicherung) ist eine Aufgabe, der sich der Sozialstaat nicht entziehen kann. Die bestehende Selbstverwaltung der deutschen Rentenversicherung ist technischer Art ohne wesentliche Entscheidungsbefugnis. Da es um eine zentrale Staatsaufgabe geht, ist eine Delegation der Verantwortung auf die gesellschaftliche Selbstverwaltung ausgeschlossen (Gegenbeispiel: Gewisse berufsständische Versorgungseinrichtungen).

7. Trotz der lohn- und damit weitgehend beitragsproportionalen Leistungen, die auf dem Austauschprinzip der Versicherung beruhen, sind die Renten Staatsleistungen, keine Leistungen aus (erzwungener) Selbsthilfe der Bürger. Entscheidend dafür sind nicht so sehr der Staatszuschuß oder die Durchbrechung der versicherungsmathematischen Aquivalenz durch Umverteilung als vielmehr ein Umschlag von der Quantität in die Qualität: Eine Zwangsversicherung, die finanziell einheitlich geführt wird, nahezu das gesamte Volk umfaßt und auf der Solidarität der Generationen beruht, ist notwendig staatlich.

8. Daraus folgt, daß es für Rentenansprüche allenfalls einen abgeschwächten Eigentumsschutz geben kann. Die Sicherung des Bürgers liegt in seinen Teilhabeansprüchen, nicht im Eigentum. Die technische Ähnlichkeit zum Versicherungsrecht ist nicht zu bestreiten, im Grundsätzlichen sind aber die Lösungen im öfentlichen Recht zu suchen, wobei auf Parallelen zum Abgaben- und Beamtenrecht besonders hinzuweisen ist.

9. Für die Arbeitslosenversicherung gilt Ahnliches, zumal sie mangels eines kalkulierbaren Risikos kaum als echte Versicherung (und damit auch nur mit Vorbehalten als Teil der So- 
zialversicherung) anzusprechen ist. Neuerdings hat das Arbeitsförderungsgesetz (AFG) schärfer als bisher das AVAVG herausgearbeitet, daß die wichtigste staatliche Aufgabe in diesem Bereich nicht die Hilfe für die Arbeitslosen, sondern die Verhütung der Arbeitslosigkeit ist. Dahinter steht das Recht auf Arbeit und die Pflicht des Staates, für Vollbeschäftigung zu sorgen. Nur wo das mißlingt, tritt die finanzielle Hilfe für den Arbeitslosen ein.

10. Die Krankenkassen sind weitgehend auf dem Prinzip genossenschaftlicher Selbsthilfe aufgebaut. Der Spielraum der Selbstverwaltung ist auf der Einnahmeseite erheblich (freilich politisch geringer als juristisch), zudem treten die Krankenkassen gegenüber den Arzten als Tarifpartner mit bedeutender sozialer Macht auf. Ebenso wie bei der Unfallversicherung kann man hier mehr als bei der Rentenversicherung von staatlich regulierter Selbsthilfe sprechen. Sie funktioniert, da in der Regel keine langfristigen Verpflichtungen entstehen.

C Das Recht der sozialen Sicherung und die Handlungsformen des formellen Verwaltungsrechts

\section{Der Verwaltungsakt}

11. Der Verwaltungsakt (VA), aus Polizeibefehl und Steuerbescheid entwickelt, hat sich in der Leistungsverwaltung erst nach dem 2. Weltkrieg voll durchgesetzt, und zwar zu einer Zeit, als die Generalklausel eingeführt war, aber der Rechtsschutz nur gegen VAe möglich zu sein schien. Heute ist in Deutschland - anders als nach der positiven gesetzlichen Regelung in Osterreich, wo es grundsätzlich nur die Bescheidbeschwerde gibt - geklärt, daß der Rechtsschutz nicht mehr von der Annahme eines VA abhängt, vielmehr auch eine Leistungsklage möglich ist. Daher kann sich die Behörde auch mit der schlichten Erfüllung eines Anspruchs begnügen. Ein VA ist notwendig, wo eine Ermessensentscheidung zu treffen ist. Er ist darüber hinaus sinnvoll, wo eine verbindliche Entscheidung über einen Anspruch ohne gerichtliches Verfahren getroffen werden soll. Der VA als frei widerrufliche oder auch nur frei zurücknehmbare Entscheidung über gesetzlich fixierte Ansprüche ist sinnlos - ganz anders als im Polizeirecht.

12. Das Fürsorge- und Versorgungsrecht wuchs in das vom Denken in VAen bestimmte Verwaltungsrecht hinein. Im Fürsorgerecht ist der VA zur Konkretisierung der Ansprüche unentbehrlich. Rücknahmeprobleme ergeben sich selten, weil i.d. $R$. keine Dauerleistungen zugesagt werden. Im Versorgungs- 
recht ist der Bescheid teilweise gesetzlich vorgeschrieben (z. B. in der Kriegsopferversorgung mit Regelung des Rücknahmeproblems), teilweise wird auch schlicht geleistet (Kindergeld).

13. Das Sozialversicherungsrecht arbeitete früher nicht generell mit VAen, sondern vielfach mit schlichter Erfüllung oder quasirichterlichen Entscheidungen, denen besonders vorgeschriebene rechtskraftfähige Bescheide gleichgestellt waren. $\S 77$ SGG, der nach seinem klaren Wortlaut, wenn auch kaum nach der Absicht des Gesetzgebers, allen VAen der Sozialversicherung Bestandskraft verleiht, ist zu undifferenziert.

14. Im Leistungsrecht bietet die schlichte Erfüllung ohne vorherigen Bescheid, soweit zulässig, einen Ausweg aus der starren Bindung durch § 77 SGG. Die Dauerwirkung falsch berechneter Rentenbescheide entfällt praktisch nach der neueren Rechtsprechung des BSG, so daß das schwerstwiegende Problem entschärft zu sein scheint.

15. Im übrigen kann $\S 77$ SGG nicht durch das allgemeine Verwaltungsrecht überspielt werden. Möglich sind aber Analogien zu spezielleren Normen, z. B. für Beitragsangelegenheiten zum Steuerrecht.

\section{Andere Handlungsformen}

16. Im Sozialversicherungsrecht hat die öffentlichrechtliche Willenserklärung Privater, sei es als Antrag, sei es als einseitiges Rechtsgeschäft einen verhältnismäßig weiten Anwendungsbereich.

17. Im Sozialrecht, insbesondere im Sozialversicherungsrecht, hat das sogenannte schlichte Verwaltungshandeln einen wichtigen Platz. Die schlichte Erfüllung und der mit ihr korrespondierende unmittelbare Leistungsanspruch widersprechen nicht dem Wesen des öffentlichen Rechts und auch nicht der staatlichen Souveränität. Hinzuweisen ist darüber hinaus vor allem auf die Beratung der Bürger. Auch bei der Vermittlung von Arbeitsstellen durch die Arbeitsämter gibt es keine VAe.

\section{Das Dauerverhältnis}

18. Das Versicherungsverhältnis ist ein Dauerverhältnis, das veränderten Verhältnissen angepaßt werden kann und muß. Die Abänderung - sei es durch Gesetz, sei es durch Satzung - muß sich im Rahmen des Angemessenen halten (etwa im Sinn der schweizerischen Willkürrechtsprechung). Deshalb bietet der Gleichheitssatz dem Versicherten mehr Schutz als die Eigentumsgarantie.

19. Das Versicherungsverhältnis ist als ein Dauerschuldver- 
hältnis zu qualifizieren, auf das neben der Amtshaftung auch die Regeln über die Schadensersatzpfichten bei der Verletzung von Schuldnerpflichten anwendbar sind.

$D$ Notwendigkeit und Zweckmäßigkeit der öffentlichrechtlichen Handlungsformen

20. Das Fürsorge- und Versorgungsrecht, das Recht der Rentenversicherung und das Recht der Aufgaben der Bundesanstalt für Arbeit ist notwendig öffentliches Recht, insofern, als es sich um typische Staat-Bürger-Beziehungen handelt. Technisch wäre in der Rentenversicherung auch eine verwaltungsprivatrechtliche Abwicklung denkbar. Letztlich handelt es sich - wie meist bei der Wahl öffentlichen oder privaten Rechts um eine Zweckmäßigkeitsfrage, die vor allem danach entschieden werden muß, ob der VA ein passendes Gestaltungsmittel der Rentenversicherung ist.

21. In der Kranken- und Unfallversicherung bestünden gegen eine genossenschaftlich-privatrechtliche Abwicklung noch weniger Bedenken, wenn Versicherungszwang und Leistungen durch Normativbestimmungen gesichert wären. Eine Erfüllung der Aufgaben mit Privatautonomie wäre auch hier nicht möglich. 



\section{Die Rechtsformen der sozialen Sicherung und das Allgemeine Verwaltungsrecht}

\section{Aussprache und Schlußworte}

Thieme (Diskussionsleiter): Zur Gliederung der Diskussion möchte ich Ihnen nach Absprache mit den Referenten den folgenden Vorschlag machen: Man sollte versuchen, zunächst grundsätzliche Fragen vorweg zu diskutieren, soweit nicht beabsichtigt ist - ich bitte diesen Nebensatz zu beachten - die Grundsatzfragen im Zusammenhang mit einer Detailfrage anzusprechen. Soweit es sich darum handelt, aus der Grundsatzfrage Detailfragen abzuleiten, sollte das viellleicht lieber in diesem Zusammenhang geschehen. Aber es wird sicherlich auch der Wunsch bestehen, Grundsatzfragen vorweg einzeln zu diskutieren. Dazu kämen in diesen ersten Abschnitt etwa das von Herrn Henke aufgeworfene Problem der "Sozialisierung" unseres Verwaltungsrechts, des Freiheitsraumes, der großen und der kleinen Freiheit, wie er es genannt hat, nach meiner Auffassung auch die grundsätzliche Rechtsstellung des Bürgers im Sozialrecht, etwa das Problem des besonderen Gewaltverhältnisses, vielleicht auch einige Aspekte des Dauerschuldverhältnisses. Mit diesen Bemerkungen ist sicherlich keineswegs der Katalog der Fragen, die in diesem Zusammenhang angeschnitten werden könnten, abgeschlossen. Dagegen möchte ich mir die Anregung gestatten, in diesem Zusammenhang nicht etwa das Problem der Charakterisierung von Versicherung, Versorgung und Fürsorge zu erörtern; das könnte man vielleicht zwanglos unter einem der folgenden Detailpunkte tun.

Ich möchte Ihnen vorschlagen, die folgenden vier Einzelprobleme zu unterscheiden: Einmal die grundsätzlichen Fragen, sodann zweitens die Probleme der Organisation, wozu das Problem von Staatsverwaltung, Selbstverwaltung und genossenschaftlicher Selbsthilfe und auch die Frage der organisatorischen Zuordnung zum öffentlichen oder Privatrecht gehört. Einen dritten großen Bereich würden dann die Probleme der Handlungsformen ausmachen, das Problem des Verwaltungsaktes einschließlich der Bindungswirkung und des Rechtsschutzes, aber auch der sonstigen Probleme der Handlungsformen, wobei hier dann wiederum sowohl Fragen des Dauerschuldverhältnisses als auch Fragen der Abgrenzung zwischen öffent- 
lichem und Privatrecht akut werden könnten. Und es wären dann noch viertens und fünftens zwei Fragenkreise zu bilden, nämlich das Problem der Entschädigung und der Finanzierung.

Ich gehe davon aus, daß das nur Anregungen sind, die keineswegs eine bindende Wirkung haben. Ich bin ja insofern in einer glücklicheren Lage, als Herr Quaritsch gestern, der konfrontiert war mit Diskutanten, die über das Problem der Toleranz nachdachten, während ich hier Diskutanten habe, die sich mehr mit dem Problem der Sozialität beschäftigen. Ich hoffe also, da $B$ das ein akzeptabler Vorschlag ist, aber ich bitte um weitere Anregungen, sofern etwas gewünscht wird.

Bettermann: Ich bin der Meinung, daß die öffentlich-rechtliche Entschädigung mit dem Thema nichts zu tun hat.

Thieme: Herr Bettermann, nachdem der eine Referent einen großen Teil seines Referates darauf verwandt hat, gehört es einfach zur Diskussion, wobei es Ihnen natürlich freisteht, in der Diskussion nachzuweisen, daß der Referent unrecht hat.

Ipsen: In diesem Sinne wollte ich zu Punkt 4 sprechen.

Thieme: Dann darf ich um weitere Anregungen bitten. Wenn das nicht der Fall ist, möchte ich jetzt, bevor wir mit dem Punkt 1 beginnen, noch Herrn Schnorr das Wort geben. Herr Schnorr will noch einige Ausführungen über die besonderen österreichischen Verhältnisse machen.

Schnorr: Meine Herren, ich möchte mir zunächst einige grundsätzliche Bemerkungen zu den Referaten erlauben und anschließend aus dem österreichischen Verwaltungs- und Sozialversicherungsrecht einige Kontrastpunkte zu dem setzen, was wir heute früh hier gehört haben.

In beiden Referaten wurde eine grundsätzliche Frage transparent, die Frage: Paßt das an der Eingriffsverwaltung orientierte Instrumentarium des öffentlichen Rechts überhaupt noch adäquat auf die besonderen Probleme der Leistungsverwaltung oder, wie man auch sagen könnte, der staatlichen Daseinsvorsorge? Herr Henke hat diese Frage vom Grundsätzlichen her in Zweifel gezogen. Herr Rüfner hat zumindest Bedenken gegen den Verwaltungsakt als einzig mögliches Mittel zur Daseinsvorsorge angemeldet. Nun, einem Soziologen, hätte er heute früh diese beiden Referate gehört, würde das Herz höher klopfen. Denn das, was wir heute früh von den beiden Referenten gehört haben, war eigentlich ein soziologisches Problem, 
das grundlegende Problem der sozialen Rolle, die von Ralph Linton bereits in den dreißiger Jahren in seinem berühmten Buch "The Study of Man" aufgezeigt und auf das Recht projiziert worden ist. Und meine soziologisch-politologische geistige Hälfte hat tatsächlich großen Gefallen an diesen beiden Referaten, ganz besonders an dem Referat von Herrn Henke, gefunden. Aber dem Staatsrechtler wie dem Juristen überhaupt müssen einige Zweifel kommen. Es ist heute früh mehrfach betont worden, der Verwaltungsakt wie überhaupt das Instrumentarium des öffentlichen Rechts habe sich an der Eingriffsverwaltung entwickelt, und die staatliche Daseinsvorsorge als Leistungsprinzip sei eben etwas ganz anderes als die Eingriffsverwaltung, bei der man vor allem in erster Linie an die Polizeiverfügungen $u$. ä. denkt. Ich bin nicht ganz der Meinung, $\mathrm{da} \beta$ ein so großer Unterschied zwischen der Daseinsvorsorge und der Eingriffsverwaltung besteht. Herr Henke hat einmal aber das steht $\mathrm{m}$. E. etwas im Widerspruch zu seinen sonstigen Ausführungen - angedeutet, da $\beta$ sich im Sozialversicherungsrecht Eingriffsverwaltung und Leistungsverwaltung nicht scharf trennen lassen. Worum geht es? Gerade dadurch, daß durch die klassische Staatsrechts- und Verwaltungslehre des vorigen Jahrhunderts (Jellinek, Otto Mayer und Georg Meyer) der Machtanspruch des Staates, das Gewaltverhältnis, betont und überbetont wurde, war der Anstoß gegeben, den Einzelnen durch ein fast lückenloses System normativer Kautelen vor diesem Machtanspruch, vor der Gewalt des Staates, zu schützen. $\mathrm{Da}$ sich dieses System der Kautelen - ich denke an die Beschränkung des verwaltungsbehördlichen Ermessens, an die Gesetzesbindung der Verwaltung, an die Rechtsweggarantien - gerade an der Eingriffsverwaltung orientiert hat, war historischer $\mathrm{Zu}-$ fall, weil man die staatliche Daseinsvorsorge zur Zeit Otto Mayers und Georg Meyers noch nicht kannte. Die Eingriffsverwaltung war historische Einmaligkeit. In Wahrheit ging es unseren klassischen Staats- und Verwaltungsrechtlern gar nicht um eine Kanalisierung der Eingriffsverwaltung im engeren technischen Sinne, sondern um eine rechtliche Kanalisierung der staatlichen Macht an sich. Hier scheint mir der springende Punkt zu liegen. Staatliche Macht kann nicht nur durch Eingriffe in die persönliche Sphäre ausgeübt werden, sondern staatliche Macht kann gerade auch durch vermögenswirksame Leistungen an den Einzelnen ausgeübt werden. Ums Geld geht alles. Wenn der Staat Daseinsvorsorge betreibt, wenn der Staat - ich spreche jetzt einmal ganz vulgär - dem Einzelnen etwas gibt, dann will er auch etwas von dem Einzelnen; dann ist der Einzelne auch durch vermögenswerte Leistungen seitens des 
Staates irgendwie dem Staat verpflichtet. Es ist also keineswegs so, daß der Staat mit der Daseinsvorsorge ein Benefizium leistet; ganz im Gegenteil, der Staat übt auch im Wege der Daseinsvorsorge obrigkeitliche Macht aus. Den Unterschied zwischen Eingriffsverwaltung und Daseinsvorsorge sehe ich wohl, aber ich sehe ihn graduell, nicht prinzipiell.

Nun steht in diesem Zusammenhang eine andere Frage: Wie soll man sich denn das vorstellen, wenn der Verwaltungsakt im klassischen Sinne als Instrument der Daseinsvorsorge nicht adäquat ist? Herr Henke hat von einem Verwaltungsrechtsverhältnis gesprochen, das gegenseitige Pflichten und Rechte zwischen Staat und Bürger erzeugt - ein Konglomerat von Rechten und Pflichten. Wenn wir dieses gegenseitige Rechte- und Pflichtenverhältnis einmal ganz pointiert ausdrücken, dann können wir sagen: das ist der verwaltungsrechtliche Vertrag; $d . h$., der Staat steigt von seinem Thron der Uberordnung herab, gibt sich den Anschein einer vielleicht gesellschaftlich begründeten Gleichordnung mit dem Einzelnen und verhandelt mit dem Einzelnen auf vertraglicher Grundlage. Hier muß ich Sie um Verzeihung bitten, wenn ich vor Offentlichrechtlern etwas in das Privatrecht abschweife. Aber die hochinteressanten intrasystematischen Ausführungen von Herrn Henke, die er in der Einleitung seines Vortrages gegeben hat, zwingen mich dazu. Es ist doch ein Märchen, heute anzunehmen, daß ein RechtePflichtenverhältnis auf der Grundlage der Koordination dem Einzelnen mehr Freiheit gibt. Die Formel: Privatrecht oder Vertragsfreiheit oder Willenseinigung, oder wie Sie es nennen wollen, ist gleich ursprüngliche Freiheit, die stimmt gar nicht mehr. Ganz im Gegenteil, der Vertrag, auch der verwaltungsrechtliche Vertrag, unter dem ich jetzt einmal sozusagen als Wertposten dieses ganze Netz der gegenseitigen Rechte und Pflichten zwischen dem Staat und dem Einzelnen zusammenfasse, ist heute zu einem Instrument der Festigung von Machtpositionen geworden. Ich erinnere Sie nur an die allgemeinen Geschäftsbedingungen oder an die Lehre vom sogenannten sozialtypischen Verhalten im Zivilrecht, wo mit Hilfe der massentypischen Leistungen einfach ein Vertrag fingiert wird und sich auf diese Weise die Wirtschaft ein Eigenrecht extra legem schafft. In diesen Fällen wird eine Koordination der Partner angenommen, die in Wahrheit nicht besteht. Auch der Staat weicht weitgehend schon auf den Vertrag als verwaltungsrechtliches Instrument aus. Ich nenne nur als Stichwort die österreichische Privatwirtschaftsverwaltung. Staatliche Politik, betrieben in privatrechtlichen Formen, bedeutet eine Potenzierung der Macht. 
Ich will meine allgemeinen Bemerkungen dahingehend zusammenfassen, daß ich nicht glaube, daß zwischen der Eingriffsverwaltung und der Daseinsvorsorge ein so prinzipieller Unterschied besteht, daß man das öffentliche Recht mit seinem Instrumentarium, vor allem den Verwaltungsakt, über Bord werfen müßte.

Nun möchte ich zur Illustration dieser allgemeinen Bemerkungen einige Kontrastpunkte aus dem österreichischen Verwaltungs- und Sozialrecht setzen. Zunächst eine allgemeine Bemerkung: In Osterreich ist man weder in der Rechtslehre noch in der Rechtsprechung bisher auf den Gedanken gekommen, den Verwaltungsakt aus der Daseinsvorsorge, insbesondere aus dem Sozialversicherungsrecht, zu eliminieren. Hier sind trotz der gemeinsamen historischen Wurzeln beider Rechtssysteme ganz erhebliche dogmatische und systematische Unterschiede zu beobachten. Die scheinbare Ähnlichkeit zwischen unserem Recht der Sozialversicherung und dem deutschen Sozialversicherungsrecht trügt. Die Grundlagen sind anders, und ich möchte vor allem drei wichtige Punkte erwähnen.

Der erste Punkt: Der Unterschied zwischen der deutschen und der österreichischen sozialversicherungsrechtlichen Auffassung liegt schon im Begriff der Verwaltung begründet. Mit Hans Peters kennt das deutsche öffentliche Recht den sogenannten materiellen Verwaltungsbegriff, einen Verwaltungsbegriff, der sich am Zweck der Verwaltung orientiert. Verwaltung ist - wie Hans Peters einmal gesagt hat - die Verfolgung staatlicher Zwecke im Einzelfall. Der Zweck ist natürlich weit genug, um soziologische Gedankengänge in sich aufzunehmen. Daher sind für deutsche Verhältnisse die Zweifel an dem Instrumentarium des überkommenen Verwaltungsrechts akzeptabel. Wir in Osterreich haben nach wie vor den formalen Verwaltungsbegriff. Um mit Antoniolli zu sprechen: Verwaltung ist gesetzes- und weisungsgebundene Staatstätigkeit. $\mathrm{Da}$ haben wir es ja schon: gesetzes- und weisungsgebundene Staatstätigkeit, ein ganz formaler Begriff, unter den sich sowohl die Eingriffsverwaltung als auch die Daseinsvorsorge, die Leistungsverwaltung, subsumieren läßt. Der Zweck spielt keine Rolle. Wir können daher mit dem herkömmlichen Instrumentarium des Verwaltungsrechts auch die soziale Leistungsverwaltung bewältigen.

Thieme: Ihre Beiträge beziehen sich auf Einzelpunkte. Ob man vielleicht doch so verfährt, daß Sie die weiteren Ausführungen, die Sie geplant haben, jeweils zu den einzelnen Punkten bringen? 
Schnorr: Darf ich dann überschriftsweise die drei Punkte nennen, zu denen ich sprechen wollte? Der erste ist der bereits erörterte Verwaltungsbegriff. Der zweite ist die Anwendung des Allgemeinen Verwaltungsrechts, besonders des Allgemeinen Verwaltungsverfahrensgesetzes, auf die Selbstverwaltung in der Sozialversicherung. Der dritte Punkt behandelt die Frage der verwaltungsrechtlichen Handlungsformen.

Scheuner: In der Frage unseres Verhandlungsgegenstandes den Versuch zu machen, allgemein zu sprechen, ist nicht einfach, weil sich besondere und allgemeine Punkte verbinden. Ich bitte um Nachsicht, daß ich dabei auf den Punkt Entschädigung vorgreife, weil er so eng mit dem der sozialen Freiheit zusammenhängt. Ich möchte die Frage stellen: Wo ist eigentlich der Platz des Sozialversicherungsrechts in unserem Verwaltungsrecht? Weshalb empfinden wir es als Sondergebiet, dessen Verbindung zum Verwaltungsrecht ein Problem bildet? Sicherlich liegt der Grund hierfür - das hat Herr Henke für mich überzeugend dargelegt - nicht in dem Unterschied zwischen Offentlichem und Privatem. Dieser Unterschied ist - ich folge Herrn Henke hier gern - sicherlich ein rein historischer, und die Grenze ist hier in ständiger Wandlung begriffen. Nur Folgendes darf ich anfügen: Die Frage, ob die Unterscheidung von öffentlichem und privatem Recht für ein Rechtsgebiet von Bedeutung ist, ist vielfach davon abhängig, ob der Staat von diesem Bereich voll Besitz ergriffen hat oder ob es sich um ein Gebiet handelt, in dem noch ein gewisses Ausmaß privater, freier, persönlicher Autonomie vorhanden ist. Im einzelnen kann - ich würde hier meinem Vorredner durchaus zustimmen - auch in öffentlichrechtlichen Verhältnissen durchaus eine private und persönliche Mitwirkung stattfinden. Keineswegs dürfen wir uns öffentlichrechtliche Verhältnisse nur als Zwang, Eingriff, Befehl vorstellen. Wir sind wohl über diese älteren Vorstellungen $O$. Mayers allmählich hinausgewachsen. Sicherlich aber wird man gerade für unseren Bereich feststellen können, daß es sinnvoll ist, in größeren Bereichen - und darin möchte ich beiden Referaten zustimmen - eine Mischung öffentlichrechtlicher und privatrechtlicher Beziehungen anzuerkennen. Wir kennen das aus dem Schulrecht oder dem Recht der öffentlichen Sachen, und mir ist heute fraglich, ob die Tendenz, die ich einst in jugendlicher Stimmung vertrat, das Wegerecht ganz in das öffentliche Recht zu ziehen, wirklich die Vorzüge bietet, die man ihm dogmatisch wie in der Lösung praktischer Fragen gelegentlich zuschreibt. In einer neueren Abhandlung hat ein Autor (Wittig DVBl. 1969 S. 680 ff.) mit Recht darauf aufmerksam gemacht, daß das Hamburger Wegerecht mit seinem öffent- 
lichen Eigentum in einer Reihe von Punkten für die Freiheit des Einzelnen eine ungünstigere Gestaltung aufweist als die übliche privatrechtliche Formung. Ich würde daher auch darin Herrn Henke zustimmen, daß das Arzt-Patient-Verhältnis und andere Momente der Sozialversicherung ohne Schaden im Privatrecht belassen werden können. Freilich sollte man auch wieder nicht der Meinung verfallen - ich folge meinem Vorredner - daß ohne weiteres Privatrecht Freiheit, das öffentliche Recht Zwang verkörpert. Vielfach bringt heute der Staat eine stärkere Gewährleistung der individuellen Freiheit als das Privatrecht, in dem die Gruppenmacht im Wege von "freien" Verträgen Zwangslösungen zu erzwingen vermag. Ebensowenig können wir den Platz des Sozialversicherungsrechts klar innerhalb der Leistungs- und Eingriffsverwaltung bestimmen. Hier haben beide Referate Fragezeichen gesetzt. Sicherlich steht es der Leistungsverwaltung näher, aber dadurch, daß es die Menschen zur Wohlfahrt nötigt, enthält es auch Zwangsmomente.

Das führt mich auf eine der von Herrn Rüfner aufgeworfenen Fragen. Es gibt sicherlich Aufgaben, die der Staat zwingend erfüllen muß. Ob die Sozialversicherung hierhin gehört, läßt sich vielleicht nicht in allen Bereichen bejahend beantworten. Aber ich stimme Herrn Rüfner $\mathrm{zu}$, daß heute ein gehöriges Stück Daseinsversorge zu jenen Gebieten gehört, die der Staat in eigener Regie zu führen hat und die er nicht auf genossenschaftliche Vorkehr oder freie Initiative des einzelnen abwälzen kann. Unter diesem Gesichtspunkt hat Herr Rüfner recht, dies Gebiet mehr zur Staatsverwaltung als zur Selbstverwaltung zu rechnen.

Mir scheint, Herr Rüfner hat richtig den entscheidenden Punkt bezeichnet, an dem wir bei der Sozialversicherung einsetzen müssen, das Problem der Freiheit. Dieses Problem findet sich, und hier darf ich beide Referate zu ergänzen versuchen, auch im Grundrechtsbereich überhaupt. Unsere Grundrechte kennen das Problem der Freiheit oft nur in einer altliberalen, nicht mehr ganz der heutigen sozialen Wirklichkeit entsprechenden Form. Ein deutlicher Beweis hierfür ist Art. 12 GG. Er ist nur noch für die unter $10 \%$ liegende Zahl der Mitbürger von Bedeutung, die selbständige Unternehmer oder Betriebsinhaber sind. Für die Arbeitnehmer enthält er zwar auch Aussagen, die aber kaum praktische Bedeutung erlangt haben. Ähnliches gilt für das Eigentum. Eigentum und Schutz der Gewerbefreiheit waren die Palladien der selbständigen Lebensführung und Lebenssicherung des Liberalismus. An ihrer Stelle muß heute eine Lebenssicherung treten, die sich in Altersvorsorge, Kranken- 
schutz usw. auswirkt, so daß der Freiheitsbegriff heute nicht mehr nur in der Staatsferne und in der Abwehr staatlicher Eingriffe, sondern gerade auch in der Prästation notwendiger staatlicher Leistungen sich realisiert. Von dieser Seite her kommen wir der Sozialversicherung auch grundrechtlich näher, und hier hat Herr Rüfner einen entscheidenden Zusammenhang angesprochen, wenn er ausgeführt hat, die Arbeitslosenversicherung könne in ihrer eigentlichen Tiefe nur von dem Recht auf Arbeit her verstanden werden, das sie in praktischer Weise verwirklicht. So wie dies Herr Henke in seinem Schlußwort getan hat, soziale Sicherheit und persönliche Freiheit gegenüberzustellen, das scheint mir eine unrichtige, bereits veraltete Betrachtungsweise. Der heutige Staat garantiert denen, die noch das Risiko der Freiheit und Selbständigkeit auf sich nehmen, durch Art. 12,14 GG und andere Bestimmungen diese Freiheit. Er wird aber der Masse seiner Bürger, die das nicht mehr können oder wollen, die Freiheit durch Lebensvorsorge zu sichern haben, und hier ist der rechte Platz, wo sich die Sozialversicherung in den Bereich der Grundrechte einfügen läßt.

Darum ist dies Gebiet so merkwürdig verwandt mit der Schule. Die Schule ist auch eine Form, in der der Staat eine Daseinsvorsorge übernommen hat und in der wir ganz ähnlichen Problemen wie hier begegnen. Herr Rüfner hat etwa die Frage angesprochen, ob heute noch kleinere Nebenversicherungen für Ärzte, Apotheker, Schornsteinfegermeister sinnvoll erscheinen. Durchaus, weshalb nicht? Aber der Staat muß natürlich den allgemeinen Plafond der Sozialversicherung sowie die allgemeine Möglichkeit einer sozialen Sicherung für alle bereitstellen. Ähnlich beobachten wir im Schulrecht, wie sich eine gewisse soziale Umverteilung mit Daseinsvorsorge verbindet. Gewährleistet wird freie Bildung, aber verwirklicht werden kann sie erst durch Unterstützung von Studenten und Schülern.

Ich möchte abschließend nur noch einen Punkt berühren, den der Vorsitzende auch zu Punkt 1 rechnet, das Dauerverhältnis. Hier liegt ein wesentlicher Punkt. So sehr ich die lebhafte Verteidigung des Verwaltungsakts durch Herrn Schnorr begrüße und durchaus teile - ich glaube, beide Referenten haben den Verwaltungsakt nicht eliminieren oder beseitigen wollen - die Berichte haben doch darauf aufmerksam gemacht, daB der Verwaltungsakt einen engeren Anwendungsbereich hat, als oft angenommen. Das Deutsche Verwaltungsrecht Otto Mayers weist den gleichen Fehler auf, den auch das Bürgerliche Gesetzbuch zeigt. Das Dauerverhältnis wird in seiner Bedeutung unterschätzt. Das bürgerliche Recht hat für den allgemeinen 
Teil des Schuldrechts den Kauf zum Muster genommen, nicht die Miete. Ebenso im Verwaltungsrecht Otto Mayers. Er stellt aktförmige, justizförmige Verwaltungsakte heraus, aber nicht administrative Verhältnisse, die sich in langer Zeit abwickeln. Ich würde gegen Herrn Schnorr nicht dafür sprechen, solche Verhältnisse nur vertragsähnlich zu sehen. Wir müßten dann jedenfalls einen anderen, weiteren Begriff des öffentlichrechtlichen Vertrages haben. Ich glaube, der Begriff des öffentlichen Dauerverhältnisses ist durchaus in der Lage, dieses ausgedehnte Geflecht öffentlichrechtlicher Beziehungen zu erfassen, das sich aus zeitlich langfristigen Relationen ergibt. Dies gilt vor allem auch unter dem Gesichtspunkt ihrer dynamischen Gestaltung. Es geht bei der Frage der Rechtsbindung nicht nur um Rechtsbestand und Rechtssicherung des einzelnen, sondern zugleich beiderseits um Möglichkeiten der Anpassung und Fortbildung des Verhältnisses.

Zum Schluß möchte ich nur noch darauf hinweisen, daß zwischen der sozialen Sicherheit und der öffentlichen Entschädigung ein tiefer Unterschied besteht. Er ist stärker als der von Herrn Henke hervorgehobene zwischen Enteignung und öffentlichrechtlicher Fehlhandlung. Jene beiden Institute ruhen auf dem öffentlichrechtlichen Gedanken der Opfergleichheit der Bürger und der Verantwortung für gewisse staatliche Eingriffe, seien sie rechtmäßige Inanspruchnahme von Vermögen, seien sie schädigende Fehlhandlungen des Staatsapparates. Schon in der Mitte des 19. Jahrhunderts hat ein vorausblickender Zivilrechtler auf einem Juristentage den Vorschlag gemacht, die ganze Staatshaftung in einer Risikohaftung nach der Methode der Versicherung zu erledigen. Hier wird gewiß eine Brücke zwischen öffentlichrechtlicher Entschädigung und Versicherung sichtbar, aber eine Brücke, die nicht die dogmatische Verschiedenheit der Grundlagen aufhebt. Die Basis der Sozialversicherung ist eine ganz andere als die der Entschädigung. Sie ist die Sicherung der sozialen Freiheit und nicht etwa das Aufkommen für staatliche Eingriffe. In dieser Hinsicht halte ich daher die Einbeziehung der öffentlichrechtlichen Entschädigung in unseren heutigen Zusammenhang nicht für berechtigt.

Zacher: Das Thema bezog sich auf die Rechtsformen sozialer Sicherung, und Herr Henke ließ mehr oder weniger dahingestellt, was diese soziale Sicherung ist. Er griff breit aus in etwas, was man "Sozialrecht" nennen könnte. Und da ist nun die Frage: gibt dieser Rahmen „Sozialrecht" überhaupt etwas für die Einbeziehung in das Verwaltungsrecht her? Ich glaube nicht. Sozialrecht im allgemeinen läßt sich nur teleologisch, nur 
funktional definieren als das Recht, das soziale Unterschiede abbaut und Abhängigkeiten mildert. Und auch hier besteht ein Differenzpunkt zwischen Herrn Henke und mir, weil Sozialrecht nämlich nicht nur, wie Herr Henke sagt, Schicksalsschläge oder schicksalhafte Schädigungen ausgleicht, sondern auch sonst Vermögens- und Wohlstandsdifferenzen abbaut. (Beispiel: Vermögensbildungsproblematik. Sie gehört zweifellos in den sozialrechtlichen Rahmen im weiteren Sinne der sozialrechtlichen Aufgabenstellung.) Wir können Sozialrecht immer nur schwerpunktartig fixieren und wir können deshalb auch gar kein System des Sozialrechts als solches bilden. Wir haben kaum typische sozialrechtliche Handlungsformen. Wir haben umfassend nur sozialrechtliche Ziele.

Ich glaube also, wir müssen enger werden. Und der Vorstand hat deshalb auch das Thema im Sinne von sozialer Sicherung gefaßt. Herr Rüfner stellte sich nun mit Recht auf den Standpunkt - der auch bei Herrn Henke anklang -, soziale Sicherung sei gleich Sozialversicherung, Versorgung und Fürsorge. Hier möchte ich doch kurz ausholen und auf den weiteren Beziehungsrahmen dieser engeren sozialen Sicherung hinweisen. Wir können ihr gegenüberstellen zunächst die Selbstsicherung des Einzelnen, die sich im wesentlichen im Rahmen des Eigentumsgrundrechts abspielt. Wir können dagegenstellen ferner die kollektive Sicherung des Einzelnen im Rahmen der Privatversicherung, wobei wir in der Sozialversicherung interessante organisations- und interessenstrukturelle Parallelen haben: in der eher anstaltlichen Struktur eine Parallele zum kapitalistischen Versicherungsunternehmen und in dem Versicherungsverein auf Gegenseitigkeit eine Parallele zur genossenschaftlichen, körperschaftlichen Struktur. Dann haben wir noch ein drittes Feld, nämlich die Tätigkeit der Wohlfahrtsverbände, die auch in den weiteren Rahmen der sozialen Sicherung fallen. Sie bringen sehr eigentümliche Rechtsstrukturen mit sich. In der Dimension Staat-Wohltätigkeitsverbände sehen wir einerseits die Kooperation, die sich ausdrückt in einem Subventionsverhältnis, auf der anderen Seite die Ermächtigung, etwas anstelle öffentlicher Träger $\mathrm{zu}$ tun, und zugleich die korrespondierende Kontrolle (die allerdings im allgemeinen sehr schwach zu sein pflegt), also etwas, was wir sonst mit der Figur des Beliehenen ansprechen. In der Verband-Bürger-Dimension haben wir dann die „prekaristischen" Rechtsverhältnisse, von denen wir eigentlich gar nicht wissen, was sie sind. Wenn sich jemand als Hilfeempfänger in die Hände der Inneren Mission oder der Caritas begibt, dann ist das rechtlich eine sehr unklare Sache. Das schwankt zwischen Rechtsverhältnissen und eben 
einem - Gewaltverhältnis will ich nicht sagen — „karitativen“ Verhältnis.

Von diesen privatrechtlichen oder wenigstens dem Privatrecht zugewandten Flanken sozialer Sicherung möchte ich nun wieder zurückkehren zu der sozialen Sicherung im engeren Sinne, also zur herkömmlichen Trilogie Sozialversicherung, Versorgung und Fürsorge. Warum diese Konzentration? Weil diese leistungsfähige soziale Sicherung gegen die elementaren sozialen Risiken - jetzt müssen wir ja auf den Risikoschutz abstellen, wie bei der sozialen Sicherung immer -, weil also diese soziale Sicherung umfassend und verläßlich leistungsfähig nur geschaffen und erhalten werden kann aufgrund staatlicher Anordnung und staatlicher Organisation und unter bleibender staatlicher Verantwortung, vor allem in Hinsicht auf die finanzielle Garantie. Daher also der öffentlichrechtliche Bezug und daher auch das verwaltungsrechtliche Feld, in dem das ganze liegt. Was ist damit nun aber über die einzelnen Rechtsfiguren gesagt? Hier würde ich Herrn Henke zustimmen: damit ist noch sehr wenig gesagt. Oder an den gerichtet, der die „begrifflichen" Implikationen der Zuordnung zum öffentlichen Recht fürchtet: Einbeziehung ins öffentliche Recht ist zunächst noch unschädlich, wenn man dann offen bleibt dafür, wie die Rechtsfiguren im öffentlichen Recht geregelt werden. Ein Beispiel ist der Kollektivvertrag, der in dem Grenzfeld zwischen öffentlichem und privatem Recht liegt. Wir haben ja auch beim Tarifvertrag den Streit, ob er nicht eine öffentlichrechtliche Figur ist. Wir beobachten also im Kollektivvertrag eine der kollektivrechtlichen Erscheinungen, die im privaten und im öffentlichen Recht vorkommen und mit den je eigentümlichen Machtabhängigkeiten und dergleichen fertig werden müssen. Auch über den Verwaltungsakt ist mit der Einbeziehung der sozialen Sicherung in das öffentliche Recht zunächst noch sehr wenig gesagt. Denn wenn im Recht der sozialen Sicherheit der Verwaltungsakt eine zunehmend geringere, wenn auch sicher eine bleibende Rolle spielt, dann ist das doch nur ein Signum dafür, daß wir vielleicht unter dem Eindruck der Generalklausel auch im übrigen Verwaltungsrecht ein bißchen viel Erwartungen in den Verwaltungsakt gesetzt haben und ein bißchen wenig an Realakte, an sonstige öffentliche Rechtsgeschäfte und dergleichen gedacht haben. Zu Privatrecht und Freiheit meine ich im übrigen genau das, was Herr Scheuner gesagt hat.

Nun von diesem engeren Kreis der sozialen Sicherung aus möchte ich einige Beziehungsfelder öffnen, und davon schwerpunktartig eines: soziale Sicherheit - oder besser soziale Sicherung - ist ein Bestandteil der sozialen Umverteilung. Es ist ja 
eigentümlich, daß wir immer noch weder über eine ökonomische noch über eine juristische Dogmatik der Umverteilung verfügen, obwohl wir uns in einem Staat permanenter umfassender Umverteilung - nicht nur zwischen reich und arm, sondern zwischen allen - befinden. Umverteilung geschieht vornehmlich auf zwei Wegen: über öffentliche Haushalte, d. h. also auch über eine öffentliche Organisation, oder zwischen Privaten, etwa im Sinne entsprechend verfremdeter Lohn- und Preisregelung. Wir haben ein Beispiel des Alternierens ganz deutlich in der Lohnfortzahlung, die wir teilweise so geregelt haben, daß sie unter Privaten direkt stattfindet, teilweise so, daß sie über öffentliche Organisationen stattfindet. Ich klammere nun die direkte Umverteilung unter Privaten wieder aus und komme speziell zu der Umverteilung über öffentliche Haushalte. Soziale Umverteilung über öffentliche Haushalte kann im Nehmen, im Medium des Haushalts oder der Organisation und im Geben entweder spezifisch sein, $d$. h. exklusiv sozial determiniert, oder unspezifisch. Beispiel für das Unspezifische im Nehmen: das allgemeine Steuerrecht, wobei wieder ja die Eigenart die ist, daß wir hier soziale Implikationen und Modifikationen haben; denn beim Unspezifischen kann man das immer noch sekundär einbauen. Unspezifisch im Geben sind etwa allgemeine Verwaltungsleistungen; es wurde schon das Bildungswesen genannt. Die allgemeine Bereitstellung von Bildungseinrichtungen ist ein Akt der Umverteilung, die nicht speziell an Arme gibt. In die Volksschule gehen bekanntlich auch "reiche" Kinder. Spezifisch ist demgegenüber im Nehmen etwa der Sozialversicherungsbeitrag, in Haushalt und Organisation der Sozialversicherungsträger, im Geben die Sozialversicherungsleistung. Die soziale Sicherung zeichnet sich in diesem Beziehungsfeld der Umverteilung dadurch aus, daß sie im Geben immer spezifisch ist, daß sie dagegen im Nehmen und in Haushalt und Organisation entweder spezifisch sein kann oder unspezifisch. Da haben wir ferner die interessanten Rechtsfiguren des Ubergangs, etwa den Finanzausgleich und den öffentlichen Zuschuß, durch den Mittel vom unspezifischen Nehmen in das spezifische Geben hineingeraten, ebenso wie sie von der unspezifischen Organisation in die spezifische Organisation hinüberwechseln und dergleichen.

Ein weiterer Beziehungsrahmen, in den man die soziale Sicherung im engeren Sinne stellen könnte, ist die Uberschneidung mit der Wirtschaftslenkung (Wachstums- und Verteilungspolitik), die heute sehr stark in die soziale Sicherung hereinkommt, etwa indem die Sozialversicherungsträger und ihr 
Vermögen als konjunkturpolitisches Becken verwendet werden. Mehr kann ich hier dazu nicht sagen.

Ein drittes Feld ist die Begegnung - jetzt komme ich wohl in eine neue Dimension -, die Begegnung mit kooperativen Beziehungsformen zwischen Verwaltung und Bürger, womit ich die synallagmatische Kooperation ebenso meine wie die nichtsynallagmatische Kooperation. In einer synallagmatischen Kooperation steht etwa das Dienstverhältnis, und hier sehen wir gleich ein Beispiel für das Uberschneidungsfeld. Der Beamte steht in einer Beziehung sozialer Sicherung, indem er zugleich in einem Austauschverhältnis steht. (Ich habe hinsichtlich des Lohncharakters der Besoldung wohl nicht alle Beamtenrechtstheoretiker auf meiner Seite, aber ich glaube, darüber brauchen wir heute nicht mehr arg zu streiten.) Ein nichtsynallagmatisches Kooperationsverhältnis ist bekanntlich die Subvention. Und wenn Sie etwa bei der Rehabilitation bedenken, daß hier der Behinderte für sich etwas tun muß - er muß nämlich sich "bessern“, im gesundheitlichen Sinne sich „bessern" wollen, sich umschulen lassen oder so etwa -, dann haben wir die Parallele zum Subventionsverhältnis. Das sei als weitere Sachstruktur hier nur am Rande aufgezeigt.

Nun zur Sachstruktur im Inneren des Sachbereichs sozialer Sicherung. Es wurde ausgegangen von der herkömmlichen Unterscheidung Sozialversicherung - Versorgung - Fürsorge. Ich möchte vorschlagen, daß wir noch eine andere Trilogie einführen, nämlich die Trilogie von Vorsorgesystem, Entschädigungssystem und Ausgleichssystem. Das Vorsorgesystem zeichnet sich dadurch aus, daß jemand von vornherein in bezug auf ein künftiges soziales Risiko in ein System einbezogen wird und meist nun auch gleich $\mathrm{zu}$ Leistungen herangezogen wird oder jedenfalls in bestimmte Erwartungen hineinversetzt wird. Letzteres ist das Minimum; aber meist ist das auch so, daß der Einbezogene aktiv zahlend an diesem Vorsorgeunternehmen teilnimmt. Es hängt von der Art des Risikos und des Personenkreises ab, ob so ein Vorsorgesystem möglich ist. Hauptbeispiel ist die Rentenversicherung. Vorsorgesysteme zeichnen sich dadurch aus, daß sie auch im Nehmen spezifisch sein können eben durch das Beitragsaufkommen. Das hat Auswirkungen auch für die materielle Gestaltung der Leistungen. Ich kann das hier im einzelnen nicht ausführen. Ein solches Vorsorgesystem scheint mir auch die Beamtenversorgung zu sein. Sie ist als Vorsorgesystem nur organisatorisch nicht aufgedeckt. Nun zu den Entschädigungssystemen. Kriegsopferversorgung und Lastenausgleich sind heute die herrschenden Beispiele von Entschädigungssystemen. Hier kann man nicht vorher einzahlen. 
Man kann keine Kriegsversicherungskasse begründen. Herr Henke ist mir da freilich viel zu weit gegangen, indem er gewissermaßen pars pro toto an die Stelle der sozialen Sicherung setzen wollte, daß der Staat kraft seiner besonderen Verantwortlichkeit für bestimmte schädigende Ereignisse Entschädigungen auswirft. Und dazu gleich noch ein Wort, Herr Henke. Sie haben gesagt, der Richter möge einen allgemeinen Entschädigungsanspruch entwickeln. Der Richter konnte den enteignungsgleichen Eingriff ganz schön entwickeln. Das waren und sind peripherische, singuläre Fälle. Aber die Liquidation der Kriegsfolgen hätte niemals der Richter entwickeln können. Jede zentrale Veränderung unseres ökonomischen und sozialen Systems muß vom Gesetzgeber generell schon angesichts seiner Haushaltsverantwortung gesteuert und verantwortet werden. Nun haben wir noch eine zweite Art des Entschädigungssystems, in dem entschädigungspflichtige Private untereinander für den Fall ihrer Entschädigungspflicht vorsorgen, nämlich die Unfallversicherung. Da ist dann wieder eine spezifische Organisation schon im Nehmen nötig. Schließlich als dritter Typ die Ausgleichssysteme. Hauptbeispiel: Sozialhilfe. Hier wird zwischen denen, die in Not sind, und denen, die nicht in Not sind, umfassend ausgeglichen. Ein spezifisches Nehmen ist hier untypisch, genauso eine spezifische, autonome Organisation. $\mathrm{Daß}$ Sozialhilfe an die kommunale Selbstverwaltung angehängt ist, ist ja mit Recht heute vernachlässigt worden. Zugleich käme hier das Kindergeld als Ausgleichssystem in Betracht.

Schließlich noch zwei ganz kurze Bemerkungen. Anknüpfen könnte man auch an die verschiedenen Arten von Leistungen. Genommen wird regelmäßig Geld. Ausnahmsweise, wie beim Beamten, in dessen Kooperationsverhältnis, werden auch Dienstleistungen genommen; im Subventionsverhältnis, etwa beim Behinderten, werden auch ähnliche persönliche Leistungen genommen. Das Geben ist typisch aufgefächert in Dauerleistungen, in vorübergehende Leistungen, in einmalige Leistungen, in Geldleistungen, in Sachleistungen, in Dienstleistungen. Das alles bringt ganz verschiedene Strukturen des Rechtshandelns, des Gewährens und Gewährleistens mit sich, und gerade von hier müßte man dann die Analogie zum übrigen Verwaltungshandeln ziehen - von diesen Partikeln her zu den verwandten Partikeln des übrigen Verwaltungsrechts.

Und schließlich bieten sich als Sachstrukturen die verschiedenen Risiken an, die soziale Sicherung abzudecken sucht.

Stern: Nach den vorangegangenen Diskussionsbeiträgen glaube ich, daß mein Beitrag die Akzente anders setzen wird. Ich habe das Thema vor allen Dingen in der Richtung verstan- 
den, daß es um die Fragestellung geht, Sozialrecht und allgemeines Verwaltungsrecht wieder miteinander in Kontakt zu bringen, und zwar wechselseitig. Herr Henke hat das auch in seinen einleitenden Bemerkungen angedeutet. Ich habe allerdings das Gefühl, daß in der Folge sein Referat doch einen sehr zwiespältigen Eindruck macht insofern nämlich, als die Frage auftaucht: War es ein Plädoyer für die Eigenständigkeit des Sozialrechts oder ging es ihm um die Frage, das Sozialrecht wieder zurückzuholen in das allgemeine Verwaltungsrecht, das wir ja noch immer als den Gravitationspunkt unseres Verwaltungsrechts ansehen. Im letzteren Falle würden wir in einer Parallelsituation zum Steuerrecht stehen, von dem viele von uns sich bemühen, es wieder in das Verwaltungsrecht zurückzuführen und aus der etwas schwammigen betrieblichen Steuerlehre herauszulösen - eine wichtige Frage der Durchsetzung des rechtsstaatlichen Prinzips. Ähnliches gilt etwa auch bei Fragen des Wirtschaftsverwaltungsrechts; ich erinnere an die Arbeiten von Ernst Rudolf Huber oder neuerdings an das Kulturverwaltungsrecht von Herrn Oppermann. Diese Intentionen scheinen mir nicht gelöst zu sein, obwohl Herr Rüfner deutliche Akzente gesetzt hat in seiner Auslegung der Reichsversicherungsordnung und des Sozialgerichtsgesetzes; vor allen Dingen bei Herrn Henke fand ich, daß er nur sehr partielle Bezüge zwischen beiden Rechtsgebieten hergestellt hat. Andererseits halte ich das besondere Gewaltverhältnis nicht für ein Anliegen unseres Themas. Herr Henke, Sie rennen offene Türen ein, das besondere Gewaltverhältnis zu einem Rechtsverhältnis zu machen, wiewohl ich mir selbstverständlich im Klaren darüber bin, daß dabei noch nicht alles gelöst ist, sei es Grundrechtsschutz, Verwaltungsakt und gerichtlicher Rechtsschutz. Indessen habe ich entscheidende Gesichtspunkte wie Ermessen, subjektives öffentliches Recht, beispielsweise in Auseinandersetzung mit Herrn Bogs auf dem 43. Deutschen Juristentag in München, der einen Rechtsanspruch auf soziale Sicherungsleistungen aus dem Sozialstaatsprinzip annimmt, vermißt. Damit im Zusammenhang steht die andere Frage: Kann das allgemeine Verwaltungsrecht aus den besonderen Strukturen und Rechtsformen des Sozialrechts etwas profitieren? Es ist bereits auf Rechtsschutz, die Rücknahme von Verwaltungsakten, den öffentlichrechtlichen Vertrag hingewiesen worden. Ferner würde sich anbieten: Dauerverhältnis, verwaltungsrechtliche Schuld- und Ausgleichsverhältnisse - im einzelnen brauche ich das nicht näher auszuführen.

Ein zweiter Punkt: Keiner der beiden Referenten hat den Begriff Soziale Sicherung definiert. Sicher ist, daß man den 
schwammigen Begriff Daseinsvorsorge und Daseinsfürsorge vermeiden soll. Dieser Begriff ist auch fast kaum in den Referaten aufgetaucht. Entscheidend ist $\mathrm{m}$. E. bei der sozialen Sicherung, da $B$ wir uns mit diesem Institut entschlossen haben, das römisch-rechtliche casum sentit dominus zu verlassen zugunsten eines Sekuritätsstrebens, das vielleicht etwas größer geworden ist, als es zur Zeit wünschenswert erscheint. Sekurität, das ist der entscheidende Gesichtspunkt, und damit meine ich, daß Sekurität, nicht Liberalität der entscheidende verfassungsrechtliche Ansatzpunkt ist, mit dem man diesem Thema zu Leibe gehen sollte, wobei zugegebenermaßen die Themenstellung nicht unbedingt Anlaß gab, zu den verfassungsrechtlichen $\mathrm{Be}-$ zügen Stellung zu nehmen, aber man sollte es. Und Sekurität, meine ich, muß vorausgesetzt werden, um von der Liberalität Gebrauch machen zu können. Das ist doch der Anknüpfungspunkt unseres sozialstaatlichen Prinzips, d. h. daß Verhältnisse geschaffen werden sollen, von den Grundrechten den erforderlichen Gebrauch machen zu können. Herr Werner und noch vorher - wenn ich recht im Bilde bin - Herr Leibholz in einem Aufsatz von 1949 haben uns auf die Problematik aufmerksam gemacht, die dann in die vereinfachende Formel mündete: Verwaltungsrecht ist konkretisiertes Verfassungsrecht. Von daher ergaben sich die entscheidenden verfassungsrechtlichen Implikationen. Ich halte es nicht für richtig, den Art. 3 GG umzufunktionieren in einen § 242 BGB oder gar mit ihm parallel zu setzen. Wer das tut, müßte zwangsläufig zu dem Ergebnis kommen, daß er ähnlich dem BGB-Kommentar von Staudinger zu $\$ 242$ ein Buch von über 2000 Seiten schreiben müßte.

Mit der Definition der sozialen Sicherung taucht sofort eine neue Frage auf: Wie ist eine Abgrenzung etwa zu Problemen der Strukturpolitik vorzunehmen? Hat die Zielvorstellung der sozialen Sicherung Gemeinsames mit der Subventionierung? In unserem Kreise ist bekanntlich wiederholt das Thema Subventionierung angeklungen. Soll bei der sozialen Sicherung vielleicht bloß der Einzelne in einem ganz besonderen Fall unterstützt werden? Ich darf daran erinnern, daß sich der Arbeitsminister geweigert hat, in dem in $\S 12$ des Stabilitätsgesetzes vorgesehenen Subventionsbericht seine Sozialleistungen mit anzugeben. Er hat den Standpunkt vertreten, daß diese Art von Sozialleistungen etwas ganz anderes sind als Subventionen. Zum zweiten: Fragen der Wirtschaftsförderung, gehören sie zu unserem Problemkreis oder sind sie davon Verschiedenes? Verbindungslinien unseres heutigen Themas $\mathrm{zu}$ vorangegangenen Tagungen sind offensichtlich festzustellen. 
Ein Wort noch, wenn ich vorgreifen darf, zum Stichwort Entschädigungssystem. Ich meine, das Recht der sozialen Sicherung ist präventiv, ist vorsorgend orientiert. Das öffentlich-rechtliche Entschädigungssystem ist, so wie wir es bisher verstehen, an dem besonderen Fall eines Eingriffes oder eines Fehlverhaltens orientiert. Die Verbindungslinien zur sozialen Sicherung sind damit in meinen Augen nur sehr locker, ganz abgesehen davon, daß beim Entschädigungssystem die Wurzel das Rechtsstaatsprinzip, die iura quaesita, und der Konnex mit dem ius eminens sind, worauf auch Herr Henke aufmerksam gemacht hat. Herr Henke hat in diesem Zusammenhang - das war wohl sein Anknüpfungspunkt - von einem Ausgleichsanspruch aus Verwaltungsrisiko gesprochen. Ich meine, ein solcher Anspruch ist ohne jegliche Kontur, er würde uns eine ganz gefährliche Entschädigungshypertrophie in Parallele zum Gefährdungshaftungsanspruch von Herrn Leisner bescheren, und wir alle waren uns seinerzeit auf der Freiburger Tagung doch im klaren, daß wir die Gefährdungshaftung ohne eine genaue gesetzliche Begrenzung nicht akzeptieren können. Vermutlich werden wir auch mit dem Ausgleichsanspruch aus verwaltungsrechtlichem Risiko nicht arbeiten können. In diesem Zusammenhang fiel mir auf, daB ein Urteil des BGH nicht erwähnt wurde, das entscheidend ist für die andersartige Orientierung unseres Entschädigungssystems, nämlich das Urteil des BGH über den Turnunfall in der Schule. Der BGH hat ausdrücklich gesagt, Sicherung aus dem allgemeinen Lebensrisiko, das den Schüler beim Turnen triffit, kann über das bisherige Entschädigungssystem nicht geliefert werden, sondern muß anderweitig durch den Gesetzgeber gelöst werden. Hier waren die Trennungslinien seitens der Rechtsprechung sehr deutlich gezogen, eben der Judikatur, die in entscheidendem Maße unser Entschädigungsrecht geprägt hat.

Nur ein kurzes Wort noch zur Selbstverwaltung, die Herr Henke ebenfalls angesprochen hat. Ich glaube, sein Selbstverwaltungsbegriff und die Implikationen, die er aus dem Kommunalrecht entnommen hat, sind nicht tragfähig für die Selbstverwaltung im sozialrechtlichen Bereich. Hier bestehen entscheidende Unterschiede, aber das wird an anderer Stelle zu diskutieren sein.

Und zum Schluß: Herr Henke sagte - wenn ich mich recht erinnere -, die bewährten Institutionen des liberalen Verwaltungsrechts müssen vor der Zerstörung durch eine soziale Umdeutung um der Freiheit willen bewahrt werden. Ich glaube, wir sind uns völlig einig darüber, daß es ein entscheidendes Anliegen ist, auch im Bereich des Verwaltungsrechts die Frei- 
heit zu erhalten. Aber ich meine: Unser Verwaltungsrecht ist in meinen Augen bereits kein liberales mehr, sondern ein soziales Verwaltungsrecht. Freilich bleibt zweifelhaft, ob man hier an die alten Untersuchungen von Hermann Roesler über das "soziale Verwaltungsrecht" noch anknüpfen kann. Entscheidend ist vielmehr heute, daß durch das verfassungsrechtliche Gebot des Sozialstaats eine deutliche Veränderung eingetreten ist. Was heißt dann aber "Sozialisierung des Verwaltungsrechts"? Ich kann damit nichts anfangen. Wenn es in dem Sinne gemeint ist, daß das Verwaltungsrecht völlig von seinen freiheitlichen Konturen entbunden werden soll, dann stimme ich Ihnen voll $\mathrm{zu}, \mathrm{da}$ wir dieser Sozialisierung mit allen Mitteln entgegentreten müssen.

Henke: Ich würde gerne zwischendurch etwas sagen, weil eine ganze Reihe von Punkten der Kritik schon vorgekommen sind, und weil das alles, glaube ich, nicht bis zum Schluß offen bleiben kann, auch weil mancher weiteren Kritik vielleicht noch vorgebeugt werden kann. Ich habe zunächst zur Kenntnis genommen und zur Kenntnis zu nehmen, daß sowohl Herr Zacher als auch Herr Stern ein anderes Referat zu diesem Thema gehalten hätten, als ich es gehalten habe. Ich habe es allerdings nicht als meine Aufgabe angesehen, - vielleicht habe ich den Vorstand mißverstanden - daß ich hier die Einordnung des Sozialrechts in das Verwaltungsrecht $\mathrm{zu}$ behandeln hätte, in das Allgemeine Verwaltungsrecht noch dazu - wenn Einordnung, dann höchstens doch als eines der Bestandteile des besonderen sondern ich habe mir einfach überlegt: was ist mit unseren Vorstellungen, mit unseren Rechtsinstituten des Allgemeinen Verwaltungsrechts, wenn wir nun die Existenz dieses doch zunächst im Winkel groß gewordenen Sozialrechts beachten und ernst nehmen? Dabei bin ich auf diese vier Themen gekommen und habe daher etwas ganz anderes als das, was Herr Zacher sagte, vorgebracht. - Wenn gesagt wurde, daß ich bei dem besonderen Rechtsverhältnis offene Türen einrenne, so muß ich sagen: natürlich, daß das Gewaltverhältnis ein Rechtsverhältnis ist, ist jedermann bekannt und war mir auch klar. Ich habe nur den Eindruck, daß viel zu schematisch über alle sachlichen Besonderheiten hinweg jeweils mit dem Schema der einseitigen Entscheidung - also Befehl und Gehorsam - operiert wird, daß uns dagegen im Verwaltungsrecht das fehlt, was das Bürgerliche Recht im besonderen Schuldverhältnis hat. Ansätze dazu gibt es, aber wir haben noch kein ausgearbeitetes Subventionsverhältnis, so wie wir ein bis ins einzelne ausgearbeitetes Kaufvertragsrecht haben. Es gibt Bände über die Mängelhaftung beim Kauf, ein winziges Problem aus diesem großen Be- 
reich, aber es gibt Vergleichbares bisher nicht - trotz Herrn Götz und seines Werkes über das Subventionsrecht, das einen Anfang darstellt - in den einzelnen Bereichen des Verwaltungsrechts. Die Frage der Entschädigung - ich gebe zu, daß die Verbindung zwischen diesem Punkt und dem Recht der sozialen Sicherung wohl am schwächsten war und die Darstellung dieser Verbindung auch etwas zu kurz gekommen ist, so $\mathrm{da} ß$ sie nicht ganz deutlich war. $\mathrm{DaB}$ die Rechtsprechung etwa einen Lastenausgleich oder den Ausgleich von Kriegsfolgeschäden hätte entwickeln sollen, das war natürlich nicht gemeint.

Dürig: Herr Henke, gleichsam als „goldene Brücke“ für die von Herrn Bettermann als überflüssig erachtete Einbeziehung des öffentlich-rechtlichen Entschädigungsrechts in Ihr Referat nenne ich nur als Stichwort: $\$ 539$ Reichsversicherungsordnung, der ja trotz seiner Stellung in der RVO in der Tat zum System des öffentlich-rechtlichen Entschädigungsrechts gehört.

Henke: Ich wollte auch nicht sozialversicherungsrechtliche Lösungen des Problems der Aufopferungsentschädigung verallgemeinern bzw. den Richter in die Lage versetzen, auch da, wo es den $\S 539$ Abs. 1 Nr. 9 RVO nicht gibt, in einzelnen Fällen der Verwaltung eine Lösung zu finden. Was mich dazu gebracht hat, hier zur Entschädigung etwas zu sagen, ist einfach die ungemeine Verlegenheit, in die ich jedesmal komme, wenn ich in der Vorlesung zum enteignungsgleichen Eingriff komme. Ich erzähle den Studenten da etwas, was ich selbst nicht glaube. Der „Eingriff“ ist doch wirklich weithin nicht Eingriff und nicht enteignungsgleich. Den Zusammenhang mit dem Sozialrecht sehe ich eben da - um es noch einmal mit einem Wort zu sagen - wo sich die Explosion eines Atommeilers und ein Erdbeben in den Auswirkungen einander nähern und wo der Staat wie ich das doch gesagt habe und, wie ich dachte, deutlich genug gesagt habe - sich soweit zum Verwalter der individuellen Geschicke seiner Bürger macht, daß gar kein großer Unterschied mehr besteht zwischen Unfällen, Schädigungen, die im Zuge seiner Verwaltung vorkommen, und Unfällen, Schädigungen, die schicksalhaft ohne staatliches Eingreifen vorkommen.

Zur Gegenüberstellung von Sekurität und Liberalität, wie Herr Stern es schön lateinisch gesagt hat: Herr Stern, wenn Sie sagen, wir müssen letzte Reste der Freiheit im Verwaltungsrecht bewahren, darum geht es mir auch, aber nicht nur darum. Wenn Sie jedoch sagen, unsere Freiheit beruhe auf der Sekurität - Sie haben gesagt, die Daseinsvorsorge müsse den Einzel- 
nen in Positionen setzen, in denen er von den Grundrechten Gebrauch machen kann - dann bestreite ich das, und ich bin mir im klaren darüber, wie zahlreich die Gegner in diesem Punkt sein werden. Aber ich wollte trotzdem versuchen, diesen schwierigen Punkt einmal anzubringen, gerade auch in der Erwartung von Widerspruch. Gibt es denn nicht eine liberale Position, auch heute noch, wo man wenigstens auf einen Teil der Sicherheit verzichtet um der Freiheit willen, wo man wenigstens der ständig fortschreitenden Perfektionierung der Sicherheit Grenzen steckt, weil man sich klar darüber ist, daß mit der fortschreitenden Sekurisierung die Freiheit nicht gewinnt, sondern letzten Endes verliert?

Ipsen: Nach der Replik von Herrn Henke kann ich dem künftigen Vorstand nur den dringenden Rat geben, keine Themata mehr zu bilden, deren Elemente durch das verfängliche Wört-

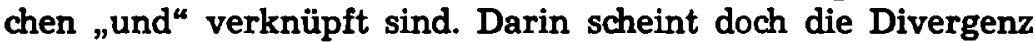
zwischen dem Referenten und beispielsweise der Auffassung von Herrn Zacher zu liegen. Ich habe mir auch die Frage gestellt, was das "und" bei diesem Thema bedeutet, und stelle deshalb eine Vorbemerkung voran, die an Ausführungen von Herrn Stern anknüpft und zur Zuordnung des Sozialrechts zum Allgemeinen Verwaltungsrecht zählt.

1. Unter Allgemeinem Verwaltungsrecht begreift das übliche Verständnis die ungeschriebenen Normen, die Rechtsprechung und Wissenschaft entwickelt haben, ohne daß es bislang zu ihrer Kodifikation gediehen ist. $\mathrm{Zu}$ diesem Punkt und in Anknüpfung an Auseinandersetzungen, die auf dem Münchener Juristentag 1960 zur Kodifikation des Allgemeinen Verwaltungsrechts stattgefunden haben, zeigen die beiden heutigen Referate deutlich, daß aus ihren Ergebnissen jedenfalls keine Gesichtspunkte für eine Kodifizierung unseres Allgemeinen Verwaltungsrechts hergeleitet werden könnten. Auch das scheint mir ein Ertrag zu sein. Aber das ist nicht das mir Wesentliche, das ich hier.ausführen wollte.

2. Mir geht es um die Frage, die auch Herr Stern aufgeworfen hat: was heißt in unserer Thematik "soziale Sicherung “, zu der beide Referenten eine Definition haben vermissen lassen? Es geht bei der sozialen Sicherung und ihrer rechtlichen Ordnung, Gestaltung und Absicherung heute um das Phänomen, $\mathrm{da} B$ in weitem Ausmaß eine "Ver-Offentlichung" der Vorsorge stattfindet, die an sich ein jeder selbst in seinem Leben für sich und die Seinen zu tragen hat. Es findet statt eine Uberbürdung der Lebensverantwortung für Risiken, die jedem begegnen können, auf die öffentliche Gewalt im weitesten Sinne des Wor- 
tes. Solche Risiken, die im Sozialversicherungsrecht und im Sozialhilferecht bewältigt werden sollen, sind, mit Schlagworten formuliert: Armut, Alter, Invalidität, Krankheit, Unfall und (womit sich eine besondere Verfassungsfrage stellt) Arbeitslosigkeit.

3. Dazu knüpfe ich an Bemerkungen an, die Herr Scheuner am Beginn machte und zu denen ich gern sogleich geantwortet hätte. Aber Sie werden sich dessen, was Herr Scheuner stets eindrucksvoll zu sagen pflegt, noch deutlich genug erinnern, so daß ich die Brücke zu ihm schlagen kann. Wir haben in dem Referat von Herrn Rüfner gehört, daß die Arbeitslosenversicherung nicht so sehr finanzielle Schadloshaltung für Arbeitslosigkeit sei, sondern Vorsorge dafür, daß ein anderer Arbeitsplatz bereitgestellt oder der Betroffene durch Umschulung und andere fördernde Maßnahmen instand gesetzt wird, einen neuen Arbeitsplatz einzunehmen. Damit wird die Brücke von unserer Thematik zum Sozialstaatsprinzip geschlagen. Als Herr Forsthoff 1953 in Bonn über das Sozialstaatsprinzip referierte, hat er bekanntlich die These entwickelt, das Verfassungsprinzip der Sozialstaatlichkeit gebe unmittelbar vollziehbar nichts her; der Sozialstaat realisiere sich in der Gesetzgebung. Angesichts unserer heutigen Referate leuchtet die Richtigkeit dieser Forsthoff'schen These für das Sozialrecht ein. Auf dem Gebiet der sozialen Sicherung hat sich erwiesen, daß es Aufgabe des Gesetzgebers ist, das Sozialstaatsprinzip zu realisieren in ständigem Fortschritt, in ständiger Bewegung und Dynamik.

Aber hier zeigt sich am Lebensrisiko der Arbeitslosigkeit ein eigenartiger Zusammenhang zwischen dem Sozialstaatsprinzip und der Funktion des Art.12, der seinerseits ja keinen Anspruch auf einen Arbeitsplatz vermittelt, aber nun mit Hilfe der Sozialgesetzgebung vollziehbar gemacht wird. Das geschieht, indem die Sozialhilfe sich ausdehnt auf staatlich vorgehaltene Förderungsmaßnahmen der Umschulung, der Berufsfortbildung usw., auf öffentliche Leistungen also, die Art. 12 selbst seinerseits nicht vermitteln kann. Wir stehen dabei selbstverständlich unter den bekannten Gefahren verplanender öffentlicher Ordnung, weil solche Maßnahmen erfolgreich auch im Rahmen einer Strukturpolitik - das Stichwort fiel bereits - nur dann wirken können, wenn der Staat gezielt und planhaft handelt. Hier zeigt sich also, wie mit Hilfe der Gesetzgebung auf dem Gebiet der sozialen Sicherung ein Grundrecht, das nach seiner Anlage als Freiheitsrecht sozialstaatlich nicht vollziehbar war, zunehmend aktiviert werden kann. Und wenn ich pflichtschuldigst auch hier meine EWG-Eskapade anschließen darf — das bin ich meinem Fach schuldig —, muß ich 
darauf hinweisen, daß das EWG-Recht in dieser Richtung wesentliche parallele Ansätze hat, vom Montanvertrag her bis hin zum EWG-Recht, in dem es Maßnahmen der Strukturpolitik gestaltend verbindet mit sichernden sozialen Maßnahmen der beruflichen Umsetzung.

4. Herr Henke hat - Herr Henke, entschuldigen Sie den Ausdruck, ich bin auch sogleich bereit, ihn wieder zurückzunehmen - mit einer dubiosen Formel gesprochen von Zeiten fortschreitender Sozialisierung von Gerechtigkeit und Freiheit. Diese Formel halte ich für verfänglich und eben: dubios. Es geht doch um die Frage, wie es um den verbleibenden Freiheitsbereich des Einzelnen bestellt ist angesichts der hier dargestellten Erscheinungen, und sie ist bei beiden Referenten, wie ich glaube, nicht deutlich genug beantwortet worden. Wenn Verantwortungen für Lebensrisiken von der öffentlichen Hand übernommen werden, darf darüber nicht vergessen werden, daß die primäre Verantwortung für diese Risiken dem Individuum obliegt und alle öffentlichen Maßnahmen sozialer Sicherung nicht so weit gehen dürfen, dort, wo private, individuelle Existenzverantwortung noch prästiert werden kann, auch sie noch zu nehmen. Das wäre ein unverhältnismäßiger Zugriff auf einen Freiheitsbereich, der bewahrt werden sollte. Ein plastisches Beispiel hierfür haben wir erlebt bei der Heraufsetzung der Pflichtversicherungsgrenze der Angestelltenversicherung mit dem Ausschuß dauernder Befreiungsmöglichkeit durch Privatversicherung. Dort ist mit der öffentlichrechtlichen Verpflichtung zur Vorsorge überhaupt, die ich durchaus bejahe, die Chance möglicher Eigenvorsorge genommen worden, und zwar in einem Perfektionismus, hinter dem auch handfeste Umverteilungspläne stehen, um nämlich der noch solventeren Angestelltenversicherung Reserven zu nehmen, damit die Invalidenversicherung über die Hürden der Utberalterung kommt. Hierzu sollte der Gesichtspunkt der Subsidiarität nicht vernachlässigt werden, wonach Maßnahmen öffentlicher sozialer Sicherung die individuelle Eigenverantwortung für Lebensrisiken nicht verkürzen dürfen, wo sie aus eigener $\mathrm{Kraft}$ gewahrt werden kann. Wenn das gleichwohl geschieht, liegt darin ein verfassungsrechtlicher Verstoß gegen das Prinzip der Verhältnismäßigkeit.

5. Endlich zu der Formel, die ich dubios genannt habe, nämlich zur fortschreitenden Sozialisierung von Gerechtigkeit und Freiheit. Was soll das bedeuten? Das kann einmal bedeuten: in Zukunft Gerechtigkeit auch für diejenigen, denen sie bisher nicht zuteil wurde, also für die sozial Schwachen. Damit rennt der Referent - ebenso wie in seiner Forderung nach Ver- 
Rechtlichung des besonderen Gewaltverhältnisses - offene Türen ein. Denn darin besteht doch das ganze Anliegen der Aufgaben der sozialen Sicherung. Wenn aber die Formel heiBen soll: Sozialisierung von Gerechtigkeit durch zunehmende Umverteilung, dann geht solche Sozialisierung auf Kosten der Freiheit. Das aber halte ich für verfänglich und unzulässig, soweit der Gesichtspunkt der Subsidiarität durchschlägt.

Rüfner: Ich habe eigentlich nur eine Gegenfrage. Herr Ipsen, Sie haben gesagt, dort wo der Einzelne die Leistung nicht mehr prästieren könne, fänden Sie sich mit der Ausdehnung der Sozialversicherung ab. Würden Sie die Ausdehnung auf das ganze Volk bei der Rentenversicherung hinnehmen?

Ipsen: Nein, noch nicht.

Rüfner: Ich glaube allerdings, daß nur wenige übrig bleiben, die zur selbstverantwortlichen Vorsorge in der Lage sind.

Ipsen: Da ergeben sich erkleckliche Zahlen, die ich nicht im Kopf habe. Aber ich weiß, daß sie existieren. Ich glaube schon, $\mathrm{da} B$ ein nicht geringer Personenkreis imstande ist, noch individuell die Verantwortung $\mathrm{zu}$ tragen, vor allen Dingen, wenn Vorsorge dafür getroffen wird, daß die Währungsumstellung nach der nächsten Inflation die Lebensversicherung besser behandelt als das bei der letzten Währungsreform geschehen ist. Das könnten wir in die nächste Verfassung hineinschreiben.

Rüfner: $\mathrm{Da}$ das schlecht zu gewährleisten ist, sehe ich kaum Möglichkeiten.

Ipsen: Es ist kein Grund, gegen rechtsstaatliche Gesichtspunkte auf etwas zu verzichten, wenn der Staat in seiner Verantwortung, für die Stabilität der Währung zu sorgen, versagt.

Rüfner: Ich sehe die Inflation als ein Faktum an, das wir resignierend hinnehmen müssen. Ich betrachte es als eine Art von Volksbetrug, die Leute auf die Eigenvorsorge zu verweisen.

Ipsen: So jung - und schon so fatalistisch!

Rüfner: In dem Punkt ja. Bei der Krankenversicherung räume ich ein, daß wir heute schon an die Grenze des verfassungsrechtlich Möglichen gehen. Ich meine, ich hätte das in meinem Referat angedeutet. 
Frowein: Nur eine unmittelbare Frage an Herrn Ipsen in diesem Zusammenhang: Sind die Bedenken, die Sie geäußert haben hinsichtlich der Möglichkeit des Gesetzgebers, die Rentenversicherung durch Steuern oder ähnliche Umlagen auf das gesamte Volk zu verteilen, Bedenken, die sich aus Grundrechten, aus Verfassungsnormen ergeben, und wenn ja, aus welchen; oder sind es andere Bedenken, die bei der Entscheidung, ob so etwas gemacht werden sollte, eine Rolle spielen könnten? Nur um meine Position anzudeuten: Ich sehe keinerlei grundrechtlichen Schutz gegen eine solche Maßnahme des Gesetzgebers, da nach meiner Ansicht Art. 2 nicht herangezogen werden kann, und wenn er herangezogen werden sollte, durch den Gesetzesvorbehalt in diesem Punkt begrenzt wäre.

Ipsen: Ich kann nur antworten: in dubio pro libertate. Ich könnte auch nichts anderes als Art. 2 Abs. 1 nennen. Ich glaube auch nicht, daß der Vorbehalt der verfassungsmäßigen Ordnung so intensiv einschränken darf, wie das weithin geschieht. Wir haben ja auch Ansatzpunkte dafür, daß die Beschränkung nicht einfach zu identifizieren ist mit einem allgemeinen Gesetzesvorbehalt. Wir haben alle Veranlassung, etwa im Sinne der Ausführungen von Herrn Rupp und Herrn Dürig, unausgesprochen immer vorneweg, anzugehen gegen die Gleichsetzung der Vorbehaltsformel in Art. 2 Abs. 1 mit einem allgemeinen Gesetzesvorbehalt. Wenn wir hier die Segel streichen, ist es mit diesem letzten Residuum vorbei.

Frowein: Wenn ich noch ein Wort dazu sagen darf: Bevor ich zu der Frage komme, ob der Gesetzesvorbehalt mit kritischen Äußerungen zum Bundesverfassungsgericht nicht anders verstanden werden sollte, müßte ja die Frage geklärt werden, ob unter den Obersatz „Freie Entfaltung“ wirklich die Freiheit von solchen Abgaben fällt.

Ipsen: Freiheit von Abgaben ist mir viel zu „irdisch“ gesehen. Es geht um die Freiheit der Eigenvorsorge für die Existenz der Person und der Seinen. Das halte ich für wesentlich gewichtiger als die Frage, ob Abgabepflichten entstehen und dagegen Grundrechtsschutz besteht.

Henke: Herr Ipsen, ich weiß nicht, ob ich richtig verstanden habe, wie Sie mich verstanden haben mit diesem "Dubiosen“. Deswegen kann ich auch nicht sagen, ob Sie es zurücknehmen sollten oder nicht. Fortschreitende Sozialisierung von Freiheit und Gerechtigkeit schien mir eine Gefahr, auf die ich hinweisen 
wollte. Sie haben es offenbar so verstanden, als ob das etwas sei, was ich proklamieren wolle. Ich bin völlig mit Ihnen einig, daß eine fortschreitende Sozialisierung von Freiheit und Gerechtigkeit verhindert werden sollte und deswegen zum Beispiel die Ausdehnung der Sozialversicherungspflicht auf solche, die sie nicht nötig haben, aber bestens finanzieren könnten, nicht stattfinden dürfte. $\mathrm{Ob}$ das aus den Grundrechten folgt oder nicht, hängt davon ab, wie man die Grundrechte versteht. Jedenfalls: die Freiheit sozialisieren, das sollte heißen: an die Stelle der großen Freiheit die kleine Freiheit setzen, an die Stelle der Freiheit vom Staat und von der Gesellschaft die Freiheit von Not, von Krankheit, vom Arbeitgeber, von Armut usw.

Ule: Ich weiß nicht, ob ich Herrn Ipsen richtig verstanden habe. Herr Ipsen hat auf das Jahr 1953 und das Referat von Herrn Forsthoff angespielt und gemeint, die heutigen Referate hätten den damaligen Standpunkt von Herrn Forsthoff bestätigt. Ich bin nicht so sicher, und ich möchte nur eine Frage stellen, die im Streit um das Sozialhilfegesetz eine Rolle gespielt hat. Könnte unser Gesetzgeber wirklich die staatliche Sozialversicherung oder Sozialhilfe durch einen Federstrich abschaffen? Dies wäre doch nur möglich, wenn das Sozialstaatsprinzip keine verfassungsrechtliche Bedeutung, sondern nur - wie damals, glaube ich, gesagt worden ist - die Bedeutung eines Blankettbegriffs hätte.

Thieme: Herr Henke macht mich darauf aufmerksam, daß wir ihn unterbrochen haben. Ich glaube, es ist nützlich, wenn wir ihn erst zu Ende sprechen lassen.

Henke: Ich wollte nur zum dritten Mal die offene Tür des Rechtsverhältnisses einrennen, aber nur, indem ich auf die Ausführungen von Bühler - Strickrodt zum Steuerschuldverhältnis in dem ersten Band seines Steuerrechts (3. Aufl. S. 347 ff.) hinweise. Da findet sich das, was auch für Sie, Herr Stern, erläutern könnte, woran ich hier denke und was im Verwaltungsrecht wirklich fehlt.

Ipsen: Herr Ule, ich habe immer die Meinung vertreten, daß Sozialversicherung als Institution kraft Sozialstaatsprinzips unter einer Gewährleistung stünde. Das habe ich irgendwo auch einmal gedruckt.

Rüfner: Vielleicht kann man Herrn Ipsen so interpretieren: Er hat nicht sagen wollen, das Recht auf Arbeit habe keine 
verfassungsrechtliche Bedeutung. Er wollte vielmehr aus Art. 12 und dem Sozialstaatsgrundsatz eine Aufgabe des Gesetzgebers ablesen. Der Gesetzgeber hat wohl eine Pflicht, aber eine Pflicht, die man nicht einklagen kann.

Oppermann: Ich wollte mich auch in diese Diskussion einschalten, die eigentlich Herr Scheuner mit dem Hinweis auf Ihre These 9 eingeleitet hatte, Herr Rüfner, wo Sie beim Arbeitsförderungsgesetz diese Formulierung vom Recht auf Arbeit oder von der Pflicht des Staates, für Vollbeschäftigung zu sorgen, hinter dem Gesetz stehen sehen. Das ist ja im Grunde auch das Problem. Ich möchte es im Sinne einer Aufklärungsfrage an Sie weitergeben: wie weit handelt es sich hier bei Ihnen mit der Erwähnung des Rechtes auf Arbeit und der Pflicht des Staates, für Vollbeschäftigung zu sorgen, nun eigentlich um eine rechtliche oder um eine soziologische Aussage? Oder rechtlich allenfalls in dem Maße, daß es eine Zielbestimmung des Staates wäre, hier etwas zu tun? Sehen Sie heute einen Fortschritt im Verhältnis etwa zu der Anerkennung des Rechtes auf Arbeit, wie wir sie ziemlich volltönend z. B. auch in der neuen Menschenrechtskonvention der Vereinten Nationen von 1966 haben? Das ist doch hier wieder die alte Frage: Gibt es vom Sozialstaatsprinzip her echte Teilhabegrundrechte oder bleiben das mehr oder weniger Aufforderungen im Forsthoff'schen Sinne an den Gesetzgeber, in dieser Richtung, aber in einem sehr breiten allgemeinen Sinne tätig zu werden. Ich bin - offen gestanden - auch noch nicht über diesen Forsthoff'schen Gedankengang hinausgekommen. Beim Recht auf Arbeit habe ich es mir noch nicht eingehend überlegt, aber dieselbe Parallele besteht etwa bei dem berühmten Recht auf Bildung. Ist das nun wirklich mehr, trotz der vielen Aufsätze, die neuerdings darüber geschrieben worden sind, als ein allgemeiner Aufruf an den Gesetzgeber, die Bildungsinstitutionen auf der Höhe der Zeit zu halten? Man kann natürlich, Herr Ule, sagen - da besteht wohl ziemlich allgemeines Einverständnis - daß es wenigstens eine bestimmte Konkretisierung des Sozialprinzips gibt im Sinne einer institutionellen Garantie der grundsätzlichen Erhaltung derartiger sozialer Einrichtungen. Aber das ist doch etwas anderes, als die Frage, um die es hier geht: wie weit gibt es tatsächlich individuelle Teilhaberechte, und deswegen meine Frage an Sie, Herr Rüfner: ist dieses Recht auf Arbeit in Ihren Uberlegungen doch schon etwas mehr in dieser Richtung entwickelt oder wie sehen Sie das?

Scheuner: Unabhängig von der Frage, wie das Sozialstaatsprinzip auszulegen ist, wird man sicherlich sagen dürfen, daß 
der Staat nicht mehr Personengruppen, die er durch Inflation oder wirtschaftliche Strukturmaßnahmen der Möglichkeit der Vermögensbildung, der Möglichkeit der eigenen Sicherung beraubt hat, auf eine solche Eigenverantwortung verweisen kann. Hier ist der Staat gehalten, seinerseits Einrichtungen zu schaffen. Da das aber die überwiegende Mehrheit des Volkes betrifft, ist eben doch das Sozialversicherungssystem bereits sehr breit fundiert. Das Recht auf Arbeit und das Recht auf Bildung gehören hier in dieselbe Kategorie. Die Menschenrechtskonvention von 1966 verpflichtet die Staaten in der Sozialkonvention nicht dazu, bestimmte Rechte zu geben, sondern nach bestem Wissen und bestem Können die in der Konvention übernommenen Verpflichtungen zu verwirklichen. Hier besteht zwischen der Konvention der politischen und bürgerlichen Rechte und der Konvention der sozialen und ökonomischen Rechte ein scharfer, auch dogmatisch absichtlich gemachter Unterschied.

Oppermann: Darf ich nur noch einmal dazwischenfragen, Herr Scheuner? Wenn nun der Staat es aber verabsäumt, die minderbemittelten Schichten in eine solche Versicherung, die für sie vielleicht das Richtige wäre, einzubeziehen, ist das dann ein Verfassungsverstoß? Das ist doch die eigentliche Kernfrage. Ist es ein Verfassungsversto $B$ in dem Sinne, daß diesen Personen irgendwelche individuell einklagbaren Teilhaberechte zustünden? Das würde ich de constitutione lata ablehnen.

Scheuner: Da sind wir einig.

Rüfner: Herr Oppermann, ich wollte keinesfalls einen einklagbaren Anspruch auf Arbeit bejahen. Die Wirtschaftsverfassung - wenn ich diesen Ausdruck einmal unpräzise gebrauchen darf - läßt sich nicht durch Annahme eines Rechts auf Arbeit revolutionieren. Man müßte nämlich die gesamte Marktwirtschaft aufgeben, wenn man ein Recht auf Arbeit gewähren wollte. Aber ich sehe es doch als eine verfassungsrechtliche Pflicht des Staates an, mit den Mitteln, die er zur Verfügung hat, für Vollbeschäftigung zu sorgen. Aus dieser verfassungsrechtlichen Pflicht ergeben sich keine einklagbaren Ansprüche, es sei denn der Anspruch auf Unterstützung des Arbeitslosen, falls die Vollbeschäftigung nicht herbeizuführen ist. Mehr ist wohl nicht erreichbar. Man kann nicht die gesamte Wirtschaftsordnung vom Recht auf Arbeit her umstürzen. Genügt Ihnen das als Präzisierung?

Partsch: Herr Rüfner hat in seinem Referat eine zwar richtige, aber nicht ganz deutliche Feststellung zu dem Recht auf Arbeit 
gemacht, indem er nämlich gesagt hat, daß die bisherige Arbeitslosenversicherung das Recht auf Arbeit in technisch weitest denkbarem Ausmaß sichert, und er hat dabei unterlassen zu erwähnen und hat wahrscheinlich unterstellt, daß wir sowieso daran denken: diese Sicherung wird gewährt, ohne gleichzeitig in das verfassungsrechtlich geschützte Recht der Freiheit der Arbeit einzugreifen. Wenn man das nämlich hinzusetzt, dann ist das, was Sie gesagt haben, völlig richtig, obwohl ich mir auf der anderen Seite natürlich sagen könnte: schauen Sie doch in die Länder, die eine Verteilung, eine dirigistische Verteilung der Arbeitskräfte haben - technisch kann es auch noch sehr viel weitergehen, aber dann ist es eben mit der Freiheit der Arbeit zu Ende. Sie haben jetzt von Marktwirtschaft gesprochen, aber es handelt sich ja hier nur um die Arbeit.

Dürig: Nur einen Satz dazu. Wenn Sie ein „Recht auf Arbeit" anerkennen würden, müssen Sie eine korrespondierende Pflicht des Bürgers annehmen, sich Arbeitseinsatz- und Arbeitslenkungsgesetzen zu unterwerfen. Von Zeiten des Booms und der Prosperität abgesehen, können Sie, solange Sie eine freie $\mathrm{Ar}$ beitsplatzwahl in der Verfassung stehen haben, auch nicht das Recht auf Arbeit verfassungsrechtlich garantieren.

Stern: $§ 1$ Stabilitätsgesetz enthält für den Staat die Rechtspflicht, für hohen Beschäftigungsstand zu sorgen, ohne dem Einzelnen einen Rechtsanspruch auf Arbeit zu gewähren.

Kopp: Ich möchte auf zwei andere Fragen nochmals kurz zurückkommen, die bereits am Anfang der heutigen Diskussion angeklungen sind und auch in den beiden Referaten am Anfang standen. Ich möchte die Fragen dahin präzisieren: 1. ob aus der besonderen Situation des Sozialrechts und der in diesem Bereich gewonnenen Erkenntnisse die Folgerung gezogen werden kann oder vielleicht sogar muß, daß der Unterschied zwischen dem öffentlichen und dem privaten Recht an Bedeutung erheblich verloren hat, und 2. ob, was eng damit zusammenhängt, der Verwaltungsakt ein Begriff ist, auf den heute teilweise oder ganz verzichtet werden kann oder sollte. Beide Fragen erscheinen mir wesentlich für die Entwicklung des allgemeinen Verwaltungsrechts; denn wenn man sie bejahen würde, müßte das allgemeine Verwaltungsrecht ganz erheblich umgebaut und zum Teil neu konzipiert werden. Das Sozialrecht ist gewissermaßen ein Paradebeispiel dafür, an dem diese Fragen geprüft werden können. 
Zur Frage, ob auf die herkömmliche Unterscheidung zwischen öffentlichem und privatem Recht verzichtet werden kann, wie es heute zum Teil, ich möchte fast sagen, modern geworden ist, möchte ich daran erinnern, daß das öffentliche Recht sich ja nicht zufällig, sondern in Antwort auf die besonderen Verhältnisse im Bereich der Verwaltung entwickelt hat und daß es eine Errungenschaft ist, um die manche andere Länder uns beneiden, wenn ich vor allem an den angelsächsischen Rechtskreis denke. Man sollte deshalb nicht leichthin darauf verzichten. Im Gegenteil glaube ich, daß die Unterscheidung von öffentlichem und privatem Recht auch - und gerade - für die Leistungsverwaltung von Bedeutung ist und auch hier ihre volle Berechtigung hat. Dasselbe gilt auch für den Begriff des Verwaltungsaktes. Auch insoweit sind die Probleme in der Leistungsverwaltung nicht wesentlich verschieden von den Problemen in der Eingriffsverwaltung, wenn man eimal unterstellt, daß überhaupt zwischen diesen beiden Bereichen eine strenge Scheidung möglich ist und nicht jede Versagung einer Leistung zugleich immer auch einen Eingriff in ein Recht oder einen rechtlich gesicherten Bereich darstellt.

Wir brauchen ein Recht, das uns die Massenerscheinungen der modernen Gesellschaft bewältigen hilft, das es uns insbesondere möglich macht, die hier auftretenden Fragen rasch und einfach und für alle Teile verbindlich mit der Wirkung der Rechtskraft oder Rechtsbeständigkeit $\mathrm{zu}$ klären und $\mathrm{zu}$ entscheiden, so daß Bürger und Staat auf die einmal getroffene Entscheidung vertrauen können. Wir brauchen insbesondere auch ein Recht, das die Gleichmäßigkeit der Anwendung gewährleistet. Das aber vermag letztlich nur das öffentliche Recht. Ich sehe insoweit keine grundlegenden Unterschiede zwischen der Leistungsverwaltung im Bereich der Sozialverwaltung und der Eingriffsverwaltung im überkommenen Sinn und möchte daher dafür eintreten, daß man doch auch an den alten und bewährten Begriffen festhält und insbesondere auch dem Verwaltungsakt seine zentrale Bedeutung beläßt, eben weil er das Instrument des öffentlichen Rechts ist, das den besonderen Verhältnissen hier Rechnung trägt. Das überkommene System des allgemeinen Verwaltungsrechts bedarf allenfalls einiger Ergänzungen, wie etwa der Ergänzung durch die Anerkennung des öffentlich-rechtlichen Vertrages - gegen dessen Ausdehnung durch die Rechtsprechung des Bundessozialgerichts ich freilich erhebliche Bedenken habe -, nicht eines völligen Neubaus oder Umdenkens.

Friauf: Ich möchte sehr nachdrücklich der Auffassung von Herrn Rüfner (Leitsatz 7) zustimmen, daß die sozialrechtlichen 
Rentenleistungen Staatsleistungen und keine Leistungen aus erzwungener Selbsthilfe seien und daß die Sozialversicherung als echte staatliche Einrichtung angesehen werden müsse. Diese Feststellung mag in unserem Kreis auf den ersten Blick beinahe als eine Banalität erscheinen. Sie ist aber keineswegs so selbstverständlich. Ich selbst habe das vor einigen Monaten sehr deutlich erlebt, als ich vor einem Kreis von Vertretern des Sozialrechts ein Referat über „Die Sozialversicherung im System der Finanzverfassung " halten durfte. Damals habe ich die These aufgestellt, es handele sich bei der Sozialversicherung um einen integrierenden Teil des staatlichen Finanzwesens und damit der Finanzverfassung im materiellen Sinne. Diese These ist in der Diskussion auf das erbittertste bekämpft worden. Man glaubte, im Versicherungsdenken stehen bleiben und die staatliche Beteiligung am Rentensystem mehr oder minder als eine zwar notwendige, aber nicht allzu bedeutsame Zutat abtun zu können. - Bei diesem Meinungsstreit geht es nicht nur um eine theoretische Frage. Er hat vielmehr für die Auslegung und Anwendung des Sozialrechts ganz erhebliche praktische Konsequenzen. Nicht zuletzt erlangt er auch unmittelbare Bedeutung für unser heutiges Thema, die Integration des Sozialversicherungsrechts in die allgemeine Verwaltungsrechtsordnung.

Dagegen halte ich es nicht für zwingend, wenn Herr Rüfner aus dem billigenswerten Leitsatz 7 ohne weiteres in These 8 die Behauptung ableitet: daraus folge, daß es für Rentenansprüche allenfalls einen abgeschwächten Eigentumsschutz geben könne. Es läßt sich nämlich nicht übersehen, daß die Voraussetzungen, unter denen das Bundesverfassungsgericht öffentlichrechtlichen Positionen Eigentumsschutz zubilligt, zumindest dem Anschein nach auch auf Rentenleistungen zutreffen können. Immerhin hat der einzelne Versicherte regelmäßig erhebliche Beiträge aus seinem Vermögen bzw. seiner Arbeitsleistung aufgebracht, um damit eine Anwartschaft zu erwerben. Gleichwohl meine ich, daß im Ergebnis Herrn Rüfner auch hier zuzustimmen ist. Gerade die Situation bei den sozialversicherungsrechtlichen Leistungen gibt uns einen akuten Anlaß, den verfassungsrechtlichen Eigentumsbegriff neu zu überdenken und von der doch nach wie vor stark in zivilrechtlichen Analogien befangenen Auslegung des Bundesverfasungsgerichts abzugehen. Mehr kann ich dazu im Augenblick nicht sagen, ohne das Thema des heutigen Tages zu überschreiten.

Gallwas: Ich möchte noch einmal hinweisen auf den zweiten Teil des Themas, auf das Allgemeine Verwaltungsrecht. Es 
ist ja doch so, daß der Aspekt der öffentlichrechtlichen Entschädigung etwas zu einseitig gewesen ist. Der Bürger, der in einem Sozialversicherungsverhältnis steht, kann ja auch von anderer Seite und in anderer Form als durch staatliche Eingriffe beeinträchtigt werden. Ich möchte meinen, man darf an einer Erscheinung nicht vorübergehen, die ich mal bezeichnen möchte als Beeinträchtigung der Versicherungserwartung. Gerade hier hätte man - da darf ich anknüpfen an das, was Herr Professor Stern gesagt hat - gerade hier hätte man eine Brücke erwartet zu dem neuerdings eine gewisse Rolle spielenden Plangewährleistungsanspruch. Ob sich nicht vielleicht doch so etwas ergibt wie ein Anspruch aus enttäuschter Versicherungserwartung ähnlich eben diesem Plangewährleistungsanspruch? Wie man überhaupt, wenn man mit Dauerrechtsverhältnissen arbeitet, daran zu denken hätte, ob nicht besondere Typen von Leistungsstörungen $\mathrm{zu}$ entwickeln wären, die vielleicht in Anlehnung an das Zivilrecht oder aber in besonderen Abwandlungen ihre Rolle spielen könnten.

Noch eine Arabeske: Herr Professor Henke, Sie sprachen davon, daß der Art. 3 GG eine Art Generalklausel des Rechts der sozialen Sicherung sei. Wenn ich Ihre Leitsätze durchlese, möchte ich fast meinen, Sie hätten eine andere Generalklausel, nämlich das Wesen des gegenwärtigen Staates. Ich möchte aber meinen, daß wir viel präziser argumentieren könnten, wenn wir, die Verknüpfung zum allgemeinen Verwaltungsrecht herstellend, nochmal nachfragen würden, wie denn dort der beeinträchtigte Bürger geschützt wird, um von dieser Seite her Reaktionsansprüche zu ermitteln. Wir könnten dann vielleicht von daher das Sozialversicherungsrecht in einen besseren Griff bekommen und in einen besseren Zusammenhang zum allgemeinen Verwaltungsrecht stellen.

Thieme: Wir gehen dann zum zweiten Themenbereich über, also zum organisatorischen Teil.

Schnorr: Die Selbstverwaltung der Sozialversicherung in Osterreich ist ein ganz eigenartiges System. Unser österreichisches Bundes-Verfassungsgesetz rechnet nämlich aufgrund der Generalklausel des Art. 102 die Sozialversicherung zur unmittelbaren Staatsverwaltung. Das österreichische Verfassungsrecht geht ja sehr sparsam mit der Selbstverwaltungsinstitution um. Wir kennen eigentlich nur die Selbstverwaltung der Gemeinden. Die Sozialversicherung ist in erster Linie unmittelbare Staatsverwaltung, und zwar mittelbare Bundesverwaltung, in der Mittelinstanz also ausgeführt durch die Länder. Aber 
nach Art. 102 Abs. 2 des Bundes-Verfassungsgesetzes 1920 kann der Bund instanzenmäßig durchgängig die Sozialversicherung auch in bundeseigene Verwaltung übernehmen. Hier haben wir doch einen ganz wesentlichen Unterschied. Der österreichische Verfassungsgesetzgeber hat gar nicht daran gedacht, irgendwie auch substantiell die Sozialversicherung aus dem allgemeinen Verwaltungsrecht herauszunehmen. DaB trotzdem auch in Osterreich durch das Allgemeine Sozialversicherungsgesetz die Selbstverwaltung eingeführt worden ist, verdanken wir der Normativität des Faktischen. Der Verfassungsgerichtshof arbeitet hier mit einem Trick. Er sagt: Eigentlich sei es verfassungswidrig, daß die Sozialversicherung nach dem Selbstverwaltungsprinzip aufgebaut ist. Aber da die Selbstverwaltung in der Sozialversicherung historisch bedingt sei, habe Art. 102 B-VG dieses Selbstverwaltungsprinzip stillschweigend rezipiert. Und dann kommt aber wieder ein Bruch. Um nun zurückzukehren zum Schutz des Versicherten nach allgemeinem Verwaltungsrecht, qualifiziert der Verfassungsgerichtshof die Sozialversicherungsträger als Behörden und die Satzungen der Krankenkassen als Verordnungen, weil nämlich nach österreichischem Verfassungsrecht Satzungen, auch wenn sie von juristischen Personen des öffentlichen Rechts erlassen werden, nicht der Verfassungskontrolle durch den Verfassungsgerichtshof unterliegen, wohl aber Verordnungen. Dieses ganze, in sich bestimmt nicht schlüssige System des österreichischen Sozialversicherungsrechts zeigt aber doch, daß es viel mehr zum allgemeinen Verwaltungsrecht neigt, als dies in Deutschland der Fall ist, wo ja gar kein Zweifel besteht, daß Sozialversicherung echte Selbstverwaltung ist.

Pfeifer: Der Herr Vorredner hat schon mit Recht darauf hingewiesen, daß in der österreichischen Verfassung die Selbstverwaltung zu kurz gekommen ist. Praktisch hat sie nur die Gemeindeverwaltung in Grundzügen geregelt. Aber niemand hat zur Zeit, als das Bundes-Verfassungsgesetz geschaffen wurde, daran gezweifelt, daß z. B. die Tätigkeit der verschiedenen Kammern auch eine berufliche Selbstverwaltung war, und auch Sozialversicherungsträger haben schon damals bestanden. Der Verfassungsgerichtshof vertritt die Versteinerungstheorie: Was damals schon Selbstverwaltung war, das ist Selbstverwaltung geblieben. Das gehört natürlich in der Verfassung entsprechend normiert, um Klarheit und Rechtssicherheit zu schaffen. Das ist die verfassungsrechtliche Seite.

Dazu habe ich noch zu sagen, daß sich Osterreich im sogenannten Osterreichischen Staatsvertrag von 1955 in Art. 6 verpflichtet hat, alle Bewohner des Staates der Menschenrechte und 
Grundfreiheiten teilhaftig werden zu lassen. Wenn man die Allgemeine Erklärung der Menschenrechte, die ja der Ausgangspunkt der völkerrechtlichen Kodifikation der Menschenrechte und Grundfreiheiten ist, durchliest, so findet man dort sehr viele Artikel, die soziale Rechte, insbesondere das Recht auf soziale Sicherheit und auf soziale Fürsorge gewährleistet sehen wollen.

Also durch den Staatsvertrag hat Österreich die Verpflichtung übernommen, das Sozialversicherungssystem oder ein gleichwertiges System der sozialen Sicherheit beizubehalten. Dieselbe Verpflichtung enthält auch Art. 12 der Europäischen Sozialcharta, die in Osterreich im Jahre 1969 parlamentarisch genehmigt und seither auch im BGBl. kundgemacht worden ist.

Es darf nur nebenbei bemerkt werden, daß sich die österreichische Sozialversicherung ständig ausgedehnt hat und sich nicht mehr nur auf die unselbständig Erwerbstätigen erstreckt, sondern auch schon auf große Gruppen selbständig Erwerbstätiger. So haben wir eine eigene gewerbliche Selbständigenversicherung in der Form der Kranken- und Pensionsversicherung. Auch die selbständigen Landwirte sind schon in die Sozialversicherung einbezogen. Es gibt eine eigene Notarversicherung für die Notare und Notariatsanwärter. Es haben sich die Ärzte ihre eigene Pensionsversicherung im Rahmen ihrer Kammern geschaffen, und der Prozeß schreitet immer weiter fort, sodaß man die schon zählen kann, die nicht unter irgendeinen Zweig der Sozialversicherung fallen.

Was mich zunächst veranlaßt hatte - wenn das vielleicht auch mehr zurücktritt - mich zu Wort zu melden, war, daß Herr Kollege Rüfner anfangs wenigstens nur zwei Systeme unterschieden hat: Fürsorge und Versorgung. Aber es hat schon ein Vorredner ganz richtig von der Trias gesprochen. Man muß eben unterscheiden: Fürsorge, dann beitragsfreie Staatsbürgerversorgung, wie sie ja in ausländischen Staaten verwirklicht war und zum Teil noch ist, und drittens die Sozialversicherung, die eben auf der Beitragsleistung der unmittelbar beteiligten Arbeitgeber und Arbeitnehmer und ihrem Mitspracherecht beruht. Das gerade war der Gegenstand meiner Habilitationsschrift „Grundsätze und Probleme des österreichischen Sozialversicherungsrechtes" (1934).

Ich wollte also sagen, da $\beta$ die Trias richtig ist. Es sind drei Zweige der öffentlichen Wohlfahrtspflege und -verwaltung: Erstens die öffentliche Fürsorge, die individuelle Hilfsbedürftigkeit voraussetzt und nur unter dieser Voraussetzung aus öffentlichen Mitteln gewährt wird. Zweitens die Versorgung aus 
öffentlichen Mitteln entweder in der Form der schon erwähnten allgemeinen beitragsfreien Staatsbürgerversorgung, wie sie in einzelnen Staaten verwirklicht war oder ist, oder sie ist wie in der Bundesrepublik und in Osterreich nur auf bestimmten Gebieten verwirklicht, wie etwa dem der Kriegsopferversorgung, bei welcher der Betreffende nicht im vorhinein für den Fall seiner dauernden Körperbeschädigung oder seines Todes im Kriege finanzielle Beiträge geleistet hat, aber doch einen Rechtsanspruch auf eine bestimmte Versorgungsleistung für sich oder seine Hinterbliebenen hat. Denn der Versorgungsberechtigte der Kriegsopferversorgung hat ja ein Opfer für Volk und Heimat gebracht.

Der dritte Zweig ist eben die Sozialversicherung, die von Anfang an von Beitragsleistungen der Arbeitgeber und Arbeitnehmer ausgegangen ist. Wenn man dies geschichtlich zurückverfolgt, so geht das im deutschen Recht auf die Fürsorgepflicht des Dienstherren zurück.

Thieme: Das betrifft allerdings nicht so sehr den Themenkreis 2 . Ob Sie das dann vielleicht wieder aufgreifen an seinem Orte? Wir sprechen im Augenblick nur über Organisation, und wir sollten dann doch vielleicht im Interesse der Förderung unserer Diskussion dabei bleiben.

Pfeifer: Selbst- und Staatsverwaltung gehören zu der Frage der Organisation, und dazu wollte ich auch noch ein Wort sagen. Ich habe anfangs schon gesagt, daß die Selbstverwaltung in unserer Verfassung viel zu kurz gekommen ist. Das ist auf Kelsen zurückzuführen, der die Selbstverwaltung nur als spezifisch organisierte Staatsverwaltung aufgefaßt hat und noch heute seine Anhänger hat, obwohl ich diese Auffassung nicht teile.

In Wirklichkeit gibt es viel mehr Selbstverwaltung als dies verfassungsrechtlich anerkannt und gewährleistet ist. Jedenfalls habe ich in meiner erwähnten Habilitationsschrift die Sozialversicherungsträger als Selbstverwaltungskörper qualifiziert, denn sie sind mit eigener Rechtsfähigkeit ausgestattet, von den Sozialpartnern (Dienstnehmer und Dienstgeber) getragene selbständige Anstalten, die eine eigene Finanzwirtschaft haben, denn sie haben ja eigene Einnahmen und eigene Ausgaben, und sie unterstehen nur dem Aufsichtsrecht des Staates. Daß sie dann vom Staat zusätzlich, insbesondere auf dem Gebiet der Pensionen, in erheblichen Maße Beihilfen erhalten, das ändert nichts daran, daß sie ihrer Entstehung und ganzen Struktur nach Selbstverwaltungskörper sind. 
Bemerken möchte ich noch zuletzt, daß die Sozialversicherungsträger in Osterreich ebenso wie die Fürsorgeträger und die Versorgungsämter in erheblichem Maße hoheitliche Verwaltung ausüben. Das zeigt sich in ihrem generellen Satzungsrecht und ganz besonders in ihrem individuellen Bescheidrecht, das sie in Verwaltungs- und Leistungssachen gesetzmäßig ausüben. Hierbei haben sie im allgemeinen nach den Bestimmungen des Allgemeinen Verwaltungsverfahrensgesetzes vorzugehen ( 357 ASVG.). Damit kann ich mich im Augenblick begnügen.

Ipsen: Nur eine kurze Bemerkung zu der These III,1 von Herrn Henke: paradigmatisch für die Selbstverwaltung sei heute nicht mehr das Kommunalrecht, sondern eher das Sozialversicherungsrecht. In dieser Ubersteigerung halte ich diese These für unbegründet. Ich würde sie sogar für unbegründet halten, wenn sie schlicht zum Ausdruck bringen wollte, daß in der Sozialversicherung Selbstverwaltung stattfinde. Gewiß geschieht das in einigen Bereichen sehr unterschiedlich. Herr Rüfner hat auf die Differenzierungen hingewiesen. Aber das Wesentliche einer Selbstverwaltung, wie wir es etwa bei Kammerorganisationen verschiedener Berufsstände noch kennen, findet dort nicht statt, und dies schon gar nicht in dem Sinne, in dem heute - wenn überhaupt noch - Selbstverwaltung im kommunalen Bereich stattfindet. Die Selbstverwaltungsfigur ist in der Sozialversicherung eine organisatorische Hülle. Im finanziellen Bereich funktioniert die Eigenverantwortung nur noch rudimentär, und im wesentlichen ist die Einkleidung in Selbstverwaltungsfiguren herzuleiten und auch heute noch gerechtfertigt aus der Separierung vom Staat. Das ist das entscheidende Element. Das berechtigt aber nicht zu einer so betonten Feststellung, wie sie in der These III,1 hervortritt.

Häberle: Lassen Sie mich der - m. E. vernachlässigten spezifisch verfassungsrechtlichen Problematik nachgehen, die sich für den von Herrn Henke in seinen Thesen III entwickelten Selbstverwaltungsbegriff stellt. Es geht um drei Fragen:

Erstens: Kann man wirklich einen Selbstverwaltungsbegriff so allgemein „vor die Klammer ziehen“, wie das im ersten Satz der These III geschehen ist, ohne das GG zu befragen? Hier scheint ein Selbstverwaltungsbegriff konzipiert zu sein, der vor der Verfassung steht. Richtiger müßte man sich doch wohl fragen, ob für die einzelnen jeweils unterschiedlich ausgestalteten Formen der Selbstverwaltung die Verfassung Direktiven und (Gemeinwohl) Kompetenzen gibt oder gewisse Organisa- 
tions- und Verfahrensprinzipien (z. B. Offentlichkeit) fordert: nämlich im Sozialstaats-, im Rechtsstaats- und Demokratieprinzip, nicht zuletzt unter dem Gesichtspunkt des Kulturstaats. Mag er formell auch nur in Art. 3 der Verfassung von Bayern als Staatsziel und Gemeinwohlauftrag zum Ausdruck kommen: die modernen Erscheinungsformen sozialer Kulturverwaltung als kultureller Selbstverwaltung im Bereich des Offentlichen, z. B. Deutsche Forschungsgemeinschaft, Documenta $\mathrm{GmbH}^{1}$ ) etc., stehen in kulturverfassungsrechtlichen Zusammenhängen. Sie bringen die Eigenart einer Form der „Selbstverwaltung" (Autonomie) zum Vorschein. Mit anderen Worten: Von einem vorverfassungsrechtlichen, staatstheoretisch allgemeinen Selbstverwaltungsbegriff kann $\mathrm{m}$. E. nicht ausgegangen werden.

Die zweite Frage: Gibt es wirklich einen, den Selbstverwaltungsbegriff, der erst hernach differenziert wird, oder ist nicht von vornherein differenziert anzusetzen, je nachdem vor welchen öffentlichen Aufgaben "die" Selbstverwaltung steht und in welchem Sozialbereich dies geschieht? Man denke an die soziale Selbstverwaltung der Tarifpartner (Art.9 Abs. 3 GG) und manche neue Erscheinungsformen im Rahmen der „konzertierten Aktion", an Aufgaben im Bereich des wohl stärker staatlichen Sozialversicherungsrechts oder im Bereich des öffentlichen, freiheitlichen Kulturverfassungs- und -verwaltungsrechts (z. B. Art. 5 Abs. 3, 12 Abs. 1,20 Abs. 1, 91 a Ziff. 1 und $91 \mathrm{~b} \mathrm{GG)}$ in ihrer eigentümlichen Verknüpfung von Freiheit vom (seinerseits offenen) Staat und (privater und öffentlicher) Freiheit durch den Staat, die autonome und doch "geplante" Zonen schaffen. Die im Bildungswesen erkennbaren neuen Formen der Selbstverwaltung sind Selbstverwaltung der und durch Öffentlichkeit, so wie (gegen den Staat erkämpfte) Selbstverwaltung überhaupt oft in einem spezifischen Offentlichkeitsbezug gestanden haben dürfte.

Endlich die dritte Frage: Stellt uns nicht sowohl der Begriff der "sozialen Selbstverwaltung" als auch die von Herrn Henke präsentierte Fülle moderner differenzierter Erscheinungen anderer Selbstverwaltungsformen die Aufgabe, die Verwaltungsfunktion insgesamt neu zu überdenken - als öffentliche Funktion -, weil hier öffentliche Aufgaben im institutionell garantierten öffentlichen Bereich und zum Teil in öffentlicher Freiheit wahrgenommen werden? Das hat Konsequenzen auch für die Staatsverwaltung selbst. Thre "Staatlichkeit" ist von der

1) Dazu jüngst Preuß, Zum staatsrechtlichen Begriff des Offentlichen, 1969, S. 67 f., 70 f., 195. 
grundgesetzlichen Offentlichkeit her neu zu überdenken: unter dem Gesichtspunkt einer unterschiedlichen Entstaatlichung des Offentlichen. Und: die staatliche Verwaltungsfunktion selbst wird zunehmend öffentlich. Ein aktuelles Stichwort hat Herr Ipsen gegeben: „Ver-Offentlichung der Daseinsrisiken“. D. $h$. hier entstehen öffentliche Aufgaben, die teils staatlich, teils in abgestuften Selbstverwaltungsformen sachgerecht erfüllt werden. Das wirft die Frage auf, was denn die öffentliche Verwaltungsfunktion als primär öffentliche (Gemeinwohl) Funktion und erst sekundär staatliche Funktion in unserer res publica angesichts dieser neuen Entwicklung ist. Dies umso mehr, als Herr Henke in III, 4 mit großem Recht auf die Skala von Ubergängen zwischen reiner Staatsverwaltung und rein gesellschaftlicher Eigenverwaltung hingewiesen hat. Die unterschiedliche „Kombination staatlicher und gesellschaftlicher Wahrnehmung öffentlicher Aufgaben" bestätigt sich durch einen Blick auf die modernen Gesetze. In deren Tatbeständen finden sich Verfahrens- und Organisationsregelungen, die zunehmend und durchaus grundgesetzkonform "die Offentlichkeit" in Gestalt von Anhörungspflichten und -rechten und sonstigen Beteiligungsformen betroffener Einzelner oder privater und öffentlicher Interessenverbände, z. B. in Form von Bekanntmachungsund Veröffentlichungspflichten hereinholen (etwa in Raumordnungs- und Landesplanungsgesetzen sowie im Stabilitätsgesetz, überhaupt im Bereich der "planification“) und zur Kooperation "zwingen". Verwaltung und Staat werden insofern (in der Konkretisierung öffentlicher Interessen) öffentlich. Und Herr Dagtoglou hat in seiner Untersuchung zum Privaten als „Fachmann und Interessenvertreter" in der Verwaltung das Seine getan, um zu der Frage zu zwingen, in welchem grundsätzlichen Wandel die öffentliche Verwaltungsfunktion als öffentliche und als Gemeinwohlfunktion überhaupt begriffen ist.

Weber: Zum Organisatorischen nur eine kurze ergänzende Bemerkung: Ich möchte Herrn Ipsen darin zustimmen, daß Herr Henke seine These über den paradigmatischen Charakter dieses oder jenes Selbstverwaltungsbereichs ein wenig forciert hat. Selbstverwaltung in der Sozialversicherung und Selbstverwaltung im Kommunalwesen sind wohl nur bedingt vergleichbar. Tatsache ist, daß diejenigen, die in der Sozialversicherung tätig sind, auf die Selbstverwaltung in der Sozialversicherung sehr großen Wert legen. Tatsache ist ferner, daß sich die Vorstellungen von Selbstverwaltung, die in der Sozialversicherung zur Verwirklichung drängen, weitgehend an dem allgemeinen Begriff von Selbstverwaltung orientieren, und zwar im Prinzipiellen wie auch im Technischen. 
Es wurde schon darauf hingewiesen, daß die Reichsversicherungsordnung ein altes Gesetz ist, das seine Technik entwickelt hat, bevor wir ein modernes Verwaltungsrecht bekommen haben. Was darin über Selbstverwaltung ausgesagt ist, läßt sich mit modernen Selbstverwaltungstechniken nur schwer vergleichen und ist im einzelnen vielfach streitig. Immerhin hat das vor einigen Jahren erlassene Bundesversicherungsamtsgesetz, dem das Bundesversicherungsamt seine Errichtung verdankt, eine Reihe von altmodischen Bestimmungen der Reichsversicherungsordnung durch einen neuen Kodex ersetzt, der die Anlehnung an modernere Selbstverwaltungsformen sucht. Der Gesetzgeber hat das veraltete Selbstverwaltungs- und Aufsichtsrecht der früheren Reichsversicherungsordnung an unsere modernen Vorstellungen von Selbstverwaltung angepaßt und hat damit ein Bekenntnis zu unserem Thema abgelegt, nämlich das ältere Recht der sozialen Sicherung in den Zusammenhang des modernen allgemeinen Verwaltungsrechts hineinzuziehen, damit bei ihm mit denselben Begriffen und Techniken gearbeitet werden kann, die in allen Rechtsgebieten herrschend sind, und das Spezialistentum der Sozialversicherungspraktiker in die allgemeine Verwaltungspraxis eingebunden wird.

Selbstverwaltung ist hier übrigens ein ambivalenter Begriff. Das eine Mal ist damit die Selbstverwaltung der Sozialversicherungsträger durch die beiden Sozialpartner gemeint. Insoweit hat wohl die These von Herrn Henke am ehesten Berechtigung, wenn er Selbstverwaltung als Mobilisierung aktueller, wirklich noch vorhandener organisierter gesellschaftlicher Formationen zur Ubernahme einer Verwaltungsverantwortung versteht. Der Gegensatz der kommunalen Selbstverwaltung zur staatlichen Selbstverwaltung ist heute in der Tat nicht mehr so manifest, wie er sich in der Gegenüberstellung der Sozialpartnerverbände und des Staates in der Sozialversicherung zeigt.

Die andere Seite der Sache ist die, daß unabhängig von dieser Art sozialpartnerschaftlicher Selbstverwaltung auch noch eine eigene Verantwortung der verschiedenen Sozialversicherungsträger als solcher besteht, nämlich eine eigene Sachverantwortung für die den Sozialversicherungsträgern gestellten Aufgaben. Allerdings ergibt sich hier, und dies besonders bei den Rentenversicherungsträgern, die eigentümliche Situation, daß sie in der Hauptsache eine vollkommen staatsgesetzlich durchnormierte Materie zu exekutieren haben. Insoweit kann von Selbstverwaltung wenig die Rede sein, sondern nur vom Vollzug einer staatlichen Aufgabe. Immerhin haben die Sozialversicherungsträger daneben ihren eigenen Apparat zu unterhalten und können sie mancherlei auch mit freien Mitteln ins Werk setzen. 
Gerade die Diskussion der letzten Monate hat gezeigt, daß etwa bei den Landesversicherungsanstalten die freiwilligen Aufgaben und Leistungen eine nicht geringe Rolle spielen. Es ist das besonders daran deutlich geworden, daß die einzelnen Landesversicherungsanstalten im Bundesgebiet eine unterschiedliche Leistungskraft aufweisen und da $\beta$ zwischen ihnen in der Erfüllung freiwilliger Leistungen ein starkes Gefälle besteht. Daraus sind nicht nur die Bemühungen hervorgegangen, die Träger der Arbeiterrentenversicherung mit Hilfe der Mittel der Angestelltenversicherung zu sanieren, sondern auch innerhalb der Landesversicherungsanstalten selbst einen Ausgleichsverbund zu schaffen, damit sie auch in ihren freiwilligen Leistungen ungefähr den gleichen Standard einhalten können. In diesem Bereich sind sehr erhebliche Momente von Selbstverwaltung enthalten.

Allgemein läßt sich sagen, daß bei den in der Sozialversicherung Tätigen das Bedürfnis offensichtlich lebhaft ist, dieses zunächst selbständig gewachsene Rechtsgebiet organisationsrechtlich und funktional den Anschluß an das allgemeine Verwaltungsrecht finden zu lassen, und da $B$ dieses Bedürfnis auch in einer ganzen Reihe von Vorgängen sich Wirkung verschafft.

Podlech: Die Frage der Selbstverwaltung scheint mir bisher kontrovers geblieben zu sein. Ich bin der Auffassung, daß die Problematik der Selbstverwaltung nicht dem traditionellen Schema "Staat - Gesellschaft" eingegliedert werden sollte. Herr Henke vermißt eine neue Grundlage der Selbstverwaltung, nachdem die alte Grundlage, die durch Stein und Gneist geschaffen wurde, nicht mehr tragfähig ist. Diese neue Grundlage kann meines Erachtens nur durch eine Funktionsanalyse geleistet werden. Wird einem sozialen Untersystem Selbstverwaltung gewährt, so erhöht dies möglicherweise die Lernfähigkeit des politischen Gesamtsystems. Rechtskybernetisch gesprochen wird ein engerer Regelkreis erzeugt gegenüber dem allgemeinen Regelkreis, der vom Bürger über Wahlen zum Parlament und zur Regierung und über Gesetze und Verordnungen zur Verwaltung läuft und dann in der Wirkung wieder beim Bürger ankommt. Dieser sehr unspezifische Rückkopplungskreis wird in der Selbstverwaltung enger gefaßt. Selbstverwaltung hat meiner Ansicht nach folgende Funktionen: Sie erhöht erstens die Chance einer rascheren und spezifischeren Reaktion; sie macht zweitens nicht rechtlich sanktionierte Kommunikationsbahnen überflüssig - etwa die einer Lobby - ; sie entlastet schließlich das politische Gesatmsystem von den Problemen des Untersystems, dem die Selbstverwaltung gewährt wurde, sie absorbiert also drittens politische Problematik. Unter 
solchen Gesichtspunkten könnte die Grundlage der Selbstverwaltung wieder neu theoretisch durchdacht werden. Die Unterschiede, die sich dabei auf dem einen oder anderen Gebiet ergeben können, werden bereits in dem Innenbereich des Sozialversicherungsrechts sichtbar. Herr Rüfner hat betont, daß die Selbstverwaltung in den einzelnen Selbstverwaltungsträgern von unterschiedlicher Effektivität ist. Ich glaube, es läßt sich von daher sehr schön zeigen, daß etwa die Effektivität der Selbstverwaltung der Krankenversicherung nicht sehr groß werden kann, während sie z. B. bei den Berufsgenossenschaften erheblich größer ist, besonders seit Erlaß des Unfallversicherungs-Neuregelungsgesetzes, das den Berufsgenossenschaften sehr viele Möglichkeiten gegeben hat, präventiv tätig zu werden, etwa im Bereich der Unfallverhütungsvorschriften. Diese Utberlegungen decken sich zum Teil mit denjenigen, die Herr Weber gerade angestellt hat.

Henke: Wenn ich zwischendurch darauf eingehen darf, dann möchte ich sagen, daß die These sicherlich forciert ist - das haben Thesen ja an sich, besonders, wenn sie kurz sind, worum ich mich hier sehr bemüht hatte. Ich glaube allerdings nicht, daß man damit auskommt, wenn man sagt, Selbstverwaltung sei Separierung vom Staatlichen. Das ist bei der kommunalen Selbstverwaltung einmal so gewesen, und das war sicherlich ihr Sinn. Aber ich meinte hier an die Stelle dieser Grundlage eine andere setzen zu müssen. Kooperation zwischen Staat und Gesellschaft ist das, was nun die Selbstverwaltung ausmacht. Ich würde mit mir darüber reden lassen, ob man nicht für dieses Phänomen einen anderen Begriff nehmen sollte, um den der Selbstverwaltung stehen zu lassen für das, was sie bisher war. Worauf es mir vor allem ankam, waren die Differenzierungen - das betrifft das, was Herr Häberle sagte. Ich habe nicht eine Definition an den Anfang gestellt und dann differenziert, so da $\beta$ Sie also mit dem umgekehrten Weg eine Alternative vorgeschlagen hätten, sondern ich wollte in diesen Begriff der Selbstverwaltung die Differenzierungen sozusagen gleich mithineinnehmen. Selbstverwaltung ist eine Kooperation mit ganz unterschiedlichen Gewichten des Anteils der verfaßten staatlichen Amtsgewalt und des Anteils der Verbände durch ihre Tätigkeit in Kompromiß und Koordination. Herr Häberle hat ferner gesagt, daß die Verwaltungsfunktion neu überdacht werden müsse. Das hängt offenbar damit zusammen, daß wir beide das Buch von Preuß über den staatsrechtlichen Begriff des Offentlichen gelesen haben. Das kann man natürlich hier nicht ausbreiten. Es hat mir insofern Eindruck gemacht, als ich 
mich zu der Frage, ob der Staat ein Monopol des Offentlichen hat, durch Herrn Preuß durchaus habe belehren lassen. Er hat es sicher nicht, aber daß man deswegen die Unterscheidung von Staat und Gesellschaft und damit von Staatsverwaltung und von gesellschaftlicher Eigenverwaltung fallen lassen könne, das glaube ich nicht. Man sollte sie allerdings entsprechend den praktischen Gegebenheiten der Kooperation beider bei der Bewältigung bestimmter öffentlicher Aufgaben in einem Begriff zusammenfassen, heiße er nun Selbstverwaltung oder heiße er anders.

Zu Herrn Podlech muß ich sagen: die Sprache, in der er gesprochen hat, ist hier ja nicht die übliche. Ich habe sie inzwischen verstehen gelernt, seit ich einer wirtschafts- und sozialwissenschaftlichen Fakultät angehöre. Sich damit wirklich auseinanderzusetzen, würde hier viel zu weit führen. Das gehört in das Kapitel "Sozialtechnologie oder Rechtswissenschaft", zu dem ich mich an anderer Stelle geäußert habe (Der Staat 1969, S. 1 ff.).

Vogel: Herr Henke hat uns heute mit freundlicher Miene ein Geschenk auf den Tisch gelegt, über dessen Sprengkraft (in Megatonnen gerechnet) wir uns noch kaum eine rechte Vorstellung machen können. Er hat es eben noch einmal sehr deutlich gesagt, daß er die Selbstverwaltung im herkömmlichen Sinne für tot ansieht; bei realistischer Betrachtung wird man ihm darin wohl folgen müssen. Gleichzeitig hat er etwas Neues an die Stelle gesetzt, was er nun seinerseits "Selbstverwaltung" genannt hat: Verwaltung öffentlicher Aufgaben durch die Gliederungen der Gesellschaft, vor allem, wenn nicht ausschließlich, durch die Verbände. Ich muß gestehen, daß ich im Moment nicht übersehe, was alles aus dieser neuen Konzeption folgt, und möchte nur darauf aufmerksam machen, da man jedenfalls diese Konsequenzen - ich unterstelle natürlich, daß das Herr Henke getan hat - sehr gründlich überdenken sollte.

Ergänzend nur eine Bemerkung: Herr Rüfner, der freilich den Begriff der Selbstverwaltung sehr anders versteht, hat für die einzelnen Sozialversicherungsleistungen gemeint, sie seien heute im Grunde weitgehend staatliche Leistungen. Wenn das in der Tat richtig ist, dann wäre die rechtspolitische Konsequenz doch wohl die, daß man die Pluralität der verschiedenen Sozialversicherungsträger mit ihrem immensen Verwaltungsaufwand zugunsten einer einheitlichen Volksversicherung abbauen müßte. Demgegenüber gibt die Henkesche These dieser Pluralität doch immerhin einen Sinn (oder besser: sie weist auf einen denkbaren Sinn der bestehenden gesetzlichen Rege- 
lung hin). Und das scheint mir, bei allen Bedenken, doch zunächst und vorläufig für diese These von Herrn Henke zu sprechen.

Rüfner: Eine Kleinigkeit gleich, Herr Vogel: Ich habe deutlich differenziert zwischen der Rentenversicherung, dem Aufgabenkreis der Bundesanstalt für Arbeit und der Krankenund Unfallversicherung. Es ist allerdings richtig, daß die Einheitsversicherung die Konsequenz aus meinen Thesen zur Rentenversicherung wäre. Ich meine, soweit wir heute die gesetzliche Rentenversicherung haben, würde die einheitliche Organisation nichts Substantielles ändern und in der Logik der Entwicklung liegen. Für Kranken- und Unfallversicherung gilt anderes, das möchte ich festhalten.

Frowein: Ich habe die Frage an beide Referenten im Zusammenhang mit dieser Selbstverwaltungsorganisation, nämlich ob wir hier nicht doch in Bereiche kommen, in denen die Gleichheitsproblematik eine Rolle spielen muß. Es wurde vorhin schon dargelegt, daß der Freiheitsvorrang, aus dem Herr Henke unmittelbar das Selbstverwaltungsgebot ableitet, problematisch ist, und ich würde unterstützen, was Herr Scheuner dazu gesagt hat. Ich habe aber eine andere Frage, herkommend von den Gleichheitsverbürgungen der Verfassung und dem Art. 28 Abs. 3, der sowohl die Gleichheitsverbürgung als die Sozialstaatsklausel unter die Gewährleistung des Bundes stellt. Ist es irrelevant, ob Kranken- und Unfallversicherung unterschiedliche Leistungen, was zum Teil wohl immer noch der Fall ist - Herr Weber deutete es an - , für dieselben Versicherungsfälle darbieten? Wir sind uns alle darüber klar, daß Art. 3 nicht unmittelbar angewendet werden kann in Fällen, in denen unterschiedliche Körperschaften oder Anstalten des öffentlichen Rechts Leistungen im Wege der Selbstverwaltung gewähren. Aber gibt es hier nicht aus Art. 28 Abs. 3 und dem Sozialstaatsprinzip eine Gewährleistungspflicht des Staates, mindestens zu verhindern, daß diese Unterschiede ein unerträgliches $M a ß$ annehmen, und wenn ja, inwieweit ist das zu beachten?

Rüfner: Herr Frowein, in gewissem $\mathrm{Ma}$ ist das Problem durch den Gesetzgeber gelöst. Es gibt Pflichtleistungen der Krankenkassen, Mindestleistungen der Unfallversicherung. Nur für die Zusatzleistungen hat die Selbstverwaltung Spielraum. Ich glaube daher, das Problem, das Sie ansprechen, ist nicht akut. Ich gebe Ihnen gerne $\mathrm{zu}$, es könnte akut werden, wenn man das ganze umkrempelte. 
Scheuner: Der Verfassungsgesetzgeber rechnet in der berühmten Formel des Art. 72 Abs. 2 Ziffer 3 GG mit solchen wirtschaftlichen und sozialen Gegebenheiten. $\mathrm{DaB}$ aus dieser Formel, die soziale Verschiedenheiten voraussetzt und daher den Gesetzgeber einengen wollte, hinterher ein Verfassungsgebot wird, die Verhältnisse einheitlich zu regeln, ist eine Bewußtseinsänderung unserer Verfassungsauslegung und unseres Verfassungsverständnisses, die einmal ein sehr interessanter Beobachtungsgegenstand für einen Verfassungswandel darstellen könnte.

Thieme: Ich schlage vor, daß wir noch zu dem dritten Gegenstand übergehen, zur Frage der Handlungsformen. Da darf ich zunächst Herrn Schnorr wieder aufrufen.

Schnorr: Vielleicht ist hier ein ganz besonderer Hinweis angebracht. Wir in Osterreich gehen von der Einheit des Verwaltungsrechts aus, d.h. - und Herr Kollege Marcic hat es gestern schon angedeutet - wir sind etwas traditionell nicht nur in den Grundrechten, sondern auch im allgemeinen Verwaltungsrecht. Wir sind in der glücklichen Lage, schon seit längerer Zeit das Verwaltungsrecht im Allgemeinen Verwaltungsverfahrensgesetz (AVG) kodifiziert zu haben. Gemäß §357 des Allgemeinen Sozialversicherungsgesetzes finden die Vorschriften des AVG subsidiär auch auf Sozialversicherungsangelegenheiten Anwendung. Insofern haben wir mit den Formen gar keine allzu großen Schwierigkeiten; denn der §357 des Allgemeinen Sozialversicherungsgesetzes, den Herr Rüfner heute vormittag zitiert hat, ist eigentlich nur eine der leges speciales, die in den sozialversicherungsrechtlichen Vorschriften enthalten sind. Sofern eine solche lex specialis im Sozialversicherungsrecht nicht eingreift, ist der Versicherte, wie übrigens auch der beitragzahlende Arbeitgeber, in voller Hinsicht durch das Allgemeine Verwaltungsverfahrensgesetz geschützt. Dies alles fungiert unter dem großen Dach des Art. 18 des Bundes-Verfassungsgesetzes. Danach sind die Verwaltungsbehörden strikt an das Gesetz gebunden. Das bedeutet ganz etwas anderes als bei Ihnen, nämlich eine sehr starke Ermessenseinschränkung. Ich glaube, auch darin ein Indiz dafür zu sehen, daß in Osterreich die Frage, ob das Sozialversicherungsrecht aus dem Instrumentarium des Verwaltungsrechts auszuklammern ist, gar nicht so akut ist. Sie ist auch nirgends bisher aufgetreten. Vielleicht wird durch diese interessante Diskussion wissenschaftlich eine Infiltration neuer Ideen nach Österreich stattfinden. Ihre Umsetzung in die Praxis wird schwer sein. 
Denn infolge der strikt interpretierten Bindung allen Verwaltungshandelns an das Gesetz können wir nicht einfach sagen, das Instrumentarium paßt nicht mehr, wir erfinden eine neue Theorie, sondern wir haben ein ziemlich starres positives Recht, auch was das allgemeine Verwaltungsrecht und das Sozialversicherungsrecht angeht. Wir müssen daher stets das Gesetz ändern, wenn wir neue Ideen, wie sie Herr Rüfner und Herr Henke heute vorgetragen haben, durchsetzen wollen.

Weber: Hierzu möchte ich nur einen kleinen ergänzenden Hinweis bringen. Es handelt sich ja jetzt um die Handlungsformen im Rahmen des Themas. In diesem Zusammenhang möchte ich für einen Moment die Aufmerksamkeit auf die Rolle der Sozialgerichtsbarkeit hinlenken. Früher wurden Versicherungsfälle in den Oberversicherungsämtern und im Reichsversicherungsamt von Spezialisten des Versicherungswesens entschieden, die weniger die Neigung als das Schicksal zu diesem Beruf geführt hatte. Gerade das Oberversicherungsamt war eine Art Abstellplatz bei den Bezirksregierungen, und im Reichsversicherungsamt setzte sich das Spezialistentum fort. Das waren Leute der Sozialversicherungspraxis, die gleichzeitig dann auch richterlich entschieden haben, sehr esoterisch, sehr abgesondert. Jetzt entscheidet die Sozialgerichtsbarkeit über alle Streitfälle, auch über die Versorgungsfälle, und sie entscheidet durch Richter, die sich außerordentlich stark dem allgemeinen Verwaltungsrecht verbunden fühlen, die nur in seltenen Fällen aus der Versicherungspraxis kommen, vielmehr gleich als ausgebildete Assessoren in die Sozialgerichtsbarkeit gehen, sie als Teil, als Sonderzweig der Verwaltungsgerichtsbarkeit empfinden und so mit den ganzen Vorstellungen des allgemeinen Verwaltungsrechts, wie sie sie in Studium und Ausbildung in sich aufgenommen haben, an ihre Aufgabe herangehen. Dazu kommen noch einige Bestimmungen im Sozialgerichtsgesetz, die materiell-verwaltungsrechtlichen Charakter haben, die ebenfalls einen Anschluß an das allgemeine Verwaltungsrecht vollziehen. Hierin liegt ein wesentliches Moment dafür, daß sich in den letzten zehn bis fünfzehn Jahren und weiterhin fortschreitend eine starke Hineinnahme auch des materiellen Rechts sowie der Handlungsformen des Sozialversicherungsrechts und des Versorgungsrechts in die allgemeine Problematik unseres allgemeinen Verwaltungsrechts vollzogen hat.

Vogel: Vielleicht sollte man auf einen Punkt noch kurz eingehen; ich bin nicht sicher, ob heute - wie gestern - der Satz "qui tacet consentire videtur" außer Kraft gesetzt ist: 
Herr Rüfner hat sich dafür ausgesprochen, im Sozialversicherungsrecht der „schlichten Erfüllung" eine größere Bedeutung zuzuerkennen (so wie er es in seiner Habilitationsschrift auch für den Bereich der öffentlichen Anstalt vertreten hat), d.h. sehr viel häufiger als bisher davon auszugehen, daß geschuldete Leistungen nicht zunächst durch Verwaltungsakt festgesetzt, sondern unmittelbar schon auf Grund des gesetzlich begründeten Leistungsanspruchs gewährt werden. Dagegen spricht jedoch - wie mir scheint - ein wesentlicher Gesichtspunkt. Unser Begriff des Verwaltungsakts zeichnet sich ja insbesondere dadurch aus, daß der Verwaltungsakt - im Gegensatz sowohl zur Norm wie zum zivilrechtlichen Rechtsgeschäft - grundsätzlich auch dann (vorläufig) verbindlich ist, wenn er rechtswidrig ist, und daß er verbindlich bleibt, wenn er nicht fristgerecht angefochten wird. Dafür braucht es weder eine metaphysische Erklärung - etwa, daB der Verwaltungsakt "Emanation der Staatsgewalt" sei - noch handelt es sich um ein böses Relikt des Obrigkeitsstaates. Den Sinn dieser Regelung kann man vielmehr ganz nüchtern darin sehen, daß es im Großbetrieb der modernen Verwaltung dringend erforderlich ist, über bestimmte Rechtsfragen in relativ kurzer Frist Klarheit zu schaffen. Die Verwaltung soll nicht jederzeit gezwungen sein, erledigte Rechtsfragen wieder aufzugreifen und sie von neuem zu überprüfen; sie soll sich vielmehr darauf verlassen können, daß die Rechtmäßigkeit einer Regelung nach Ablauf einer bestimmten Frist nicht mehr angezweifelt werden kann. Dieses Ziel kann man natürlich auch durch kurze Verjährungsfristen erreichen, wie etwa im Zollrecht. Nur gibt uns das Instrument des Verwaltungsakts die Chance einer sehr viel differenzierteren, im Einzelfall anpassungsfähigeren Regelung: so beispielsweise durch die Möglichkeit der Nachsichtgewährung bei unverschuldeter Fristversäumung. Insofern ist also das Institut des Verwaltungsakts dem der Verjährungsfrist funktional überlegen.

Wenn es nun richtig ist, daß es die rechtspolitische Funktion des Verwaltungsaktes ist, rechtliche Klarheit zu schaffen, dann muß man, meine ich, auch die von Herrn Rüfner gestellte Frage - ob eine Festsetzung der Leistung durch Verwaltungsakt oder lediglich eine schlichte Erfüllung anzunehmen sei von Fall zu Fall jeweils danach beurteilen, ob ein besonderes Interesse an dieser Klarstellungsfunktion des Verwaltungsakts besteht oder nicht. In einem Großbetrieb wie dem der Sozialversicherung würde ich das Interesse an einer Klarstellung durch Verwaltungsakte sehr hoch ansetzen: es ist aus praktischen Gründen ganz einfach notwendig, daß die Entscheidun- 
gen der Sozialversicherungsträger, auch über Leistungen, nach angemessener Frist endgültig werden und nicht mehr neu aufgerollt zu werden brauchen. Entgegen der Auffassung des Herrn Referenten würde ich deshalb doch an der bisherigen Auffassung festhalten, da $\beta$ die Leistungen der Sozialversicherungsträger i.d. R. durch Verwaltungsakt festgesetzt werden.

Thieme: Liegen weitere Wortmeldungen zu dem dritten Themenbereich vor? Wenn das nicht der Fall ist, dann kommen wir zum vierten Fragenbereich, der Entschädigung.

Götz: Unsere zivilrechtlichen Kollegen beschäftigen sich schon seit langem mit einem ganz eigentümlichen Zusammenhang von Haftung und Versicherung. Sie sind nämlich geradezu fasziniert von einer Erscheinung, die sie Ablösung oder Ersetzung der Haftung durch Versicherung nennen. Worum es geht, ist dies, daß in zunehmendem Maße versicherungsrechtliche Ausgleichslösungen an die Stelle von Schadensersatzansprüchen treten. Unter diesem Gesichtspunkt befaßt man sich von dieser Seite her wie im übrigen auch mit unserer Unfallversicherung, die keineswegs für den Versicherten nur wohltätige Wirkungen hat, sondern ihm ja die im Falle der Fahrlässigkeit des Arbeitgebers bestehenden Schadenersatzansprüche nimmt. Dies vorausgeschickt, möchte ich nun meinen, $\mathrm{da} ß$ an dieser Stelle, nämlich bei der Feststellung einer gewissen Austauschbarkeit von Schadenshaftung und Versicherung auch ein Zusammenhang zwischen Sozialversicherungsrecht und dem Recht der öffentlichen Entschädigung anzuerkennen ist. Ich würde dagegen meinen, daß keine unmittelbare Brücke von der sozialversicherungsrechtlichen Abdeckung von Lebensrisiken zur öffentlichrechtlichen Gefährdungshaftung oder zu einem - wie Sie es nennen, Herr Henke - Ausgleichsanspruch aus Verwaltungsrisiken geschlagen werden kann. Der Zusammenhang zwischen der öffentlichrechtlichen Entschädigung und der Versicherung und Versorgung, den ich anerkennen möchte, wird dagegen darin sichtbar, daß versicherungsund versorgungsrechtliche Lösungen die Entschädigungsansprüche ergänzen können, daß also an Stellen, an denen das Entschädigungsrecht versagt, in nahtlosem Ubergang versicherungs- und versorgungsrechtliche Leistungsansprüche bestehen können. Ein Stichwort von vielen möglichen hat Herr Stern schon einmal genannt: die Haftung für Turnunfälle. Weil es hier den Entschädigungsanspruch offenbar nicht gibt, muß der dringend notwendige Ausgleich über eine versicherungsrechtliche Lösung irgendwie geschaffen werden. Es ließen sich viele 
andere Fallgestaltungen bringen, die diesen Zusammenhang belegen.

Weber: Im Anschluß an das von Herrn Götz Gesagte möchte ich noch auf einen eigentümlichen Vorgang hinweisen, der sehr bezeichnend ist. Wir haben ja den $\S 539$ RVO, früher $\S 537$, den Herr Dürig vorhin schon in die Debatte geworfen hat und in dem ein ganzes Bündel von öffentlich-rechtlichen Entschädigungsansprüchen zusammengefaßt ist. Herr Götz hat schon darauf hingewiesen, daß, als die Entscheidung über den Schulturnunfall erging, sofort im Bundestag ein Initiativantrag zur Schülerunfallversicherung kam. Der Trend, solche Fälle öffentlich-rechtlicher Entschädigungsansprüche als sozialversicherungsrechtliche Tatbestände auszuformen, ist seit 1937 und der damaligen Novellierung des $\S 537$ RVO deutlich erkennbar; man hat nur von dem heutigen $\$ 539$ RVO viel zu wenig Kenntnis genommen.

Hierbei ist folgendes wesentlich: Der Bundesgesetzgeber kann den öffentlich-rechtlichen Entschädigungsanspruch als allgemeinen Anspruch nicht regeln. Er kann ihn nur akzessorisch regeln im Zusammenhang mit einem bundesrechtlichen Spezialgesetz, wie der Landesgesetzgeber mit einem etwas breiteren Aktionsradius ihn in Bezug auf andere Tatbestände regeln kann. Der Bundesgesetzgeber wird aber für einen öffentlichrechtlichen Entschädigungsanspruch sofort generell zuständig, sobald er die Sache sozialversicherungsrechtlich aufzieht. So geht also, wenn man - wie in solchen Fällen nötig, mindestens nützlich - eine bundesrechtliche Regelung anstrebt, ein starker Trend hin zur Einbeziehung in die Sozialversicherung. Herr Schellenberg und die anderen Experten des Sozialausschusses des Bundestags wissen natürlich auf dieser Klaviatur zu spielen, und so, Herr Henke, kommt von einer ganz anderen Seite her ein Sog, möglichst viele Anwendungsfälle des Aufopferungsanspruchs in eine Quasi-Sozialversicherung zu transponieren. Nach §539 trägt ja kein eigentlicher Sozialversicherungsträger dann die Kosten, sondern es sind die Länder, die sie tragen, soweit sie sie nicht auf die Gemeindeunfallversicherungsverbände und großen Städte abwälzen. Bei der Schülerversicherung, die zur Zeit diskutiert wird, fragt man sich auch: Wen finden wir denn da überhaupt als Träger? Man ist noch nicht zu einem Ergebnis gekommen, ob das die Gemeinde sein soll, ob das Land, ob die Elternschaft, die dann beisteuern soll, oder wer sonst.

Dürig: Der § 539 RVO ist schätzungsweise 90\% unserer Anwälte und Richter unbekannt. Ich wage die Behauptung, daß 
$50 \%$ der Fälle, in denen sich unsere ordentliche Gerichtsbarkeit mit Fragen enteignungsgleicher Eingriffe oder aufopferungsgleicher Eingriffe herumschlägt, innerhalb einer Woche formularmäßig von den Sozialversicherungsträgern erledigt werden würden.

Ipsen: Bis zur Tübinger Tagung wußten auch $90 \%$ unserer Vereinigung nichts von der Existenz des §539.

Scheuner: Ich möchte nur in Ergänzung meiner früheren Ausführungen und auch im Entgegenkommen an Herrn Henke noch bemerken, daß sicherlich geheime und tiefe Brücken zwischen der öffentlichrechtlichen Entschädigung und dem Bereich der sozialen Versicherung bestehen. Auf einige hat Herr Weber aufmerksam gemacht, auf andere Herr Götz. Eine vielleicht noch andere Brücke besteht darin - beide Referenten haben diese Frage nur nebenher behandelt $-\mathrm{da} \beta$ man sich fragen muß, welche Risiken eigentlich die Sozialversicherung abdeckt. Sie deckt Alter, Invalidität, Unfall, aber sie deckt sicherlich nicht Risiken ab, die aus allgemeinen staatlichen Entwicklungen und Strukturveränderungen entstehen. Von diesen Risiken hat der Staat bisher unter dem Begriff der Versorgung nur den Krieg, Erdbeben, Katastrophen und dergleichen aufgegriffen. Und hier würde ich auch sehr warnen, den Weg, den Herr Henke aufgezeichnet hat, zu betreten. Es ist unmöglich, daß der Staat eine Ausgleichsleistung oder. soziale Haftung übernimmt für unerwartete oder vielleicht sogar erwartete Folgen struktureller Maßnahmen. Wenn der Staat etwa den Import bestimmter Artikel beschränkt, weiß er, da $\beta$ die Importeure leiden. Wenn er den Export etwa durch Aufwertung außerordentlich schwer beschädigt, weiß er, daß er den Export schädigt. Hier können wir unmöglich von irgendwelchen Ausgleichsansprüchen ausgehen; wir würden in einen Sog von Ansprüchen hineingeraten, wenn wir nicht klar daran festhalten, den Umfang der Risiken, die in der Sozialversicherung oder in sozialen Ausgleichsansprüchen abgedeckt werden, ganz präzis zu umschreiben.

Rüfner (Schlußwort): Ich möchte mich zunächst für viele Anregungen bedanken, auch für den Hinweis auf manche Versäumnisse, die uns beiden unterlaufen sind. Gelegentlich wurde auch etwas angesprochen, das wir bewußt herausgehalten hatten, um die zugestandene Zeit nicht zu sehr zu überziehen. Das soll keine Kritik am Vorstand sein. Ich halte mehrstündige Referate nicht für sehr glücklich, einiges soll der Diskussion überlassen bleiben. 
Auf einige Punkte möchte ich noch eingehen: Ich habe keineswegs eine Bilderstürmerei gegen den Verwaltungsakt predigen wollen. Wir können nicht das gesamte Verwaltungsrecht umwerfen und dann neu beginnen. Aber, unser Verwaltungsrecht ist von Otto Mayer unter anderen als den heutigen Voraussetzungen entwickelt worden. Es versteht sich am Rande, daß da manches nicht paßt. Wir sollten diese Probleme sehen, uns ihnen stellen und dann eine Anpassung an die neue Situation versuchen. Dabei können wir nicht auf das Jahr 1880 zurückgehen und so tun, als hätte Otto Mayer sein Lehrbuch nie geschrieben. Es bleibt nur übrig, mit dem Vorhandenen weiter zu bauen. Ich glaube, Herr Vogel, ich könnte mich mit Ihnen in jedem Einzelfall einigen. Der Verwaltungsakt kann seinen Sinn in der Leistungsverwaltung haben. $\mathrm{Da}$ und dort wird das ein technisches, kein grundsätzliches Problem sein. Es gibt z. B. das Klarstellungsinteresse bei den Renten, das den Rentenbescheid verlangt. $\mathrm{Ob}$ der Verwaltungsakt im übrigen überall erforderlich ist, darüber läßt sich streiten.

Zum Eigentumsschutz möchte ich noch sagen: Die Rentenansprüche sind durch Art. $14 \mathrm{GG}$ etwa in demselben Maß geschützt, wie die Ansprüche des Soldaten auf sein Ruhegehalt nach der Rechtsprechung des Bundesverfassungsgerichts. Der wesentliche Schutz des Rentenversicherten liegt nicht im Eigentum, sondern darin, daß die Rentenformel vernünftig weiterentwickelt wird. Keinesfalls scheint es mir angängig zu sein, die heutige Rentenformel für alle Zeit unter Berufung auf Art. 14 GG festzulegen. Der Schutz des Bürgers liegt in der Gleichheit, aber $\mathrm{m}$. E. in einer rechtsstaatlich, nicht egalitär verstandenen Gleichheit.

Zur Interdependenz von Sozialleistung, Lenkungsaufgaben, Stabilität, Wachstum und Vollbeschäftigung noch folgendes: Ich habe gerade unter diesem Gesichtspunkt so sehr betont, die Aufgaben der Rentenversicherungsträger und der Bundesanstalt für Arbeit seien Staatsaufgaben. Eine vernünftige Sozialpolitik kann nicht ohne Rücksicht auf die wirtschaftspolitischen Auswirkungen betrieben werden. Gerade deshalb möchte ich dezidiert daran festhalten, da $\beta$ hier eine Staatsaufgabe vorliegt, die der Staat nicht übertragen kann.

Mehrfach sind noch die verfassungsrechtlichen Pflichten aus dem Sozialstaatsgrundsatz angesprochen worden. Sie binden in den meisten Fällen nur den Gesetzgeber; unmittelbare Ansprüche des Bürgers werden sich aus ihnen selten ableiten lassen. Das gilt etwa für das Recht auf Arbeit - in dem Sinne, 
wie ich es vorhin definieren und als realisierbar anerkennen wollte - oder auch für die Leistungen der Kranken- und Unfallversicherung. Der Gesetzgeber ist verpflichtet, ein Minimum an gleichmäßiger Sicherheit für Krankheit und Unfall zu gewährleisten, ein Minimum, das nicht zu gering anzusetzen ist.

Henke (Schlußwort): Ich bin Herrn Vogel vorhin noch eine Antwort schuldig geblieben auf seine Bemerkung über die nach Megatonnen berechneten Konsequenzen meiner Vorstellung von Selbstverwaltung. Herr Vogel, ich hatte nicht an eine Ausdehnung der Selbstverwaltung, sondern nur an ein gewandeltes Verständnis der vorhandenen Selbstverwaltung im jetzigen Ausdehnungsbereich gedacht.

Ich bin Herrn Scheuner sehr dankbar für den Begriff „geheime und tiefe Brücke". Das war vielleicht derjenige Begriff, der mir gefehlt hat, als ich die Verbindung zwischen dem Recht der sozialen Sicherung und der Entschädigung sah. Daß die Haftung für die Folgen staatlicher Veranstaltungen unabsehbar werden könnte, diese Gefahr sehe ich durchaus und meine, daß man den Begriff eingrenzen müßte. Ich meine nur, daß man diese Eingrenzung anhand eines Begriffs wie „sozialer Ausgleichsanspruch" sachgemäßer vornehmen kann als durch Anlehnung an die Enteignung, mit der - daran möchte ich doch festhalten - diese Dinge einfach nichts zu tun haben.

Schließlich habe ich mich zu bedanken, daß Sie das Referat zum Gegenstand der Diskussion gemacht haben, und zwar trotz des strengen Verdikts von Herrn Bettermann auch die Frage der Entschädigung. Was mich am meisten interessiert hat, als ich mich mit dem Thema beschäftigte, war - das habe ich schon gesagt - nicht das, was Herr Stern und Herr Zacher erwartet hatten, sondern war dieses soziale Prinzip, wenn ich es hier noch einmal so abgekürzt nennen darf: das soziale Prinzip Freiheit durch Sicherheit. Es scheint mir eine ganz entscheidende Frage zu sein, ob unser Verwaltungsrecht auf die Dauer und ob die Bewahrung der Freiheit in dem Verwaltungsrecht und durch das Verwaltungsrecht auf die Dauer unter diesem sozialen Prinzip gesehen wird: Freiheit durch Sicherheit, oder auf andere Weise. Und wenn ich noch einen Schritt weitergehen darf: die Worte sozial und sozialistisch hängen doch nicht zufällig zusammen, und ich weiß nicht, ob wir auf die Dauer um die Frage herumkommen, ob wir ein sozialistisches Staats- und Verwaltungsrecht haben oder ein sozialtechnologisches Staatsund Verwaltungsrecht im Sinne der positivistischen Sozialwis- 
Rechtsformen der soz. Sicherung und Allg. Verwaltungsrecht 275 senschaften oder ob wir ein anderes Staats- und Verwaltungsrecht haben, und wenn wir ein anderes haben, welcher Art dieses Staats- und Verwaltungsrecht seinen Grundlagen nach dann ist. 